Portland State University

PDXScholar

Civil and Environmental Engineering Faculty

Publications and Presentations

Civil and Environmental Engineering

$6-2015$

\title{
Seismic Retrofit Benefit Considering Statewide Transportation Assessment
}

\author{
Selamawit Tesfayesus Mehary \\ Portland State University \\ Peter Dusicka \\ Portland State University
}

Follow this and additional works at: https://pdxscholar.library.pdx.edu/cengin_fac

Part of the Civil Engineering Commons, and the Structural Engineering Commons Let us know how access to this document benefits you.

\section{Citation Details}

Mehary, S. T., and Dusicka, P.. Seismic Retrofit Benefit Considering Statewide Transportation Assessment. Report OR-RD-15-15. Portland, OR: Transportation Research and Education Center (TREC), 2015. http://dx.doi.org/10.15760/trec.123

This Report is brought to you for free and open access. It has been accepted for inclusion in Civil and Environmental Engineering Faculty Publications and Presentations by an authorized administrator of PDXScholar. Please contact us if we can make this document more accessible: pdxscholar@pdx.edu. 

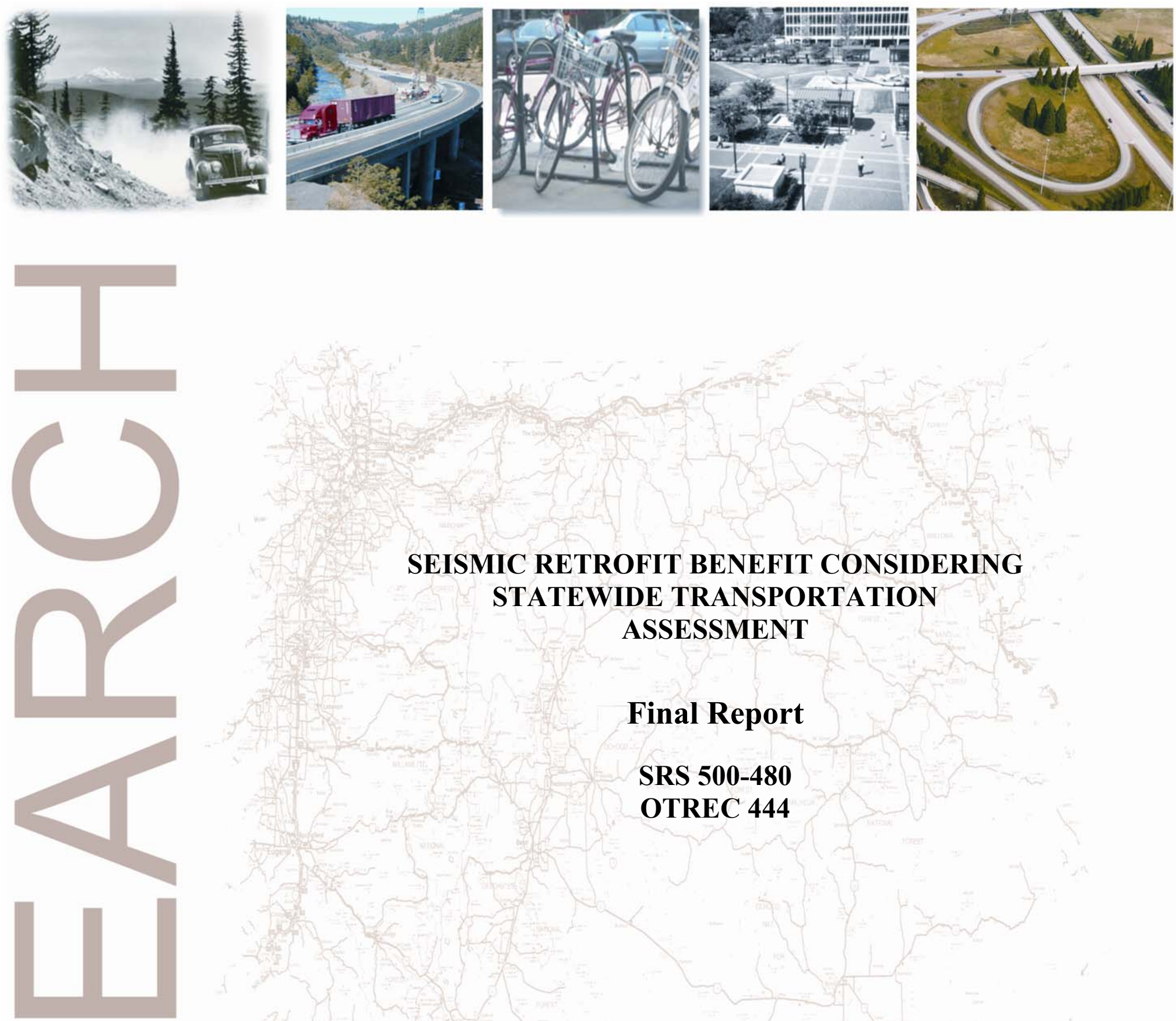

\title{
SEISMIC RETROFIT BENEFIT CONSIDERING STATEWIDE TRANSPORTATION ASSESSMENT
}

\author{
Final Report
}

SRS 500-480

OTREC 444
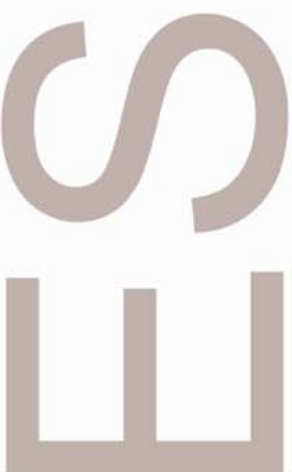

This publication is a result of joint funding by Oregon Department of Transportation (ODOT) and Oregon Transportation Research and Education Consortium (OTREC) 



\title{
SEISMIC RETROFIT BENEFIT CONSIDERING STATEWIDE TRANSPORTATION ASSESSMENT
}

\author{
Final Report
}

OTREC 444

SRS 500-480

\author{
By \\ Selamawit Tesfayesus Mehary, Research Assistant \\ Peter Dusicka, Associate Professor \\ Portland State University \\ for \\ Oregon Department of Transportation \\ Research Section \\ $55513^{\text {th }}$ Street NE, Suite 1 \\ Salem OR 97301 \\ and
}

Federal Highway Administration

400 Seventh Street, SW

Washington, DC 20590-0003

June 2015 

Technical Report Documentation Page

\begin{tabular}{|l|l|}
\hline $\begin{array}{l}\text { 1. Report No. } \\
\text { OR-RD-15-15 }\end{array}$ & 2. Government Accession No. \\
\hline
\end{tabular}

4. Title and Subtitle

Seismic Retrofit Benefit Considering Statewide Transportation

Assessment

7. Author(s)

Selamawit Tesfayesus Mehary, Peter Dusicka

9. Performing Organization Name and Address

Portland State University

Department of Civil and Environmental Engineering

PO Box 751

Portland, Oregon 97207

12. Sponsoring Agency Name and Address

Oregon Dept. of Transportation

$\begin{array}{ll}\text { Research Section and } & \text { Oregon Transportation Research } \\ 55513^{\text {th }} \text { Street NE, Suite } 1 & \text { \& Education Consortium-OTREC } \\ \text { Salem, OR 97301 } & \text { P.O. Box 751 } \\ & \text { Portland, OR 97207 }\end{array}$

3. Recipient's Catalog No.

5. Report Date

June 2015

6. Performing Organization

Code

8. Performing Organization

Report No. SRS-500-480

10. Work Unit No. (TRAIS)

11. Contract or Grant No. OTREC 444

15. Supplementary Notes

16. Abstract - The purpose of this study was to identify and demonstrate a methodology to prioritize bridges for retrofit in the State of Oregon. Given the limited resources available, retrofitting all vulnerable bridges in the foreseeable future would not be practical. Instead, a retrofit strategy needs to be developed to prioritize the inventory and enumerate the retrofit cost. In this study, a prioritization methodology used a holistic assessment of overall roadway system to consider highway route segments, rather than individual bridges. The overall assessment was based on a cost-benefit analysis including retrofit cost, expected economic loss (with or without retrofit) and social loss caused by system wide travel time delays.

A review of 2010 ODOT bridge inventory suggested that a continuous concrete girder bridge (CCGS) with three spans could be utilized to represent a sizeable portion of vulnerable inventory for Oregon highways bridges. After reviewing several potential retrofit measures, carbon fiber composite material was selected for retrofit of vulnerable columns representing those built from the 1950s to mid-1970s. Four full-scale typical square columns were tested to failure. The results showed that despite the intentionally selected square geometry of the reinforced concrete columns, the CFRP composite material showed to be an effective retrofit measure and could be deployed for to address this deficiency.

The software package REDARS2 was used for seismic risk analysis (SRA) of the highway network in this study. This platform was adopted to simulate the impact of scenario earthquakes in an effort to assess the expected benefit considering direct bridge costs as well as social costs from traffic induced delays resulting from seismic retrofitting of a particular bridge type. The assessment considered three scenario Cascadia Subsection Zone earthquakes of magnitudes 9.0, 8.5 North, and, 8.5 South. The study area included all highway routes west of the I-5 corridor, highway routes in the Portland area, the entire length of US-101 and extending partially east on I-84 Columbia River Highway. Due to the considerations of a single bridge type and other limitations identified in the seismic analysis software (REDARS2), the retrofit assessment outcomes should be regarded as a first order estimate.

\section{Key Words}

Seismic retrofit, CFRP, fragility curve, Cascadia subsection zone, Cost- benefit analysis

18. Distribution Statement

Copies available from NTIS, and online at http://www.oregon.gov/ODOT/TD/TP RES/

\begin{tabular}{|l|c|c|l|}
\hline $\begin{array}{l}19 . \quad \text { Security Classification (of this } \\
\text { report) } \\
\text { Unclassified }\end{array}$ & $\begin{array}{l}\text { 20. Security Classification (of this } \\
\text { page) } \\
\text { Unclassified }\end{array}$ & $\begin{array}{l}21 . \text { No. of Pages } \\
88\end{array}$ & 22. Price \\
\hline
\end{tabular}

Technical Report Form DOT F 1700.7 (8-72) 


\begin{tabular}{|c|c|c|c|c|c|c|c|c|c|}
\hline \multicolumn{10}{|c|}{ SI* (MODERN METRIC) CONVERSION FACTORS } \\
\hline \multicolumn{5}{|c|}{ APPROXIMATE CONVERSIONS TO SI UNITS } & \multicolumn{5}{|c|}{ APPROXIMATE CONVERSIONS FROM SI UNITS } \\
\hline Symbol & $\begin{array}{l}\text { When You } \\
\text { Know }\end{array}$ & $\begin{array}{c}\text { Multiply } \\
\text { By }\end{array}$ & To Find & Symbol & Symbol & $\begin{array}{l}\text { When You } \\
\text { Know }\end{array}$ & $\begin{array}{l}\text { Multiply } \\
\text { By }\end{array}$ & To Find & Symbol \\
\hline \multicolumn{5}{|c|}{ LENGTH } & \multicolumn{5}{|c|}{ LENGTH } \\
\hline in & inches & 25.4 & millimeters & $\mathrm{mm}$ & $\mathrm{mm}$ & millimeters & 0.039 & inches & in \\
\hline $\mathrm{ft}$ & feet & 0.305 & meters & $\mathrm{m}$ & $\mathrm{m}$ & meters & 3.28 & feet & $\mathrm{ft}$ \\
\hline yd & yards & 0.914 & meters & $\mathrm{m}$ & $\mathrm{m}$ & meters & 1.09 & yards & yd \\
\hline $\mathrm{mi}$ & miles & 1.61 & kilometers & $\mathrm{km}$ & $\mathrm{km}$ & kilometers & 0.621 & miles & $\mathrm{mi}$ \\
\hline \multicolumn{5}{|c|}{$\underline{\text { AREA }}$} & \multicolumn{5}{|c|}{$\underline{\text { AREA }}$} \\
\hline in $^{2}$ & square inches & 645.2 & $\begin{array}{l}\text { millimeters } \\
\text { squared }\end{array}$ & $\mathrm{mm}^{2}$ & $\mathrm{~mm}^{2}$ & $\begin{array}{l}\text { millimeters } \\
\text { squared }\end{array}$ & 0.0016 & square inches & in $^{2}$ \\
\hline $\mathrm{ft}^{2}$ & square feet & 0.093 & meters squared & $\mathrm{m}^{2}$ & $\mathrm{~m}^{2}$ & meters squared & 10.764 & square feet & $\mathrm{ft}^{2}$ \\
\hline $\mathrm{yd}^{2}$ & square yards & 0.836 & meters squared & $\mathrm{m}^{2}$ & $\mathrm{~m}^{2}$ & meters squared & 1.196 & square yards & $y d^{2}$ \\
\hline ac & acres & 0.405 & hectares & ha & ha & hectares & 2.47 & acres & ac \\
\hline $\mathrm{mi}^{2}$ & square miles & 2.59 & $\begin{array}{l}\text { kilometers } \\
\text { squared }\end{array}$ & $\mathrm{km}^{2}$ & $\mathrm{~km}^{2}$ & $\begin{array}{l}\text { kilometers } \\
\text { squared }\end{array}$ & 0.386 & square miles & $\mathrm{mi}^{2}$ \\
\hline \multicolumn{5}{|c|}{ VOLUME } & \multicolumn{5}{|c|}{ VOLUME } \\
\hline $\mathrm{fl} \mathrm{oz}$ & fluid ounces & 29.57 & milliliters & $\mathrm{ml}$ & $\mathrm{ml}$ & milliliters & 0.034 & fluid ounces & $\mathrm{fl} \mathrm{oz}$ \\
\hline & gallons & 3.785 & liters & $\mathrm{L}$ & $\mathrm{L}$ & liters & 0.264 & gallons & gal \\
\hline $\mathrm{ft}^{3}$ & cubic feet & 0.028 & meters cubed & $\mathrm{m}^{3}$ & $\mathrm{~m}^{3}$ & meters cubed & 35.315 & cubic feet & $\mathrm{ft}^{3}$ \\
\hline & cubic yards & 0.765 & meters cubed & $\mathrm{m}^{3}$ & $\mathrm{~m}^{3}$ & meters cubed & 1.308 & cubic yards & $y d^{3}$ \\
\hline \multirow{2}{*}{\multicolumn{5}{|c|}{$\begin{array}{l}\text { NOTE: Volumes greater than } 1000 \mathrm{~L} \text { shall be shown in } \mathrm{m}^{3} \text {. } \\
\text { MASS }\end{array}$}} & \multirow{2}{*}{\multicolumn{5}{|c|}{ MASS }} \\
\hline & & & & & & & & & \\
\hline $\mathrm{oz}$ & ounces & 28.35 & grams & $\mathrm{g}$ & $\mathrm{g}$ & grams & 0.035 & ounces & $\mathrm{oz}$ \\
\hline $\mathrm{lb}$ & pounds & 0.454 & kilograms & $\mathrm{kg}$ & $\mathrm{kg}$ & kilograms & 2.205 & pounds & $\mathrm{lb}$ \\
\hline $\mathrm{T}$ & $\begin{array}{l}\text { short tons }(2000 \\
\mathrm{lb})\end{array}$ & 0.907 & megagrams & $\mathrm{Mg}$ & $\mathrm{Mg}$ & megagrams & 1.102 & short tons (2000 lb) & o) $\mathrm{T}$ \\
\hline \multicolumn{5}{|c|}{ TEMPERATURE (exact) } & \multicolumn{5}{|c|}{ TEMPERATURE (exact) } \\
\hline${ }^{\circ} \mathrm{F}$ & Fahrenheit & $\begin{array}{l}(\mathrm{F}- \\
32) / 1.8\end{array}$ & Celsius & ${ }^{\circ} \mathrm{C}$ & ${ }^{\circ} \mathrm{C}$ & Celsius & $\begin{array}{l}1.8 \mathrm{C}+3 \\
2\end{array}$ & Fahrenheit & ${ }^{\circ} \mathrm{F}$ \\
\hline
\end{tabular}




\section{ACKNOWLEDGEMENTS}

This project was funded by the Oregon Transportation Research and Education Consortium (OTREC) and Oregon Department of Transportation (ODOT) with assistance from other contributors at Portland State University Department of Civil and Environmental Engineering, School of Urban Planning, Federal Highway Administration (FHWA), ImageCat Inc. and the REDARS2 Group. The authors would like to thank everyone who contributed their time and effort to help complete this phase of the research.

\section{DISCLAIMER}

This document is disseminated under the sponsorship of the Oregon Department of Transportation and the United States Department of Transportation in the interest of information exchange. The State of Oregon and the United States Government assume no liability of its contents or use thereof.

The contents of this report reflect the view of the authors who are solely responsible for the facts and accuracy of the material presented. The contents do not necessarily reflect the official views of the Oregon Department of Transportation or the United States Department of Transportation.

The State of Oregon and the United States Government do not endorse products of manufacturers. Trademarks or manufacturers' names appear herein only because they are considered essential to the object of this document.

This report does not constitute a standard, specification, or regulation. 


\section{EXECUTIVE SUMMARY}

The bulk of the bridge inventory in Oregon was built prior to the current understanding of bridge response and prior to current understanding of the expected earthquake demands. While some bridges are being replaced due to other deficiencies, the majority are expected to continue to stay in service for decades to come. A prioritization method is needed to aid bridge investment decisions and for allocating of the limited resources available. The overall goals of the research are to develop and apply a retrofit assessment that uses a holistic approach to the overall roadway system.

Based on 2010 ODOT bridge inventory, including 9,864 bridges and culverts, a statistical analysis showed that a representative bridge for Oregon would be a continuous concrete girder bridge (CCGS) with three spans. The bridge would have two lanes, and the length and width of the bridge would be between 120 and 140 feet and 30 and 35 feet respectively. The columns would have four No. 8, No. 9 or No. 10 longitudinal reinforcements and No. 3 transverse reinforcing hoops typically at 12 inches on center anchored by $90^{\circ}$ hooks.

Several retrofit measures were reviewed, such as steel jacketing, concrete jacketing, angle and rod hoop retrofit, external prestressing steel, and, composite materials retrofitting. For this study, CFRP composite material was selected for retrofit due to a number of identified advantages. A typical square column design, representing typical bridge columns built in the Pacific Northwest before 1971, was identified to be experimentally evaluated. Four full-scale columns (as-build vs CFRP retrofitted) were tested to failure under two difference seismic loads (standard vs subduction zone). The results showed that the retrofit helped inhibit bond failures in lap splices of longitudinal reinforcement in the plastic hinge regions with minimal spalling of concrete at the base of the column.

A public-domain software package names REDARS2 (Risks from Earthquake Damage to Roadway Systems) was adopted for this study. It uses a strategy to assess damage to a highway network with bridges subjected to scenario earthquakes. The expected costs and losses were evaluated for the bridges in its as-built and retrofitted condition. The benefit of a specific retrofit was evaluated as the difference between the expected costs of the bridge without retrofit and the bridge with retrofit. Costs without retrofit included repair and replacement of the bridge and travel time delays. Costs with retrofit included damage to the bridge and the cost of the retrofit. The Cost-Benefit ratio was then calculated as the ratio of net present benefit of the investment in retrofit to the initial cost of the retrofit. A retrofit option with the largest benefit to cost ratio has a larger expected return per amount of money invested in retrofitting. The studied area included all highway routes lying inside or west of the I-5 corridor, highway routes in the Portland area, the entire length of US-101 and a partial I-84 Columbia River Highway. The loss estimates were developed from REDARS2 analyses for three simulated Cascadia Subsection Zone earthquake scenarios of magnitudes 9.0, 8.5 North, and, 8.5 South.

To demonstrate the application of cost-benefit analysis for assessment of highway segments, seismic retrofit of the continuous reinforced concrete girder bridges along the individual routes 
was considered. The results should be regarded as first order analysis due to several limitations identified in the seismic analysis software used (REDARS2):

1. Fragility curves that have been developed for retrofitted bridges have been primarily based on numerical analyses of California type bridges (Shinozuka et al. 2002) or bridge types typical to the eastern part of the country (Padgett and DesRoches 2008). Fragility relationships relevant to retrofitted bridges typical to Oregon are needed as a future endeavor.

2. Damage states of bridges were computed comparing the bridges' median demand spectral acceleration for a given scenario earthquake to the median capacity that leads to the onset of each damage state. The median values of ground motion computed may not necessarily represent the exact levels of ground shaking at the bridge locations.

3. The software REDARES2 also included a social module, and considered travel-time delay and losses. However, significant limitations in the capability and incompatibilities between available data and the expected data for the import process limited the usefulness of the results. Travel related losses are expected to dominate the cost impact to the overall system, instead of having a minor contribution shown in the demonstration analysis.

4. Ground motion was the only earthquake hazard considered in the model. Other related potential hazards such as liquefaction and landslides were not included. Separate analyses addressing these issues would need to be conducted using tools other than REDARS2.

Due the above limitations, the benefit to cost values of retrofitting highway segments would change, but could adopt the overall methodology. More information and further research is needed to refine the inputs and establish the statewide prioritization for seismic retrofit. 


\section{TABLE OF CONTENTS}

$1.0 \quad$ INTRODUCTION............................................................................................................... 1

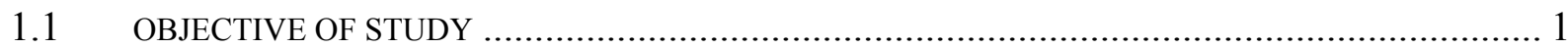

2.0 SELECTION OF REPRESENTATIVE BRIDGE TYPE FOR OREGON ................. 3

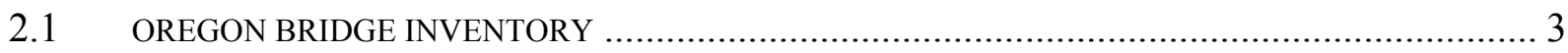

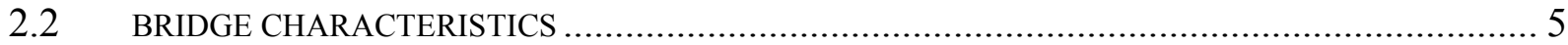

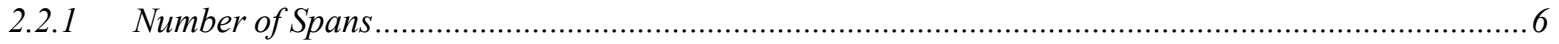

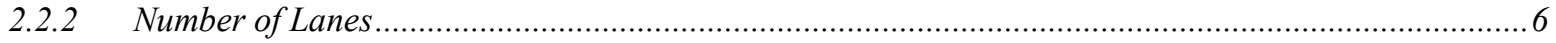

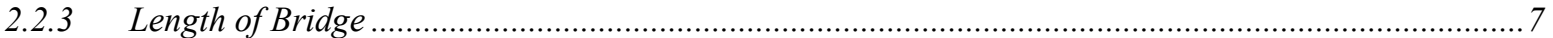

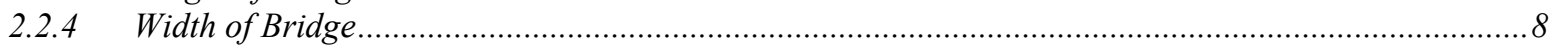

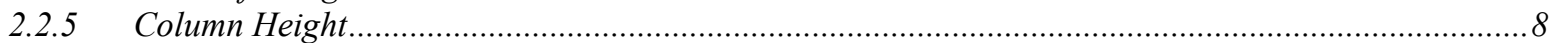

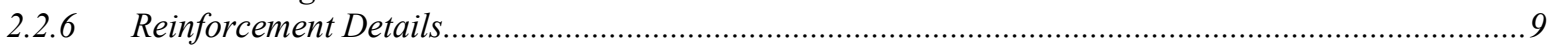

2.3 REPRESENTATIVE BRIDGE TYPE FOR OREGON INVENTORY ...................................

$3.0 \quad$ RETROFIT MEASURES ............................................................................ 11

3.1 RETROFIT OPTIONS FOR DEFICIENT COLUMNS ..................................................... 11

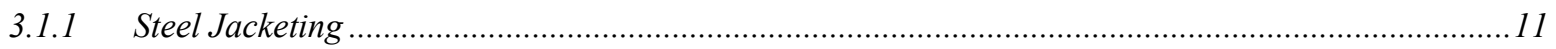

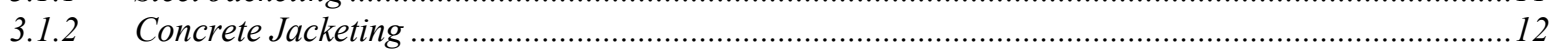

3.1.3 Angle and Rod Hoop Retrofit.....................................................................................................12

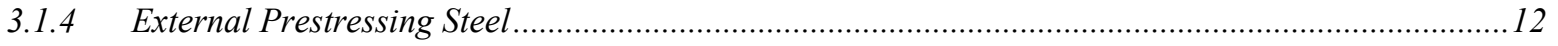

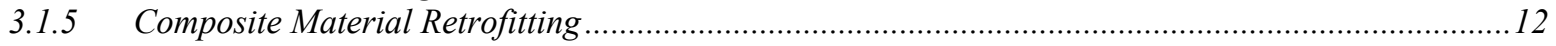

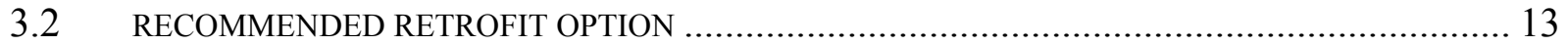

\subsection{EXPERIMENTAL STUDY OF AS-BUILT AND CFRP WRAP RETROFITTED}

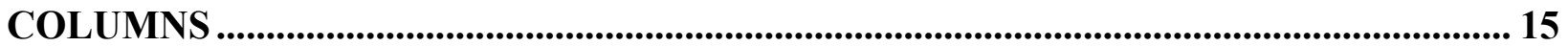

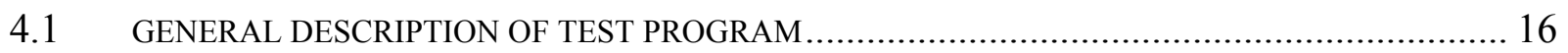

4.2 MATERIALS USED TO CONSTRUCT SPECIMENS ………............................................. 17

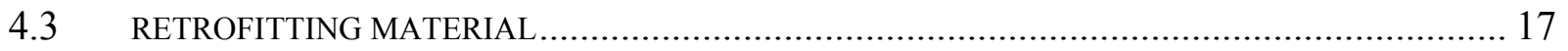

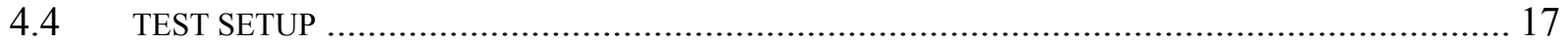

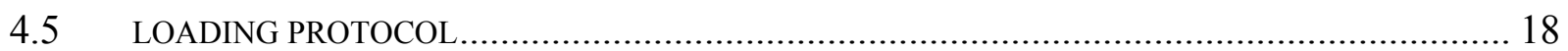

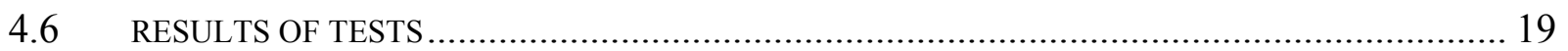

4.6.1 Visual and Measured Observations ...............................................................................................19

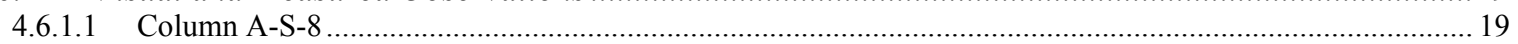

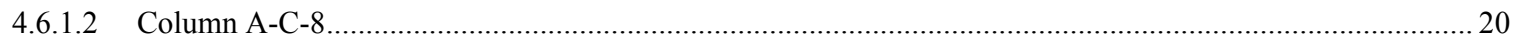

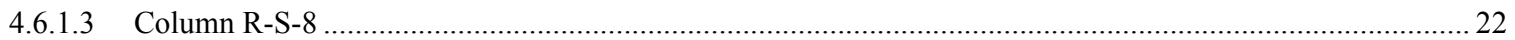

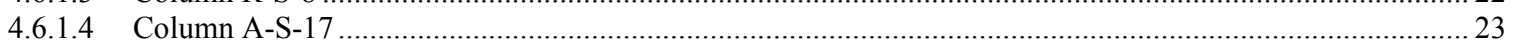

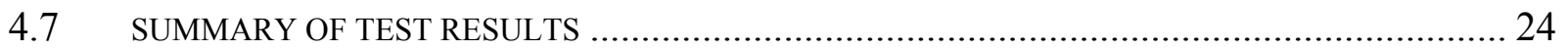

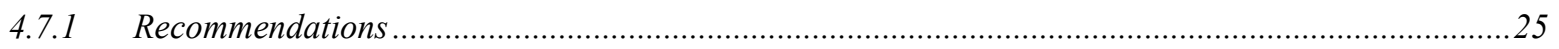

5.0 SEISMIC FRAGILITY ANALYSIS OF BRIDGES ................................................ 27

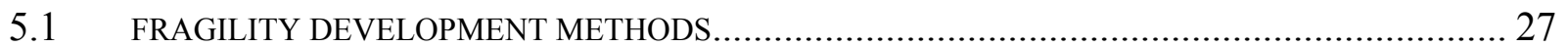

5.1.1 Fragility Curves Developed by Empirical Methods .................................................................28

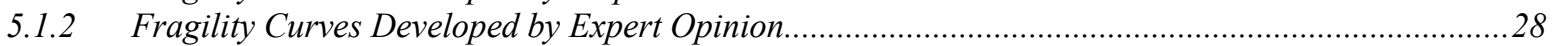

5.1.3 Fragility Curves Developed by Analytical Methods .................................................................29

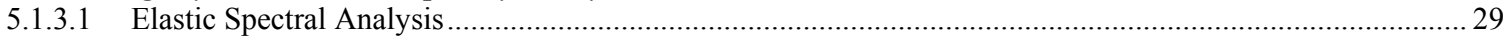

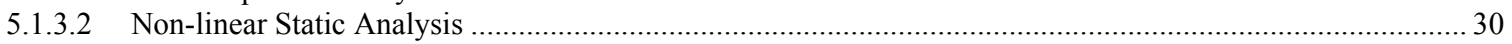

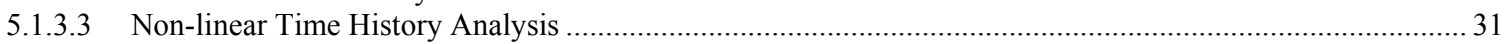

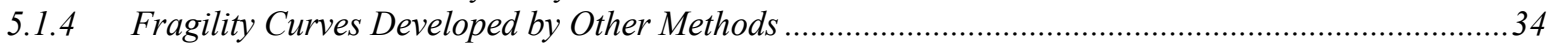


5.2 FRAGILITY CURVES FOR RETROFITTED BRIDGES ….............................................. 34

5.3 FRAGILITY CURVE FOR A DEFICIENT THREE SPAN CONCRETE CONTINUOUS GIRDER BRIDGE 35

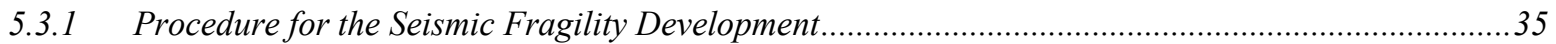

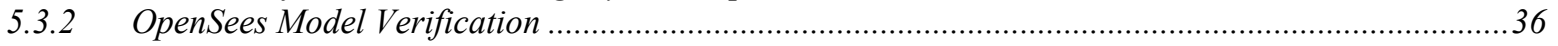

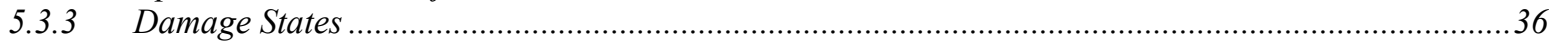

5.3.4 Developed Bridge Fragility Curves for 3-Span CCGS …….......................................................... 37

5.4 FRAGILITY CURVE FOR A RETROFITTED THREE SPAN CONCRETE CONTINUOUS GIRDER BRIDGE38

6.0 REVIEW OF SEISMIC RETROFIT PRIORITIZATION METHODS................. 41

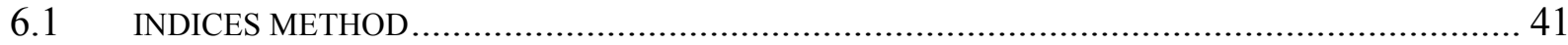

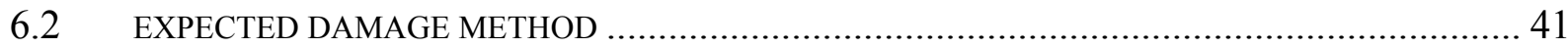

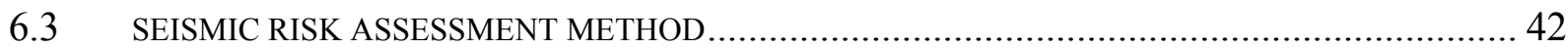

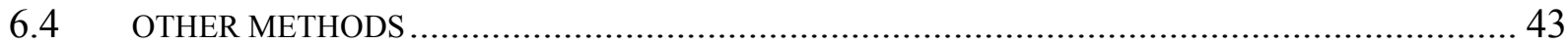

6.5 ADVANTAGES AND DISADVANTAGES OF THE DIFFERENT PRIORITIZATION

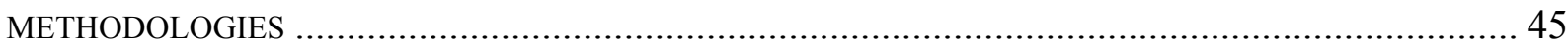

7.0 RETROFIT PRIORITIZATION METHOD .............................................................. 47

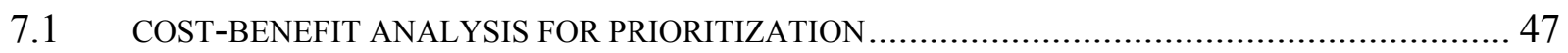

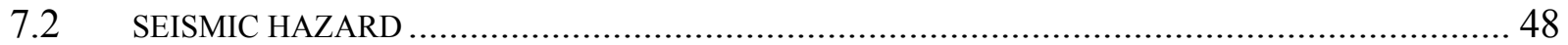

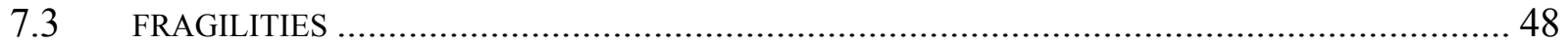

ECONOMIC MODULE

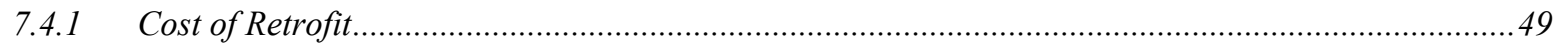

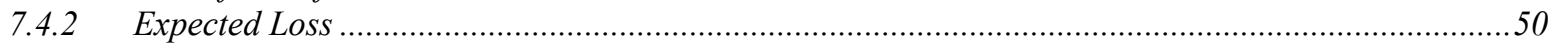

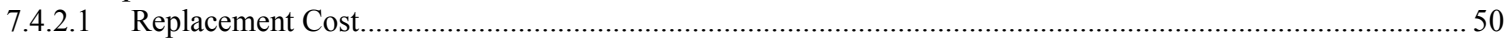

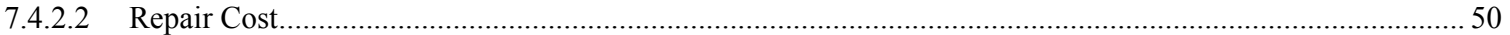

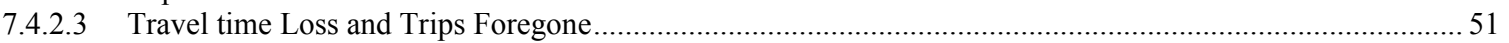

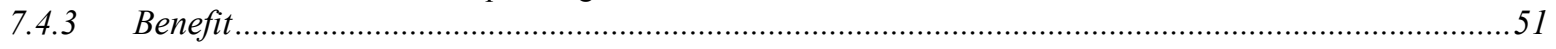

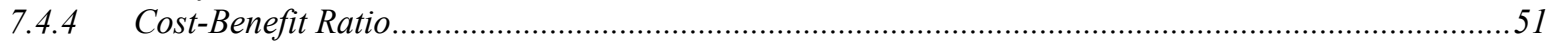

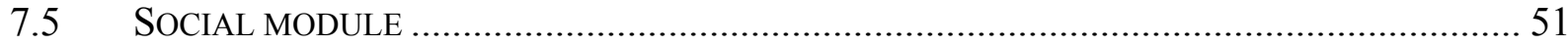

7.5.1 Downtime

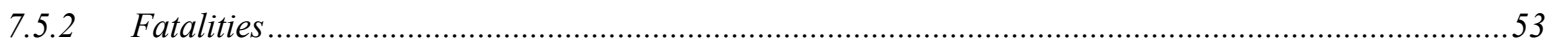

7.6 DEMONSTRATION OF COST-BENEFIT ASSESSMENT ….............................................. 54

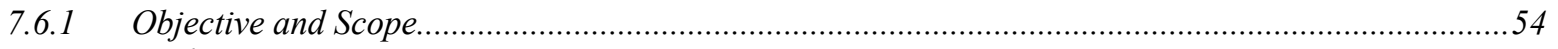

7.6.2 Study Area

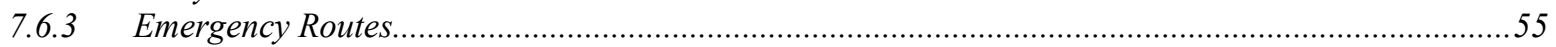

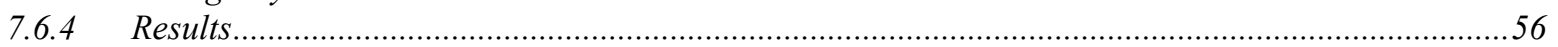

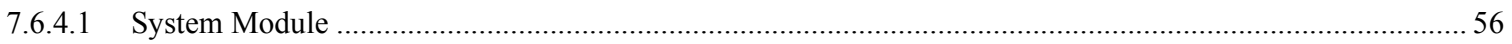

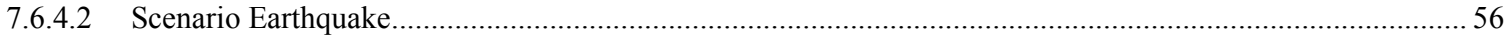

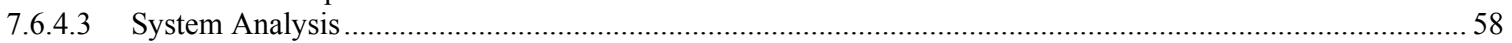

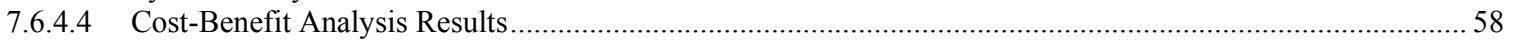

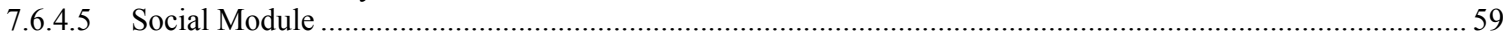

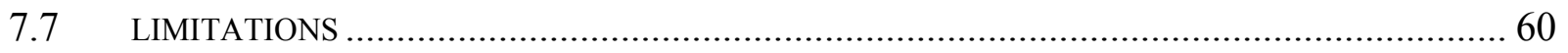

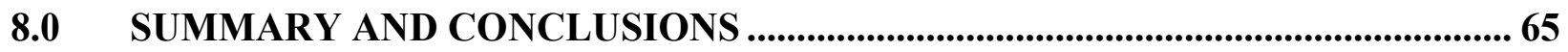

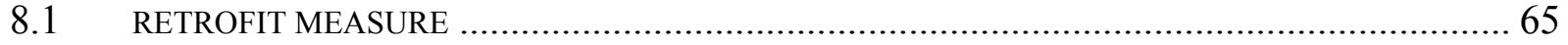

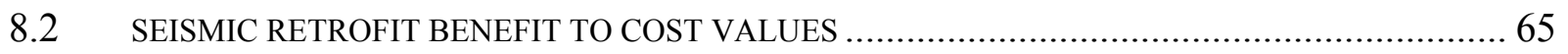

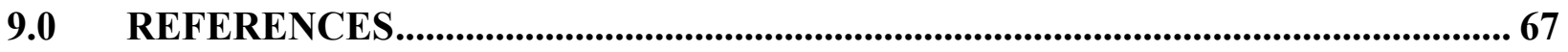




\section{LIST OF TABLES}

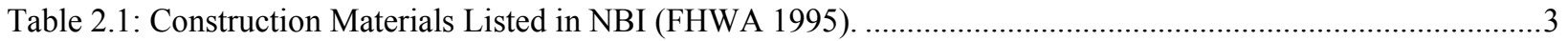

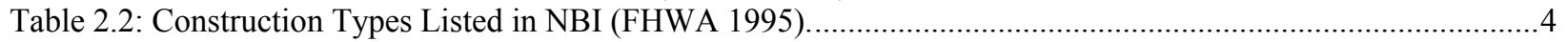

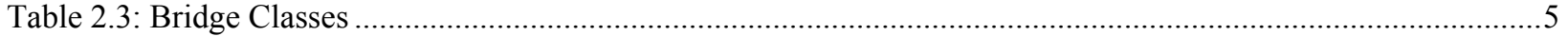

Table 2.4: Statistics of Number of Spans for major concrete bridge classes ......................................................6

Table 5.1: Damage States considered in HAZUS99-SR2 Bridge Model ...........................................................37

Table 5.2: Fragility Curve values for Typical 3-Span Bridge (Roberts and Dusicka 2011) ......................................37

Table 5.3: Fragility Curve values for Seismically Designed 3-Span Bridge (FEMA 2010) ...................................38

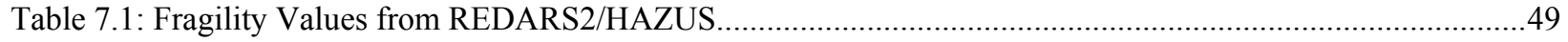

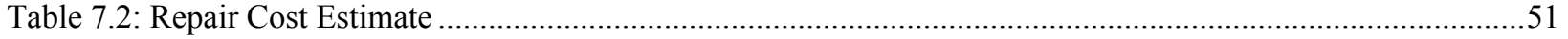

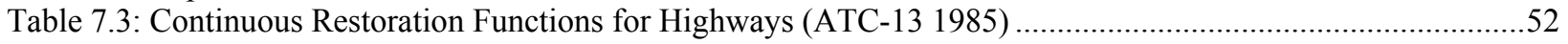

Table 7.4: Discrete Restoration Functions for Highways ..........................................................................53

Table 7.5: Default Relationships for Estimating Population Distribution (HAZUS®MH MH4 Technical manual) ..53

Table 7.6: Casualty Rates by Model Building Type for Complete Structural Damage (No Collapse) (HAZUS®MH

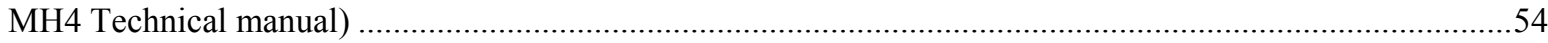

Table 7.7: Injury Classification Scale (HAZUS®MH MH4 Technical manual) ...............................................54

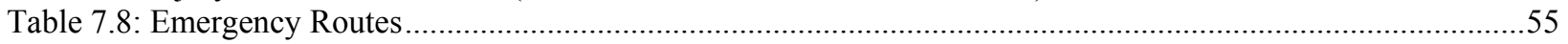

Table 7.9: Sample Retrofit Prioritization Benefit-to-Cost Values for CSZ 9.0 ...................................................61

Table 7.10: Sample Retrofit Prioritization Benefit-to-Cost Values for CSZ 8.5 North ............................................62

Table 7.11: Sample Retrofit Prioritization Benefit-to-Cost Values for CSZ 8.5 South..........................................63

\section{LIST OF FIGURES}

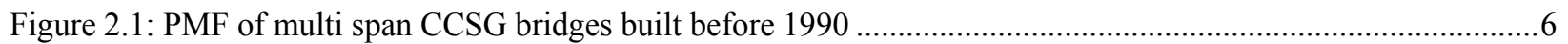

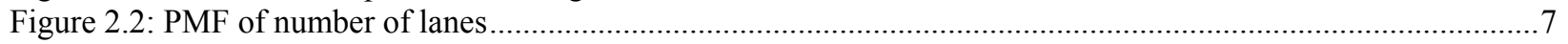

Figure 2.3: Cumulative Distribution Function for the Lengths......................................................................

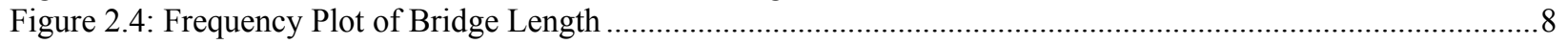

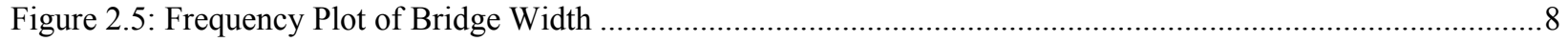

Figure 2.6: Frequency Plot of Bridge Column Height..................................................................................

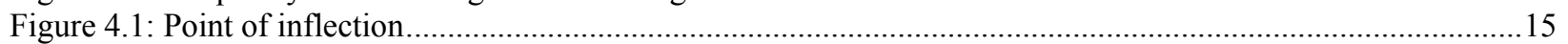

Figure 4.2: Geometry and Reinforcement of RC Bridge Column .................................................................... 16

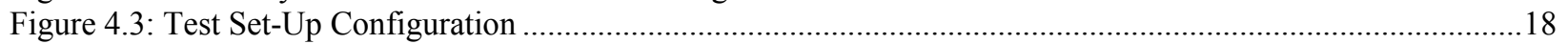

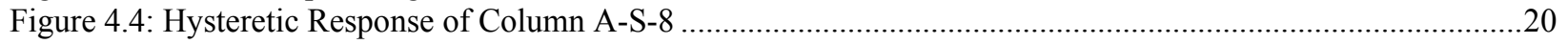

Figure 4.5: (a) Crushing of concrete at the base, (b) Lap Splice Failure and (c) Bar Buckling ..............................20

Figure 4.6: Hysteretic Response of Column A-C-8 .....................................................................................21

Figure 4.7: (a) Crushing of concrete at the base, (b) Lap Splice Failure and (c) Bar Buckling ..............................21

Figure 4.8: Hysteretic Response of Column R-S-8 ..................................................................................22

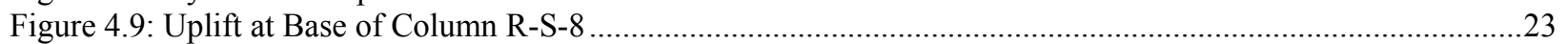

Figure 4.10: Hysteretic Response of Column A-S-17 ...................................................................................24

Figure 4.11: (a) Crushing of concrete at the base, (b) Lap Splice Failure and (c) Bar Buckling ...........................24

Figure 5.1: Damage percent by intensity for major bridges $(A T C-25$ 1991) .................................................29

Figure 5.2: Comparison of Experimental and OpenSees Model of Test Column....................................................36

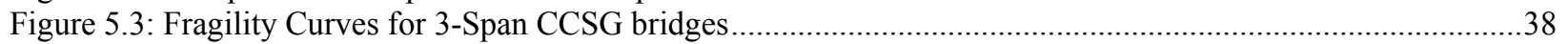

Figure 5.4: Fragility Curves for a Seismically Designed 3-Span CCSG bridges...............................................39

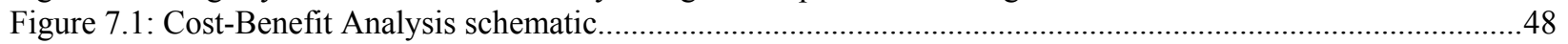

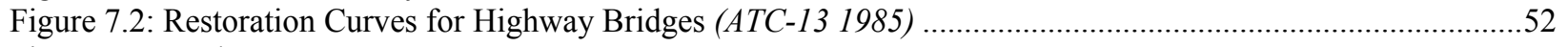

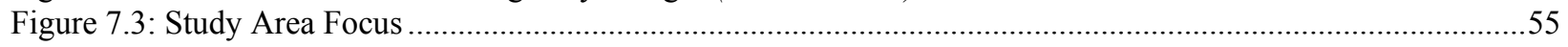

Figure 7.4: Cost-to-Benefit Comparison for Seismic Retrofit (ODOT 2009) .....................................................56

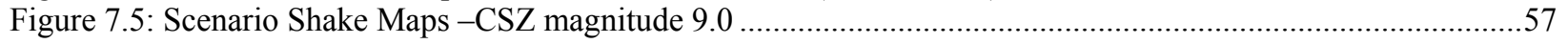

Figure 7.6: Scenario Shake Maps -CSZ magnitude 8.5 North ........................................................................57

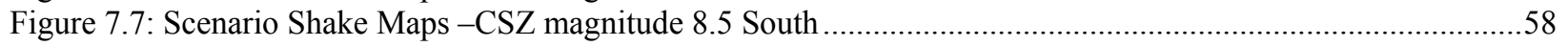




\subsection{INTRODUCTION}

The occurrence of strong earthquakes in urban areas can result in potential sudden devastating impact on the transportation infrastructure where bridges represent vulnerability points within the network. When a bridge is damaged during an earthquake, short-term or long-term disruptions to traffic flow result. This will delay emergency response in the hours after the event, and restrict the movement of people and goods for months. Therefore, it is important to develop measures to help mitigate possible risks and consequences of seismic damage on existing bridges.

In order to minimize potential bridge damage in the case of an earthquake, one approach is to retrofit seismically deficient bridges. However, often times the decision maker is faced with the difficulty of selecting only a few bridges within the inadequate ones and is forced to prioritize upgrading. Therefore, a prioritization methodology needs to be developed so that the most critical bridges are retrofitted first. Body Text 1/2/3 follows headings 1,2 and 3.

\subsection{OBJECTIVE OF STUDY}

The purpose of this study was to construct a methodology to prioritize bridges for retrofit in the State of Oregon. A statewide seismic hazard assessment model was developed and used to conduct a seismic vulnerability analysis, which was widely distributed and publicized (ODOT 2009). The results were useful in analyzing the vulnerability of the highway system and have highlighted the need for prioritization method. Oregon Department of Transportation (ODOT) recognizes that it is impossible to retrofit all vulnerable bridges in the near future. Instead, a retrofit strategy needs to be developed to prioritize and enumerate the retrofit costs of routes or segments that would result in the most benefit. ODOT had developed a cost effective strategy to select bridges that would undergo seismic retrofit. The approach focused on improving longer segments of highways with the available funding.

Similar to the approach taken by ODOT and other studies (Stevanovic and Nadimpalli 2010), the prioritization methodology in this study examined assessing the vulnerability of highway segments under seismic loading. Different routes have different retrofit needs and have different seismic risk exposure and so a Cost-Benefit Analysis can be an effective approach. The desired outcome was for consideration and prioritization of highway segments or routes instead of the conventional approach of prioritizing individual bridges. This approach addressed how much the seismic performance of the overall roadway system was improved when different sequences of route or segment retrofits were followed. System performance was measured by the amount of loss due to system wide travel time delays. The statewide model was a suitable platform for developing the prioritization method as it allowed a holistic assessment. In order to assess the benefits of retrofits, a representative bridge was selected from ODOT's inventory for which experimental and numerical retrofit evaluation was performed as a demonstration of the potential benefit realized by the retrofit. 


\subsection{SELECTION OF REPRESENTATIVE BRIDGE TYPE FOR OREGON}

\subsection{OREGON BRIDGE INVENTORY}

When analyzing the of vulnerability bridges, ideally we would need to have the detailed drawings for each bridge and then generate fragility curves for all the bridges. But this is not feasible when assessing a state wide study because it is highly time consuming and not economical. However, since many bridges that are in the same region are similar, bridges can be grouped into a general bridge class.

The NBI (National Bridge Inventory) database provides information to allow for general classification of bridges. This information is contained in three of the 116 fields in the NBI. The bridges are assigned classes based on their construction material (Table 2.1), construction type (Table 2.2) and the number of spans. The Recording and Coding Guide for the Structure Inventory and Appraisal of the Nation's Bridges serves as a guide to the NBI and lists possible construction materials and types (FHWA 1995).

Table 2.1: Construction Materials Listed in NBI (FHWA 1995).

\begin{tabular}{l|l}
\hline Description & \\
\hline Concrete & Prestressed Concrete Continuous \\
\hline Concrete Continuous & Wood or Timber \\
\hline Steel & Masonry \\
\hline Steel Continuous & Aluminum, Wrought Iron, or Cast Iron \\
\hline Prestressed Concrete & Other \\
\hline
\end{tabular}


Table 2.2: Construction Types Listed in NBI (FHWA 1995).

\begin{tabular}{l|l|l}
\hline Description & & \\
\hline Slab & Truss - Deck & Movable - Swing \\
\hline Stringer/Multi-beam or Girder & Truss - Thru & Tunnel \\
\hline Girder and Floor beam System & Arch - Deck & Culvert \\
\hline Tee Beam & Arch - Thru & Mixed Types \\
\hline Box Beam or Girders - Multiple & Suspension & Segmental Box Girder \\
\hline Box Beam or Girders - Single or Spread & Stayed Girder & Channel Beam \\
\hline Frame & Movable - Lift & Other \\
\hline Orthotropic & Movable - Bascule & \\
\hline
\end{tabular}

In the 2010 ODOT inventory, there are over 9,864 bridges and culverts. The state highway agency owns 5,280 of these. However, only 2,567 of the highway bridges are in the NBI database of which 1,997 are multi span. This study concentrated on multi-span bridges that were built before 1990. Table 2.3 shows the bridge classes and proportions of these multi span bridges that were built before 1990 . 
Table 2.3: Bridge Classes

\begin{tabular}{l|l|l}
\hline Bridge Types & Number & Percentage \\
\hline Concrete Continuous Stringer/Girder & 523 & $28.93 \%$ \\
\hline Prestressed Concrete Stringer/Girder & 231 & $12.78 \%$ \\
\hline Concrete Continuous Multiple Box Beam & 145 & $8.02 \%$ \\
\hline Concrete Continuous Slab & 139 & $7.69 \%$ \\
\hline Prestressed Concrete Slab & 119 & $6.58 \%$ \\
\hline Steel Stringer/Girder & 105 & $5.81 \%$ \\
\hline P/S Concrete Continuous Multiple Box Beam & 73 & $4.04 \%$ \\
\hline Steel Concrinuous Stringer/Girder & 61 & $3.37 \%$ \\
\hline Wood or Timber Stringer/Girder & 59 & $3.26 \%$ \\
\hline Concrete Stringer/Girder & 51 & $2.82 \%$ \\
\hline Concrete Channel Beam & 50 & $2.77 \%$ \\
\hline Steel Truss-Thru & 39 & $2.16 \%$ \\
\hline Steel Truss-Deck & 32 & $1.77 \%$ \\
\hline Steel Continuous Multiple Box Beam & 23 & $1.27 \%$ \\
\hline Concrete Arch-Deck & 20 & $1.11 \%$ \\
\hline Prestressed Concrete Multiple Box Beam & 19 & $1.05 \%$ \\
\hline Steel Continuous Girder-Floorbeam & 15 & $0.83 \%$ \\
\hline Steel Continuous Frame & 15 & $0.83 \%$ \\
\hline Concrete Continuous Girder-Floorbeam & 12 & $0.66 \%$ \\
\hline Other & 10 & $0.55 \%$ \\
\hline Total & 67 & $3.71 \%$ \\
\hline & 1808 & $100 \%$ \\
\hline & &
\end{tabular}

As can be seen from Table 2.3, concrete continuous stringer/girder bridges are the most common type of bridge in Oregon.

\subsection{BRIDGE CHARACTERISTICS}

The NBI provides general information on the bridge classes but actual bridge drawings are needed to assign typical details to each class. From the data provided in the database, the information such as number of spans, number of lanes, maximum span length, deck width, skew angle, year built/rebuilt, etc. can be inferred. Since concrete continuous stringer/girder bridges (CCSG) are the most common type of brides in Oregon, the study of bridge characteristic focused on these 523 bridges. 


\subsubsection{Number of Spans}

To examine the frequency of data at each span length a probability mass function (PMF) was generated. PMF is the probability that a discrete random variable $X$ takes on a particular value $x, P(X=x)$. Here bridges of equal number of spans were grouped together and counted and each group was then divided by the total number of bridges. Figure 2.1 shows the PMF of CCSG multi-span bridges built before 1990 .

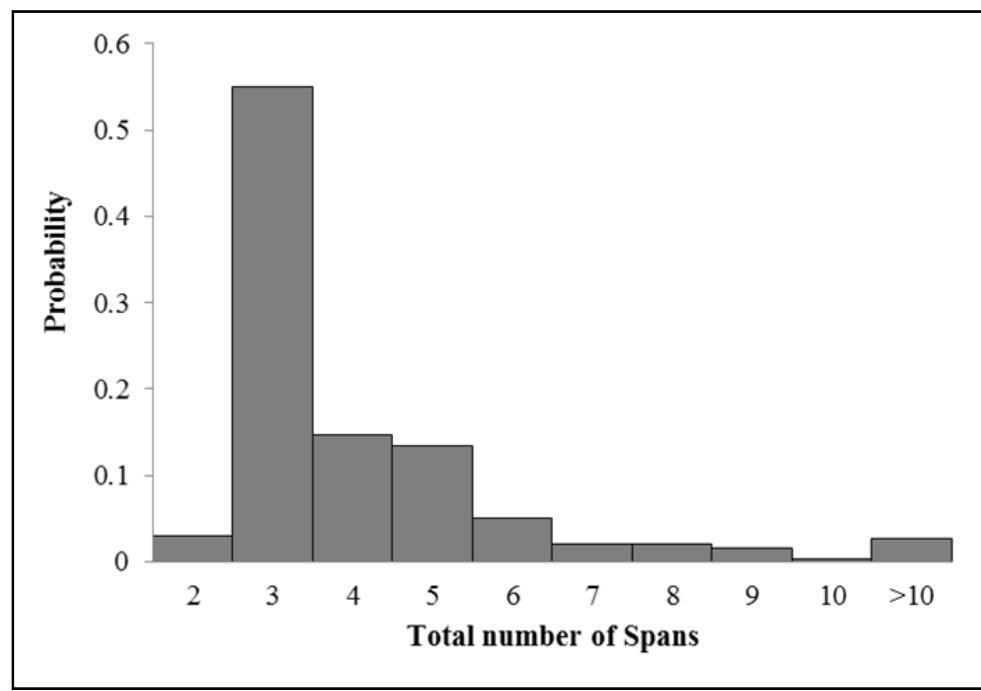

Figure 2.1: PMF of multi span CCSG bridges built before 1990

Table 2.4: Statistics of Number of Spans for major concrete bridge classes

\begin{tabular}{l|c|c|c|c}
\hline Bridge Class & Mean & Std. Dev. & Median & Mode \\
\hline Concrete Continuous Stringer/Girder & 4.28 & 3.2 & 3 & 3 \\
\hline Prestressed Concrete Stringer/Girder & 3.92 & 2.01 & 3 & 3 \\
\hline Concrete Continuous Multiple Box Beam & 4.35 & 2.64 & 3 & 3 \\
\hline Concrete Continuous Slab & 3.8 & 2.92 & 3 & 3 \\
\hline Prestressed Concrete Slab & 3.6 & 2.26 & 3 & 3 \\
\hline
\end{tabular}

Figure 2.1 shows that over $50 \%$ of the bridges have three spans. And as it can also be seen from Table 2.4, the most probable number of span number for all the other major concrete bridge classes is three as well. Therefore, it was safe to assume a representative CCSG bridge in Oregon should have three spans.

\subsubsection{Number of Lanes}

The PMF of number of lanes for CCSG bridges can also be generated to study the characteristics of the database with regard to number of lanes. From Figure 2.2, we can easily see over $80 \%$ of the bridges have two lanes. 


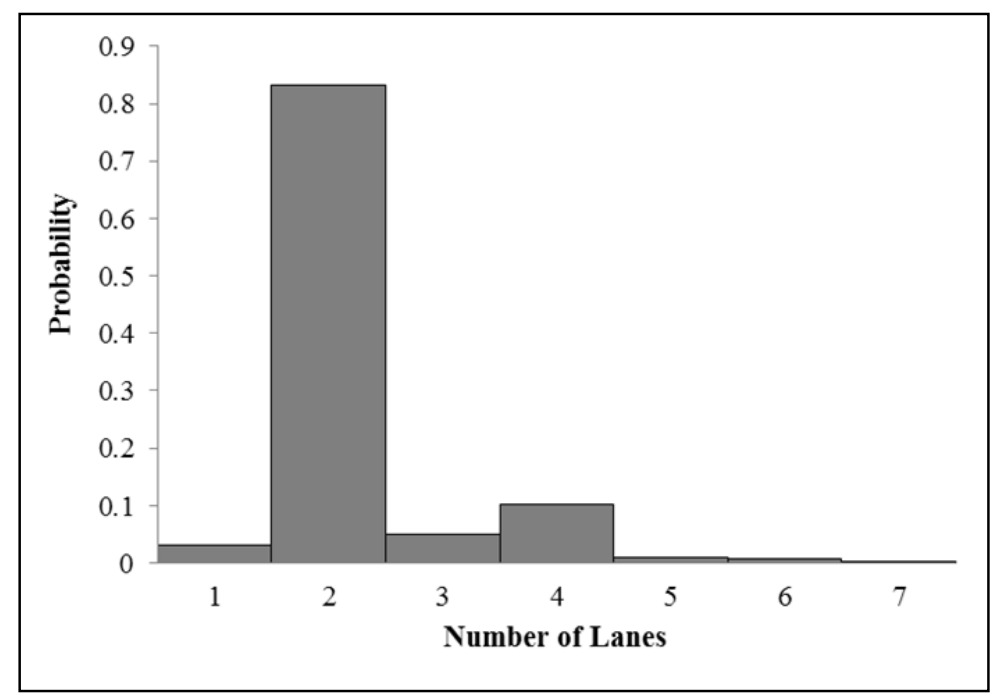

Figure 2.2: PMF of number of lanes

\subsubsection{Length of Bridge}

The empirical cumulative distribution functions (CDFs) for the length of the CCSG bridge class give a complete description of the data distribution and is shown on Figure 2.3. The average total length for the CCSG is $123 \mathrm{ft}(38 \mathrm{~m})$, with a standard deviation of $39 \mathrm{ft}(12 \mathrm{~m})$ and median value of $123 \mathrm{ft}(38 \mathrm{~m})$. This shows that half the bridges have lengths longer than $123 \mathrm{ft}$ and the other half have lengths shorter than $123 \mathrm{ft}$. Figure 2.4 also shows that of these CCSG bridges have a length in the range 120 to 140 feet.

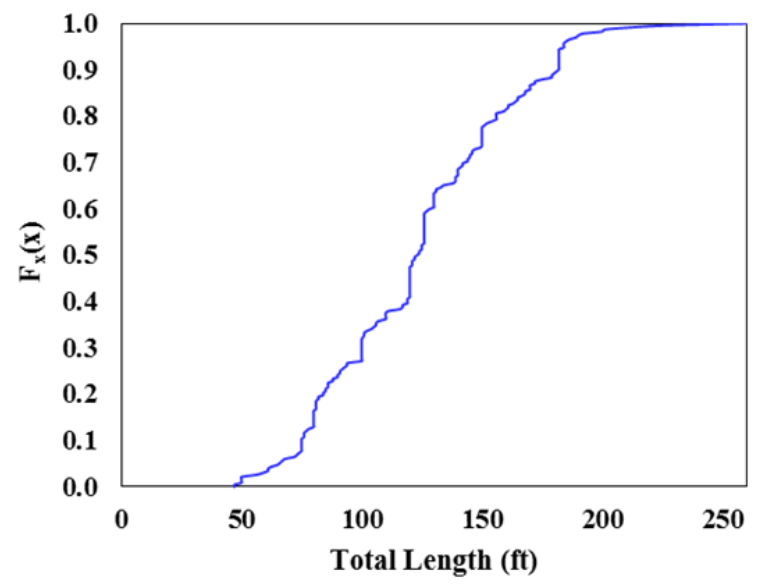

Figure 2.3: Cumulative Distribution Function for the Lengths 


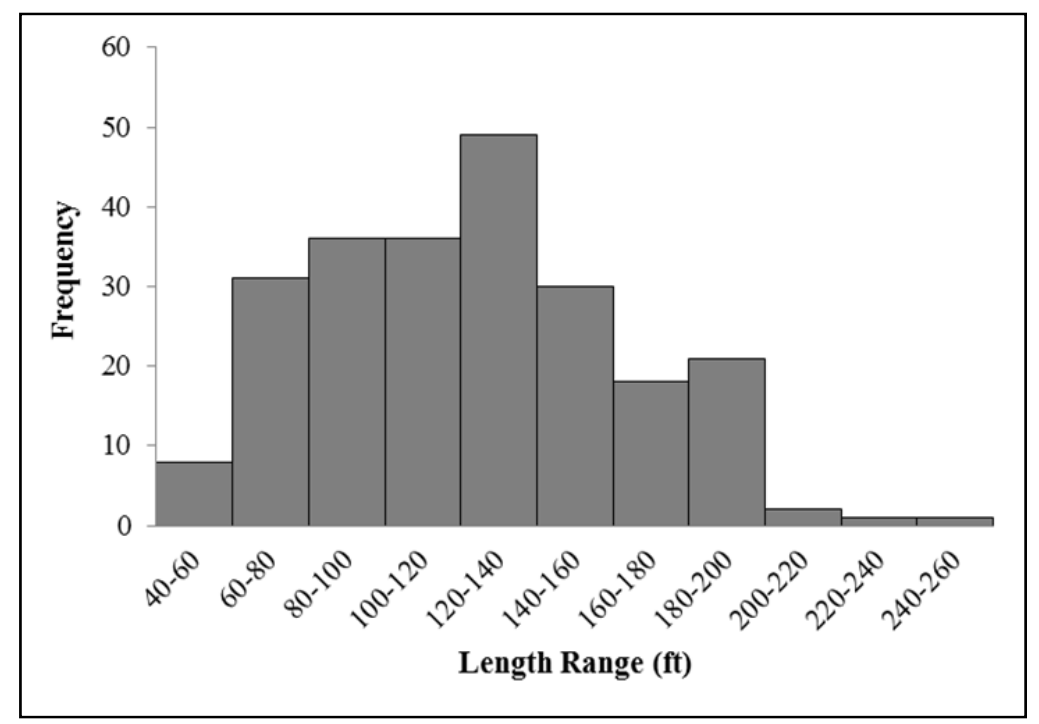

Figure 2.4: Frequency Plot of Bridge Length

\subsubsection{Width of Bridge}

The deck width is measured in feet and is used for modeling purposes later in this study. The deck widths of the majority of the concrete continuous stringer/girder bridge classes range on average between 30 and 35 feet as can be seen from Figure 2.5.

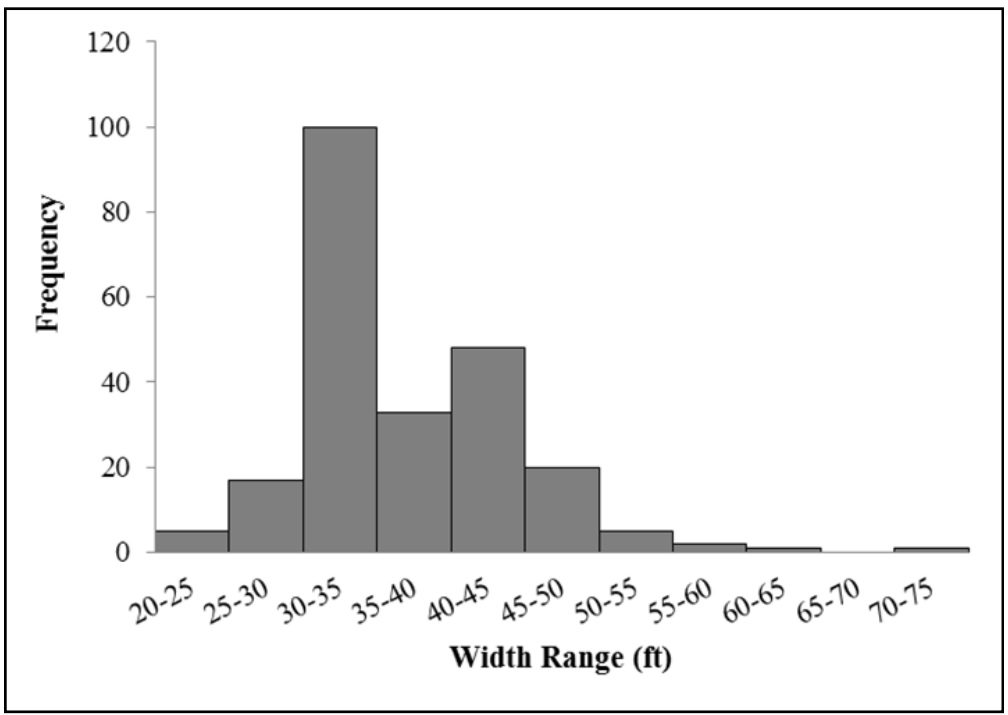

Figure 2.5: Frequency Plot of Bridge Width

\subsubsection{Column Height}

Column height greatly affects the sensitivity of the seismic response of a bridge. Since the NBI does not record column heights, column heights were extracted from available bridge drawings. From what can be seen in Figure 2.6, the majority of columns have a height in the range 15 to 25 feet. 


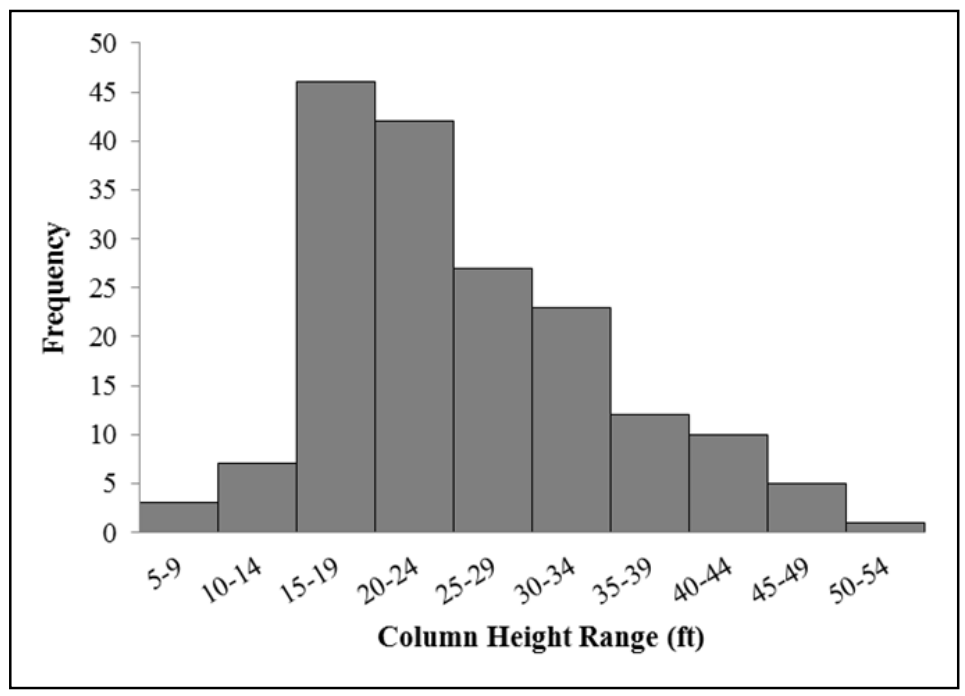

Figure 2.6: Frequency Plot of Bridge Column Height

\subsubsection{Reinforcement Details}

For majority of the bridges, the columns use 4 - \#8, \#9 or \#10 bars to provide longitudinal reinforcement. The transverse reinforcement is provided by \#3 bars spaced at 12 inches center to center for over $80 \%$ of these continuous concrete stringer/girder bridges.

\subsection{REPRESENTATIVE BRIDGE TYPE FOR OREGON INVENTORY}

After taking a closer look at ODOT's bridge inventory, a representative bridge for Oregon would be a continuous concrete stringer/girder bridge (CCSG) with three spans. The bridge would have two lanes, and the length and width of the bridge would be between 120 and 140 feet and 30 and 35 feet respectively. The columns would have four No. 8, No. 9 or No. 10 longitudinal

reinforcements and No. 3 transverse reinforcing hoops typically at 12 inches on center anchored by $90^{\circ}$ hooks. 


\subsection{RETROFIT MEASURES}

Reinforced concrete columns constructed before 1971 are commonly deficient in flexural ductility and shear strength as bridges were designed primarily for gravity loads without much consideration to lateral forces from seismic loading. These columns lack sufficient transverse reinforcement to provide satisfactory performance in a major seismic event. Typically, No. 3 or No. 4 hoops at 12 inches on center were provided in columns regardless of the column crosssectional dimensions. The stirrups were anchored by $90^{\circ}$ hooks with short extensions and intermediate ties were seldom used. All these details contribute to the columns' deficiency and make the columns vulnerable to shear failure and provide limited flexure capacity since the hoops do not provide sufficient confinement. The longitudinal reinforcements could also buckle since the hoops provide minimal restraint once the concrete coves spalls.

Bridges built prior to 1971 also have inadequate lap splices, which normally occur in the potential plastic hinge zone at the base of the column. This detail can also potentially be a cause for reduced column ductility and can result in rapid loss of flexural strength of the column.

The ability of structures to achieve adequate deformation capacity plays a significant role in the prevention of structural failures in seismic events. Ductile structures dissipate more energy and thereby may be designed for lower lateral loads than brittle structures. The deformation capacity of existing bridges can be enhanced by modifying certain substructure elements and connections. Bridge columns are typically retrofitted to increase the overall ductility of the bridge. The performance of seismically vulnerable bridge columns can be upgraded using various techniques including reinforced concrete jacketing, steel jacketing, active confinement by prestressing wire, and composite fiber/epoxy jacketing.

\subsection{RETROFIT OPTIONS FOR DEFICIENT COLUMNS}

\subsubsection{Steel Jacketing}

Steel jacketing was originally developed for circular columns. Previous research studies (Chai et al. 1991) have shown that steel jacketing is an effective retrofit technique for seismicallydeficient concrete columns. Based on satisfactory laboratory results, steel jackets have been employed to retrofit both circular and rectangular columns around the world. For rectangular columns, the recommended procedure is to use an oval jacket, which provides continuous confining action similar to that for a circular column. Rectangular steel jackets are also effective in enhancing shear resistance of columns. These jackets can improve column ductility by eliminating the brittle shear mode of failure. The failure mode may shift to a flexural mode for which the rectangular jacket can provide only limited assistance, since the confining action of the rectangular jackets can only be developed as a result of lateral bending of the jacket sides, which is a very flexible action compared to the membrane action developed in an oval or circular jacket. Detailed design guidelines for steel jacketing are found in the Seismic Retrofitting Manual for Highway Structures (FHWA 2006). 


\subsubsection{Concrete Jacketing}

This application follows the same principles as concrete design. The concrete jacket is applied by drilling holes in the existing column and lateral ties are placed through these holes and are anchored on both sides of the column. Concrete jackets have been used to force yielding away from the location of starter bar splices, and in such cases, the need to improve the performance of the lap-splice has been avoided.

Experimental investigations by (Rodriguez and Park 1994) showed significant improvement of strength and stiffness over as built columns compared to retrofitted damaged and retrofitted undamaged columns. Concrete jackets increase the flexural strength and stiffness of a column even more than a steel jacket, which can cause undesirable effects on bridge performance (FHWA 2006). Retrofit using a fiber-reinforced concrete sleeve can potentially perform better than steel jackets in areas of corrosive environment and are a better choice in certain areas (Dunwoodie 1997).

\subsubsection{Angle and Rod Hoop Retrofit}

In the angle and rod hoop retrofit measure, steel angles are placed at each corner of the column and connected by threaded rods that act as hoops spaced along the specimen. These hoops provide confinement under cyclic loading and provide shear reinforcement. In a laboratory experiment (Mclean and Bernards 1992), it was found that strength and ductility of columns were moderately improved. Tested specimens showed an increase in lateral load capacity of about seven percent. Smaller hoop spacing resulted in larger ductility capacity and a slower internal tie yielding.

\subsubsection{External Prestressing Steel}

External prestressing steel wires under tension are wrapped around a column to achieve confinement. This retrofit method has successfully increased the flexural ductility of circular columns with lap splices at the critical section, but its effect on shear strength has not yet been quantified (FHWA 2006).

An advantage of this practice is that it does not affect the flexural strength and stiffness of the columns. However, the high cost of designing a machine that is big enough to produce the required tension to wrap prestressing wire around the columns makes it uneconomical. Saatcioglu and Yalcin applied external prestressing to columns in transverse direction using individual hoops that consist of prestressing strands and specially designed anchors (Saatioglu and Yalcin 2003). They tested the columns under constant axial compression and incrementally increasing lateral deformation reversals. Their results show that this retrofit methodology can reduce shear failure and increase flexural capacity and inelastic column deformability.

\subsubsection{Composite Material Retrofitting}

Recent developments in the manufacturing of fiber reinforced polymer (FRP) composite materials have made these materials available for a wide range of applications, including seismic retrofit of reinforced concrete columns. Compared to steel and concrete jacketing, FRP wrapping 
has several advantages, including very low weight-to-strength ratios, high elastic moduli, resistance to corrosion, and ease of application. FRP can improve column ductility without considerable stiffness amplification while maintaining the bridge dynamic properties (Haroun and Elsanadedy 2005).

Carbon fiber reinforced polymer (CFRP), glass fiber reinforced polymer (GFRP) and aramid fiber reinforced polymer (AFRP) are the most commonly used FRP composite materials. CFRP has a higher modulus of elasticity and has the highest tensile strength. The Washington State Department of Transportation recommends using CFRP to retrofit bridges because it is less affected by moisture than GFRP (WSDOT 2006).

FRP retrofit systems can be effective for both circular and rectangular columns. However, circular jackets provide a circular column with a continuous confinement pressure, whereas rectangular jackets provide confinement pressure at the corners only. Hence, the corners of rectangular columns are typically rounded prior to retrofitting to avoid stress concentrations at the corners (Seible et al. 1995).

Endeshaw et al. saw that columns retrofitted with CFRP jackets designed based on ACTT-95/08 recommendations for rectangular-shaped retrofits resulted in satisfactory performance, but bulging of the CFRP jacket was observed towards the end of testing (Endeshaw et al. 2008). They increased the thickness of CFRP jackets, which resulted in reduced bulging of the CFRP jacket. They also retrofitted a specimen with a CFRP jacket designed based on $150 \%$ of the ACTT-95/08 recommendations, and they observed that it improved the column's performance.

\subsection{RECOMMENDED RETROFIT OPTION}

For this study, after considering other retrofit practices, CFRP composite material was selected for retrofit due to its many advantages. The expectation from this retrofit method was to adequately increase the ductility of the plastic hinge zone so that the region does not prematurely degrade leading to a possible shear failure and lap splice failure. 


\subsection{EXPERIMENTAL STUDY OF AS-BUILT AND CFRP WRAP RETROFITTED COLUMNS}

The seismic performances of full-scale, square cross section, reinforced-concrete bridge columns were experimentally studied. The specimens and the laboratory arrangement were intended to model typical Oregon bridge columns constructed in the 1950s to mid-1970s.

To simplify analysis and fabrication, the reinforced concrete column design was idealized as a cantilever column fixed at one end and free on the opposite end. The test setup is representative of the internal loads of a full height column due to the assumed location of the inflection point. The inflection points in the deflected shape of the column are the points at which the curvature of the column change sign and are also the points at which the internal bending moments are zero. This property is shown in Figure 4.1. Each column had a heavily reinforced concrete footing, through which it was fixed to the laboratory strong floor for testing. The specimens represented the bottom half of a flexural column and were 9 -ft 5 -in high, 24 -in by 24 -in cross section with a 35 times longitudinal bar diameter $\left(\mathrm{d}_{\mathrm{p}}\right)$ lap splice height. A detail commonly used in the pre-1971 columns is splicing of the longitudinal bars at the base of the columns, which is a potential plastic hinge region. Starter bars often extended 20 to 35 times the column longitudinal bar diameter $\left(\mathrm{d}_{\mathrm{b}}\right)$ from the footing. The longitudinal flexural steel was spliced to the foundation dowels directly above the fixed base. In these tests, the axial load on the column was held nearly constant at $\sim 8 \%$ of the column axial capacity $\left(0.08 \mathrm{Ag}_{\mathrm{g}} \mathrm{f}_{\mathrm{c}}\right)$ while cyclic lateral loads were applied to cause column deformations in the inelastic range. Specimens were tested in their as-built and retrofitted states. The columns were retrofitted with carbon fiber reinforced polymer (CFRP) composite wrapping applied over the rebar splice region. Specimen performance was evaluated based on failure mode, displacement ductility capacity and hysteretic behavior.

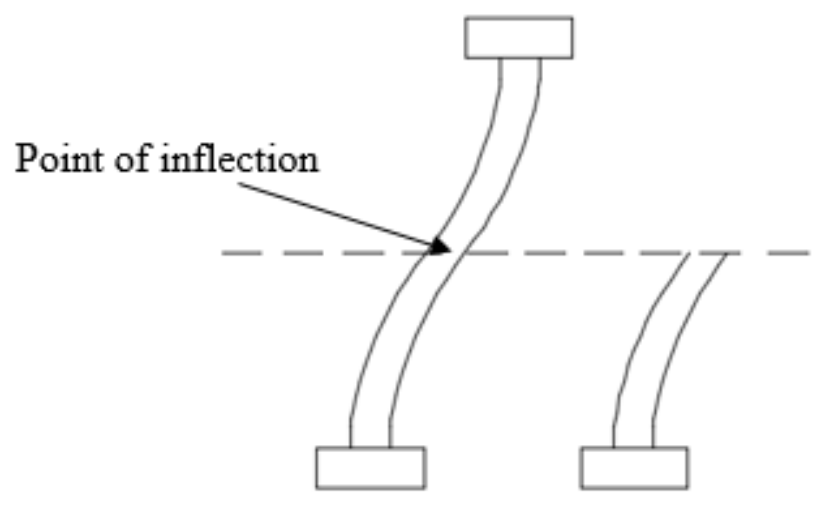

Figure 4.1: Point of inflection 


\subsection{GENERAL DESCRIPTION OF TEST PROGRAM}

The experimental program consisted of four test specimens intended to represent full-scale models of typical bridge columns. All four specimens had the same material properties, crosssectional dimensions and reinforcement ratios. The variables in the testing program were the column conditions (as-built and retrofitted), loading protocol and axial load. The performance of these specimens was intended to reveal vulnerabilities in the existing columns and to establish benchmarks to evaluate the effectiveness of the applied retrofit measures.

The longitudinal reinforcement in each prototype column consisted of 4 No. 10 bars on four corners with No. 3 stirrups with $90^{\circ}$ hooks at 12 in center to center spacing and 2 inches of clear cover concrete confined the column core. The applied vertical load was approximately 8 percent of the gross cross-section strength of the column for the first three tests and 17 percent for the last column tested. A sketch of the prototype column reinforcement detail and cross section is shown in Figure 4.2.

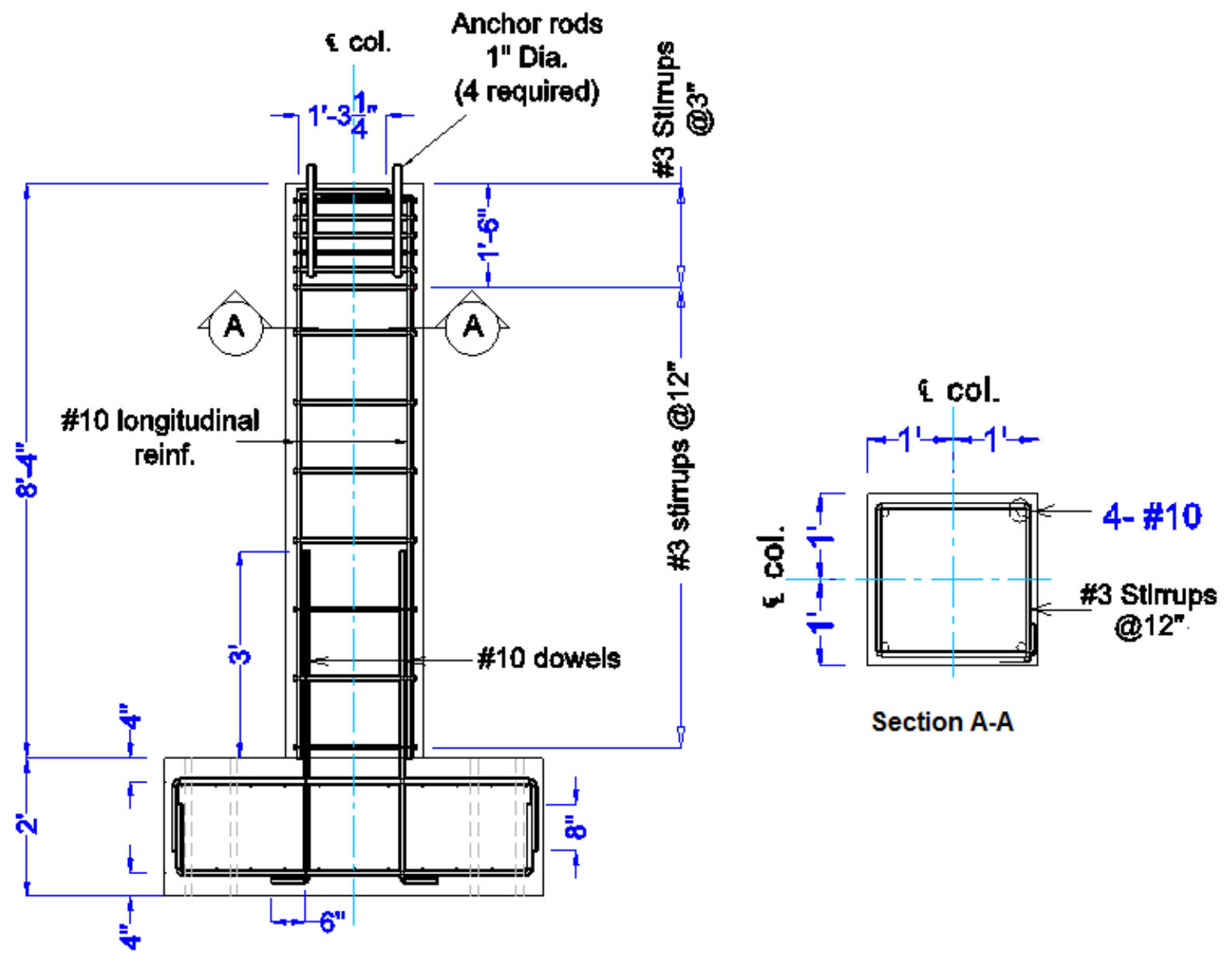

Figure 4.2: Geometry and Reinforcement of RC Bridge Column 
The columns in the experimental program were given an identification that denoted the column condition (As-built (A), Retrofitted (R)), loading protocol (Subduction (S), Conventional (C)) and axial load ratio in percentage ( 8 and 17). The identifications for the four columns in the experimental program were A-S-8, R-S-8, A-C-8, and A-S-17.

\subsection{MATERIALS USED TO CONSTRUCT SPECIMENS}

All reinforcing steel used to construct the test specimens consisted of Grade 60 deformed bar conforming to the American Society of Testing and Materials (ASTM) Designation A615. Normal weight concrete was used to construct the test specimens with target 28-day strength of 3500 psi. Standard compression testing of 6 -inch by 12 -inch concrete cylinders was performed at approximately 7 -day intervals up to 28 days and the day of test completion.

\subsection{RETROFITTING MATERIAL}

For this project a CFRP composite material called Tyfo ${ }^{\mathrm{S} C H}-41$ was used for retrofit and was selected due to its many advantages. Tyfo ${ }^{\circledR S C H}-41$ composite is comprised of epoxy and reinforcing carbon fabric and has unidirectional carbon fabric orientated in the $0^{\circ}$ direction. One major advantage is the capability to improve column ductility without considerable stiffness amplification while maintaining the bridge dynamic properties. Preliminary design calculations showed that three layers of the Tyfo SCH-41 composite would give a displacement ductility factor of 9.3. Therefore, three layers of this CFRP were wrapped from top of the footing up to the potential plastic hinge region ( 3 feet) and were provided in order to enhance the deformation capacity of the columns. The expectation from this retrofit method was to adequately increase the ductility of the plastic hinge zone so that the region did not degrade leading to a possible shear failure and lap splice failure.

\subsection{TEST SETUP}

The columns were tested in the upright position. The top of the column was free to translate and rotate. The cyclic lateral loading was applied through a horizontal actuator connected to a steel beam on top of the column. The lateral force was applied under displacement control. The applied lateral load was reacted against a steel reaction frame connected to the laboratory strong floor. Load cells were used to monitor the applied load during testing.

To simulate the dead load on bridge columns, $\sim 7 \%$ of the column axial capacity $\left(\sim 0.07 \mathrm{f}^{\prime} \mathrm{cAg}\right)$ was applied through four high-strength rods located on the east and west sides of the column, attached to the horizontal steel beam, which also served to transfer the actuator lateral loads. Four hydraulic rams were placed on top of the steel beam through the four tension rods. Load cells were used to monitor the applied axial load during testing. The footing was secured to the laboratory floor with post-tensioning rods. The rods were placed on four corners of the column. A schematic representation of the laboratory test set up is shown in Figure 4.3.

Strain gages were used to measure the strain at specific points in the specimens. A total of 12 strain gages were mounted on the flexural reinforcing bars, ( 2 on the longitudinal bars and 10 on the dowels). All strain gages were placed at and below the plastic hinge, which was a little less 
than 24". Installation of all strain gages was performed prior to the placement of the concrete. LVDTs were used to measure displacements of specified points on the specimen.

Failure was defined as a 20\% drop in peak lateral load for each specimen. First yield displacement was predicted from moment curvature curves and was updated during the test. The force at the specified yield displacement were recorded (both directions) and the stiffness of the columns was calculated based on the first yield displacement from moment curvature and these forces. The updated yield displacement was then calculated as the ratio between the theoretical strength when $e_{c}=0.004$ and the calculated stiffness.

\subsection{LOADING PROTOCOL}

For this experiment program two types of loading protocols have been used, namely, standard (conventional) cyclic loading protocol and subduction zone loading protocol. Commonly, the seismic performance of reinforced concrete bridge columns is assessed using a standard cyclic loading protocol (Cheung et al. 1991; Priestley et al. 2002; Kowalsky et al. 2009). Experimental studies have demonstrated that this type of loading protocol may not be representative of the demands imposed by earthquake excitations, which would generally contain many small inelastic cycles and only a few large inelastic cycles before collapse occurs (Kunnath et al. 1997; Song and Lee 2012).

Quasi-static loading protocols that reflect the increase in the inelastic demands of bridge columns subjected to subduction zone earthquakes of large magnitude and long duration have been developed (Bazaez and Dusicka 2013) and were employed in this study. Subduction zone loading protocols are expected to capture more closely the inelastic demands and therefore their application would improve the seismic assessment of bridge columns through testing.

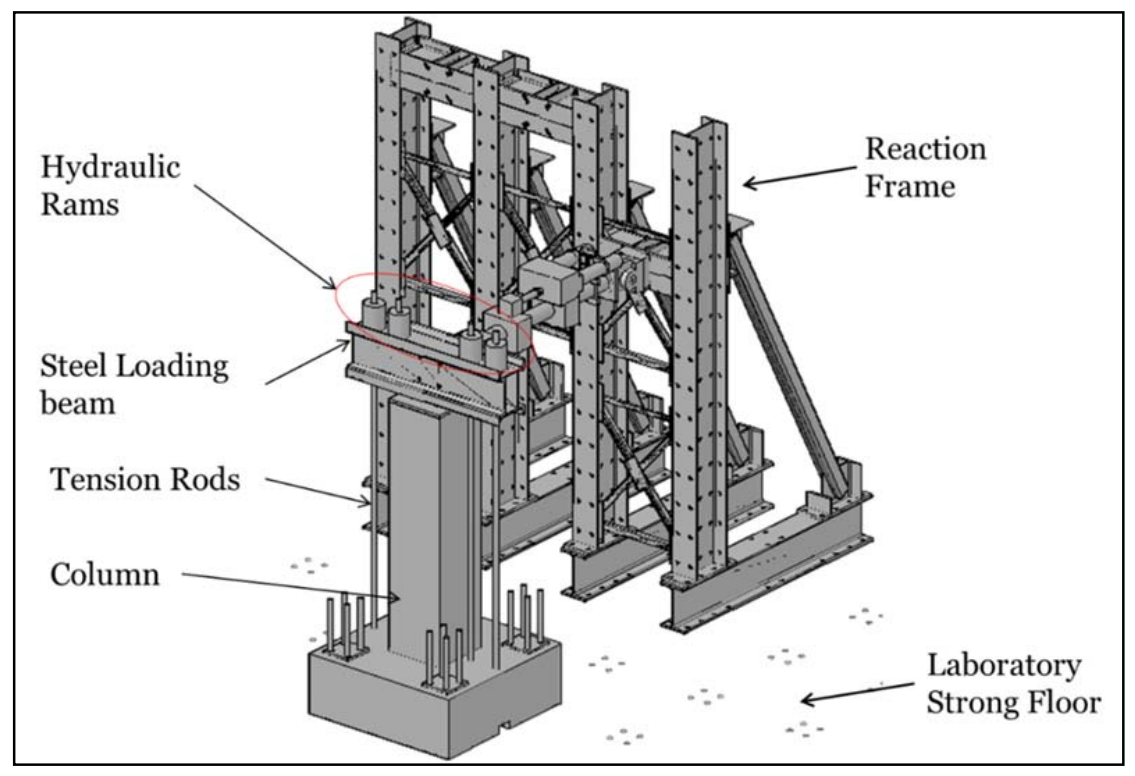

Figure 4.3: Test Set-Up Configuration 


\subsection{RESULTS OF TESTS}

\subsubsection{Visual and Measured Observations}

Before the experimental testing, each column was checked for cracks. And once the test was started, new cracks that were observed on the column faces after the first peaks of specific displacement cycle were indicated with marking pens. In all the tests, except column R-SU-160, the spalling height increased progressively with increasing lateral displacement of the column. Most of the damage in all the columns occurred at the base of the column. However, numerous flexural cracks, visible under applied loading, were observed mostly up to the mid-height of the column and the formation of flexural cracks continued with increasing levels of displacements for the unretrofitted columns.

Failure in the as-built specimens was caused by crushing of concrete at the base followed by lap splice failure, which in the end led to buckling of the dowels.

\subsubsection{Column A-S-8}

Column A-S-8 exhibited a moderately ductile behavior. The primary mode of failure for the column was crushing of concrete at the base of the column causing plastic behavior to be concentrated at the base where a cold joint between footing and column existed followed by lap splice failure. Longitudinal reinforcements also buckled at the base of the column once the concrete cover spalled. Its load-displacement response is shown in Figure 4.4. The lateral load vs. displacement hysteresis curves for this specimen indicates reasonable ductility and energy dissipation. Specimen A-S-8 was able to attain a maximum displacement ductility, $\mu_{\Delta}$, of 6 .The peak lateral load was 46 kips and occurred at a lateral displacement of approximately -4.6 in. The specimen exhibited a significant decrease in lateral strength at a displacement level of $-5.7 \mathrm{in}$, and at 4.25 in the applied load dropped below $80 \%$ of the peak.

The concrete cover over the lap splice showed only minimal signs of vertical cracking. At a displacement of 1.2 in. $(30 \mathrm{~mm})$, spalling of the concrete cover at the base of the column began due to flexural loading, exposing the column reinforcement. Once the concrete cover was lost, the longitudinal bars in this region began to buckle. Photos of the test are shown in Figure 4.5. 


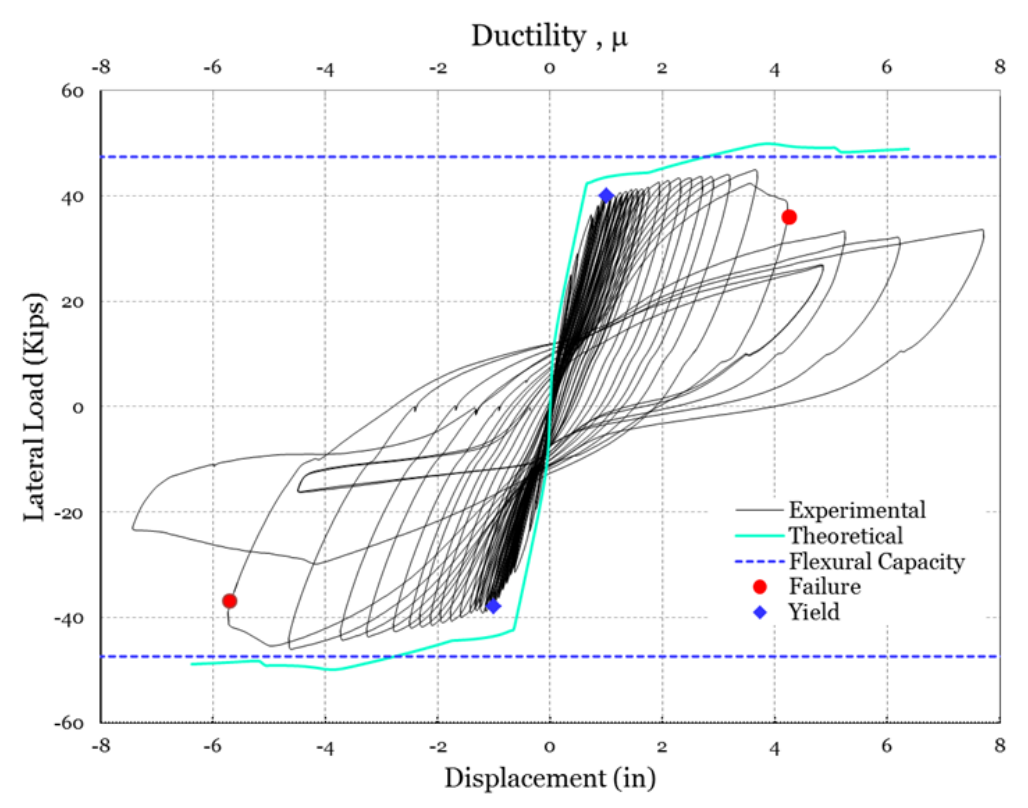

Figure 4.4: Hysteretic Response of Column A-S-8

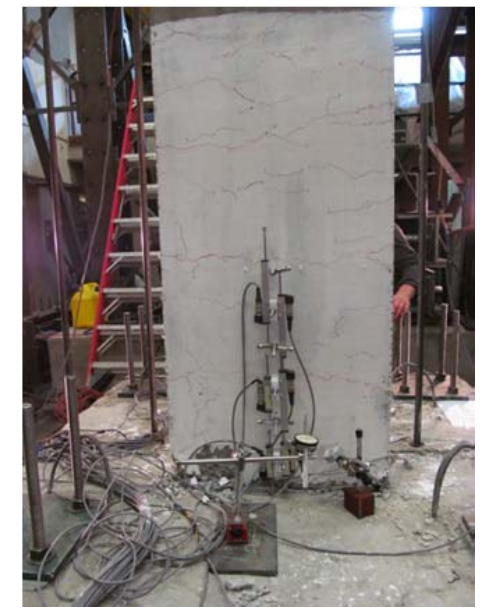

(a)

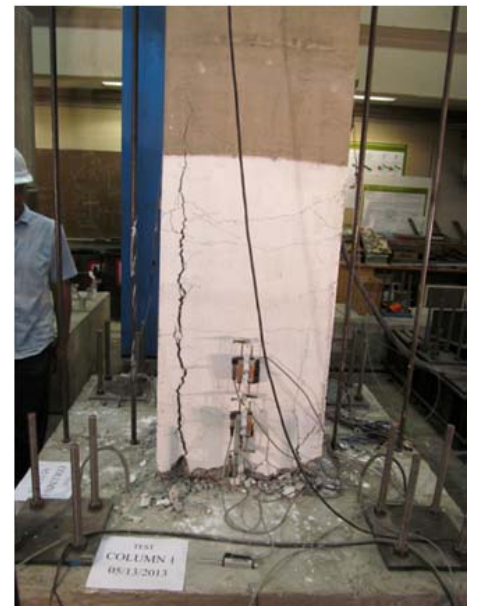

(b)

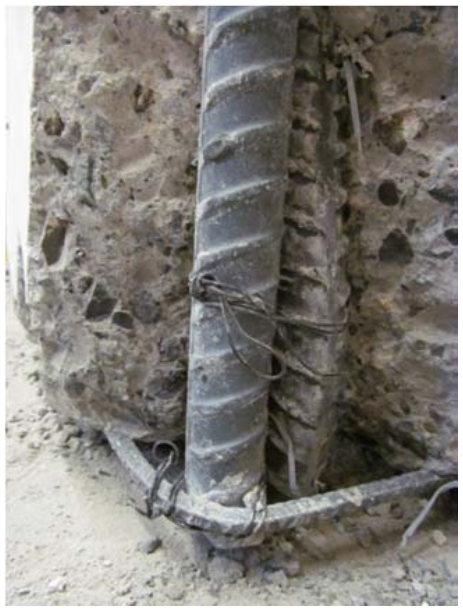

(c)

Figure 4.5: (a) Crushing of concrete at the base, (b) Lap Splice Failure and (c) Bar Buckling

\subsubsection{Column A-C-8}

A-C-8 showed a failure mode similar to A-S- 8 but reached ductility above 6 pulling and about 4.5 pushing. Column A-C-8 did not show as much degradation compared to A-C-8 at same ductility amplitudes. There also was a noticeable lap splice failure and crushing of concrete at the cold joint connection between the column base and footing. The loaddisplacement response is shown in Figure 4.6. 
Specimen A-C-8 was able to attain maximum displacement ductility, $\mu_{\Delta}$, of 4.8 . The peak lateral load was -46 kip and occurred at a lateral displacement of approximately -5.6 . The specimen exhibited a significant decrease in lateral strength at a displacement level of 7.75 in (ductility 6.2) in, and at 6 in (ductility 4.8) the applied load dropped below $80 \%$ of the peak. Photos of the test are shown in Figure 4.7.

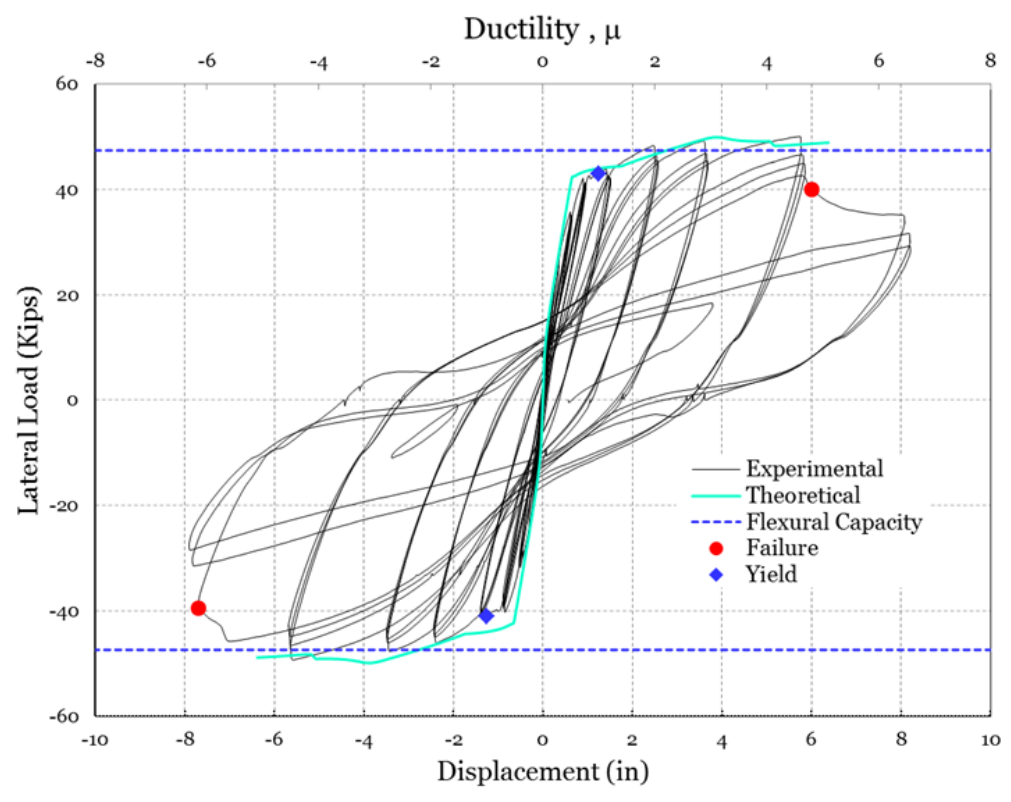

Figure 4.6: Hysteretic Response of Column A-C-8

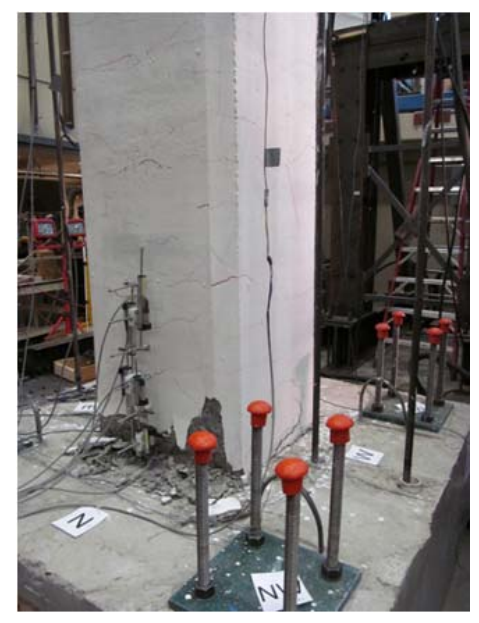

(a)

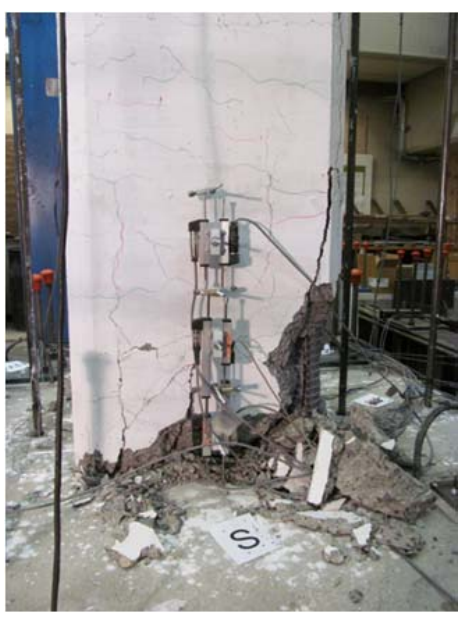

(b)

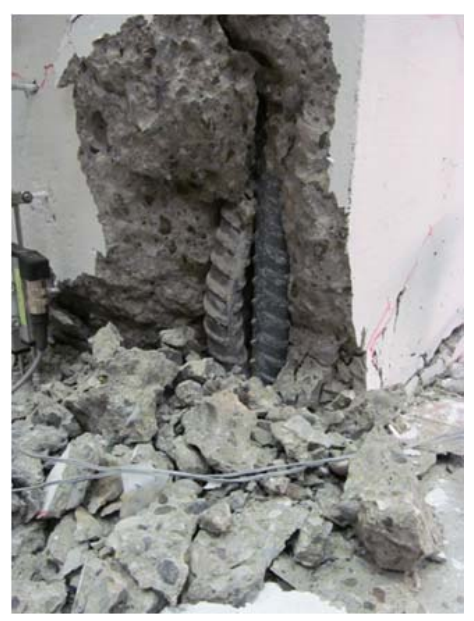

(c)

Figure 4.7: (a) Crushing of concrete at the base, (b) Lap Splice Failure and (c) Bar Buckling 


\subsubsection{Column $R-S-8$}

The test on column R-S-8 showed that retrofitting with CFRP wraps considerably enhanced displacement ductility of these deficient columns. The retrofit helped inhibit bond failures in lap splices of longitudinal reinforcement in the plastic hinge regions and provided confinement producing very minimal spalling of concrete at the base of the column. Failure was not achieved due to the limitation in test setup. The column achieved a displacement ductility of $>8$. There was significant rocking at the cold joint between the column base and footing and horizontal cracks were observed on the faces of the columns above the FRP throughout the testing.

Specimen R-S-8 was able to attain a maximum displacement ductility, $\mu_{\Delta},>8$, even though the column did not fail during the experiment due to limitation. The peak lateral load reached was 57 kips and occurred at a lateral displacement of approximately -4.6 in. The load-displacement response is shown in Figure 4.8, and photos of the test are shown in Figure 4.9.

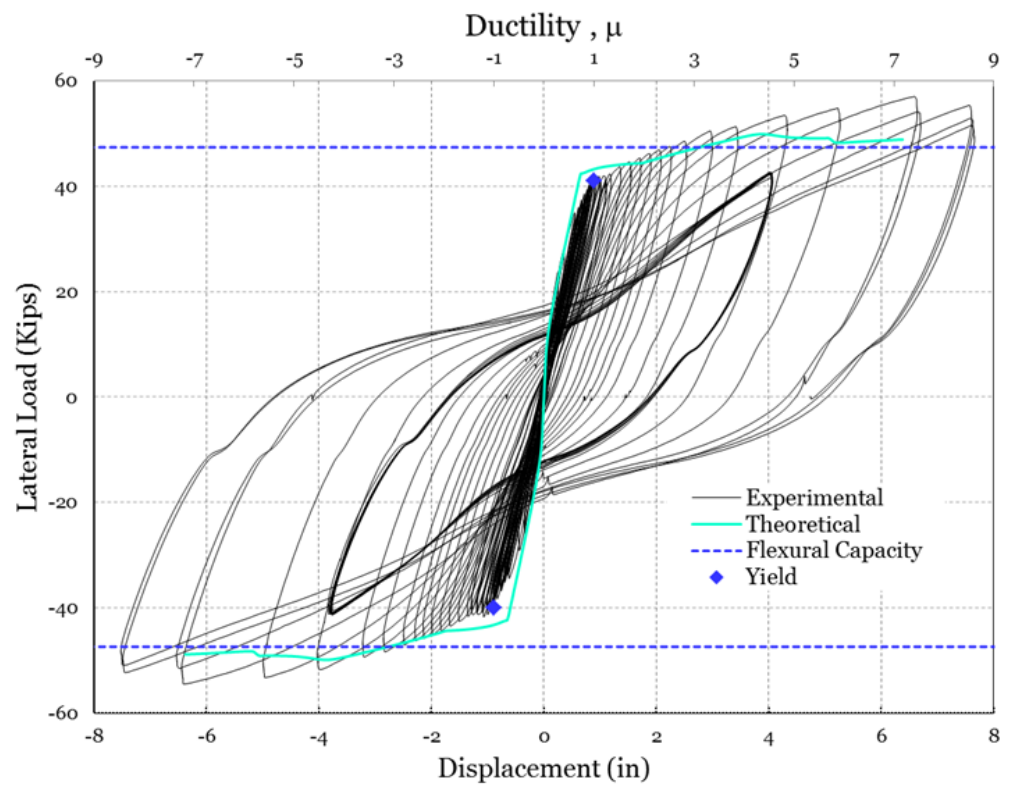

Figure 4.8: Hysteretic Response of Column R-S-8 


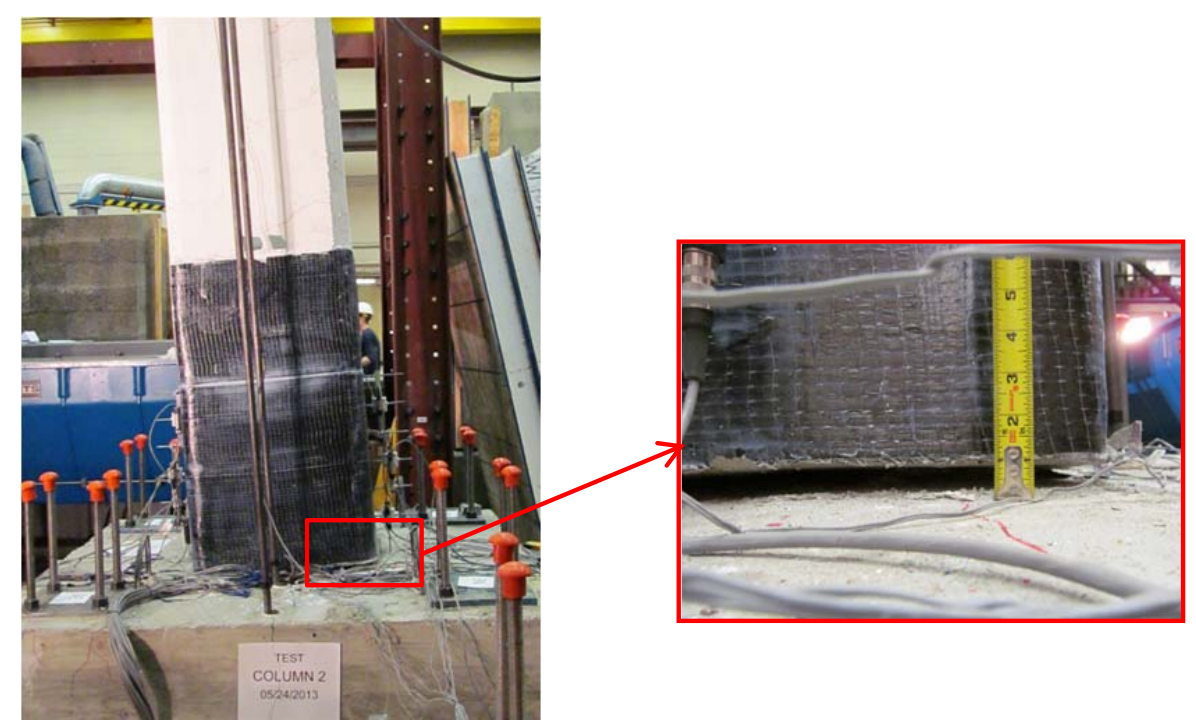

Figure 4.9: Uplift at Base of Column R-S-8

\subsubsection{Column A-S-17}

Column A-S-17 had an axial load that was more than twice of what was applied on the other three columns. This test showed that increasing axial load (gravitational load) did not change the ductility that much. A-S-8 and A-S-17 showed similar ductility at failure. However, the lateral load at yield or failure was significantly higher for the latter case. There was rocking at the cold joint between the column base and footing, and horizontal cracks were observed on the faces of the columns as well as diagonal shear cracks.

Specimen A-S-17 was able to attain maximum displacement ductility, $\mu_{\Delta}$, of 3.4. The peak lateral load was -66 kip, and it occurred at a lateral displacement of approximately 2.82 (ductility 2). The specimen exhibited a significant decrease in lateral strength at a displacement level of -5.2 in (ductility 4) and 4.8 in (ductility 3.4) where the applied load dropped below $80 \%$ of the peak. The load-displacement response is shown in Figure 4.10, and photos of the test are shown in Figure 4.11. 


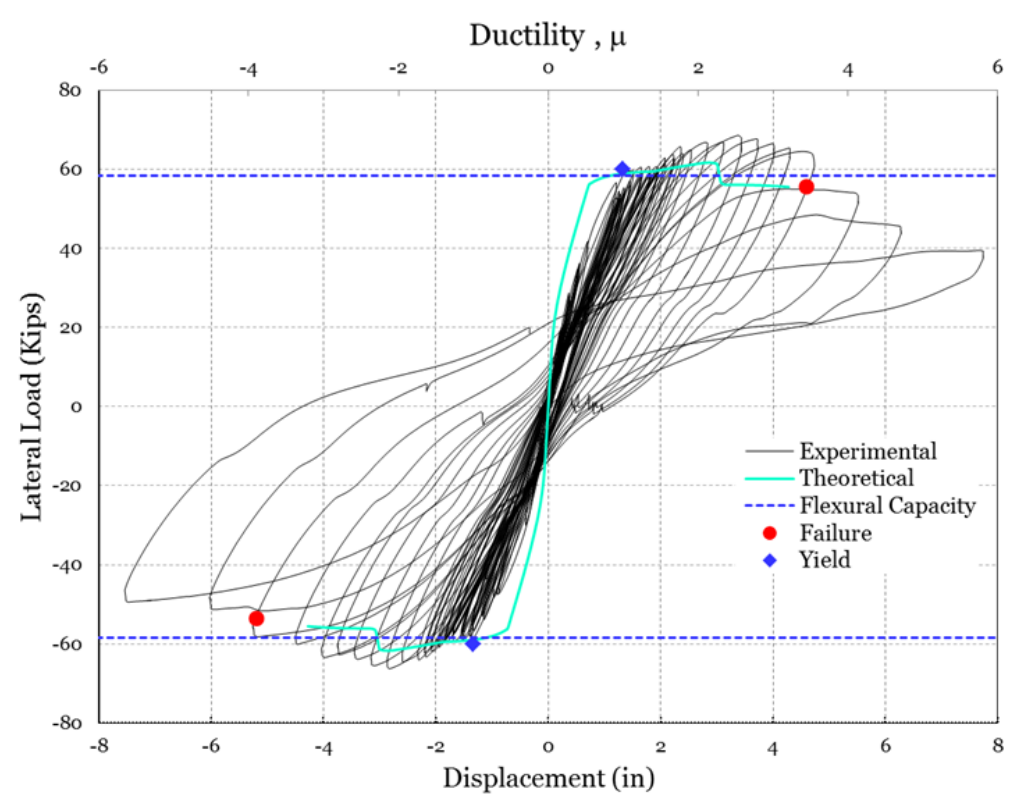

Figure 4.10: Hysteretic Response of Column A-S-17

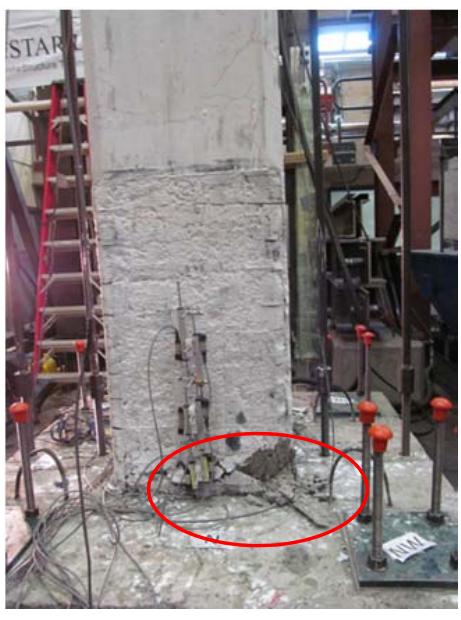

(a)

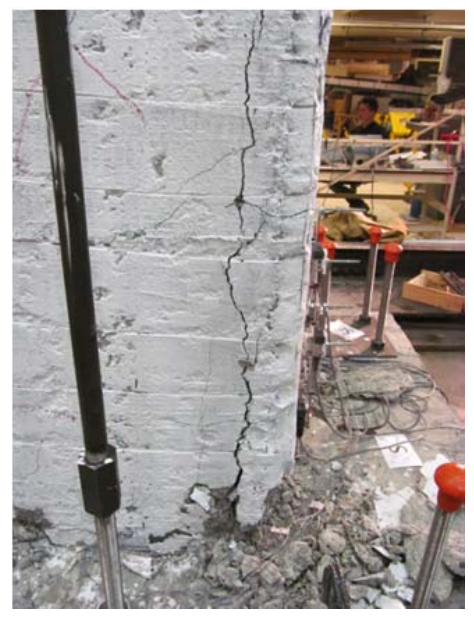

(b)

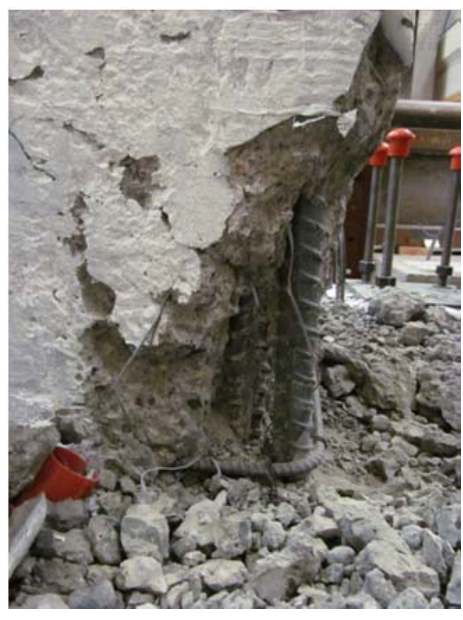

(c)

Figure 4.11: (a) Crushing of concrete at the base, (b) Lap Splice Failure and (c) Bar Buckling

\subsection{SUMMARY OF TEST RESULTS}

The experimental results of this study indicate that square columns in bridges in the Pacific Northwest before 1971 have unexpected deformation capacity that could be taken advantage of and potentially reduce the cost of retrofit. Failure in the specimens representing the as-built conditions was caused by crushing of concrete at the base of the column causing plastic behavior to be concentrated at the base where a cold joint between footing and column existed, followed by lap splice failure. Reasonable energy dissipation and ductility were achieved in the as-built specimens, reaching a displacement ductility level of 6 and above for both conventional and 
subduction loading protocols. This moderately ductile performance of the as-built columns is likely a result of a reasonably long lap splice length (35dp), a low axial load level $\left(0.07 \mathrm{f}^{\prime} \mathrm{c} \mathrm{Ag}\right)$ and a low longitudinal steel reinforcement ratio $(\rho=1.2 \%)$.

Nonetheless, the surprising moderately ductile performance of the as-built column was considerably enhanced using the CFRP retrofit, reaching large displacement ductilities without failure. The retrofit helped inhibit bond failures in lap splices of longitudinal reinforcement in the plastic hinge regions and provided confinement producing only minor spalling of concrete at the base of the column. The CFRP retrofit was shown to be effective, despite the square cross section of the columns.

These experimental tests also demonstrated that subduction loading protocols reduce the displacement ductility capacity of reinforced concrete columns and can change the failure mode. Subduction zone protocols have more damaging cycles and fewer large inelastic cycles representing subduction zone demands. The primary mode of failure for the column was by lap splice failure for the column tested under subduction loading protocol while under the standard cyclic loading protocol, the primary mode of failure was crushing of concrete at the base of the column causing plastic behavior to be concentrated at the base where a cold joint between the footing and column existed. The CFRP retrofit addresses both of these types of failure mode.

\subsubsection{Recommendations}

Two major practical outcomes resulted from the above experimental efforts that directly benefit ODOT as they can be readily adopted in bridge assessment and retrofit.

- The demonstrated moderate levels of ductility achieved by as-built deficiently detailed reinforced concrete columns can be taken advantage of by designers who are assessing vulnerable bridges. The design demand at a particular bridge site can impose column demands that while plastic, could be below the ductility capacity demonstrated by the as-built condition. In these cases, column retrofit would not be necessary and would decrease the cost of the overall retrofit. These cases could occur in assessing as-built bridges, or can be part of an overall retrofit strategy. In either case, cost savings would be realized for the retrofit.

- The effectiveness of the CFRP wrap to retrofit deficiently detailed reinforced concrete columns of square or rectangular cross section presents a viable retrofit measure. The measure was found to be effective under the more severe subduction loading protocol and could therefore be deployed for bridge retrofit in regions where the Cascadia Subduction Zone governs the demand. 


\subsection{SEISMIC FRAGILITY ANALYSIS OF BRIDGES}

Earthquake loss methodologies that are integrated with a geographic information system have been used in large-scale simulations of transportation networks. Several projects, such as 1999 HAZUS software (Basöz and Mander 1999), associated PEER highway demonstration research (Moore et al. 2006), and REDARS (Werner et al. 2006) have modeled transportation networks to assess the economic impact analysis of damage caused by an earthquake event to a transportation network. The hazard assessment components of these methodologies follow well-known hazard analysis methods and rely on application tools developed in HAZUS. Damage to bridges in the highway network contributes significantly to both direct and indirect losses. Bridge damage fragility curves describe the conditional probability of exceeding a level of direct or indirect bridge damage for a given level of seismic hazard.

Bridge seismic retrofit practices in Oregon were reviewed along with the current state of the art in bridge fragility curve development with the intention to establish a framework for further investigation of the development of analytical fragility curves for bridges in their retrofitted conditions. Once the benefits of different retrofit measures considered were achieved through experimental and numerical retrofit evaluation of a representative bridge, a retrofit measure was decided upon and fragility curves were developed for typical bridges in their unretrofitted and retrofitted state. Cascadia subduction zone scenario strong motion records as well as crustal earthquake records were used, and nonlinear dynamic response analysis was done by creating a model of a representative bridge using the Open System for Earthquake Engineering Simulation (OpenSees) computational analysis program for use in the fragility analysis.

Currently, limited bridge fragility has been developed for retrofitted bridges. Fragility curves that have been developed for retrofitted bridges have been primarily based on numerical analyses of California type bridges (Shinozuka et al. 2002) or on bridge types typical to the eastern part of the country (Padgett and DesRoches 2008). In order to have more relevant results for Oregon and in order to assess the effectiveness of a retrofit, fragility relationships relevant to the Oregon bridge inventory are needed.

\subsection{FRAGILITY DEVELOPMENT METHODS}

Fragility curves can be developed by using empirical methods, expert opinions, or through analytical methods. Empirical fragility curves are developed by utilizing observed damage data during past earthquakes, and fragility curves based on expert opinion are very subjective and depend on the opinions of experts. Analytical fragility curves, on the other hand, are developed by numerical simulations of the response of a structural model of a particular type of bridge subject to earthquake ground motions. Analytical fragility functions can be elastic spectral response, non-linear static analysis, or non-linear time history analysis. An overview of the literature on the above mentioned methods is provided below. 


\subsubsection{Fragility Curves Developed by Empirical Methods}

Empirical fragility curves are developed utilizing bridge damage data obtained from past earthquakes, particularly Loma Prieta (Prieta 1989), Northridge (Northridge1994), and Kobe (Kobe 1995). Empirical fragility method is relatively straightforward compared to the other methods. Fragility curves are expressed in the form of two-parameter lognormal distribution functions of peak ground acceleration to represent the intensity of the seismic ground motion. Earthquake damage reports are used to establish the relationship between the ground motion intensity and the damage state of each bridge.

Basöz and Kiremidjian conducted studies to develop bridge fragility curves by statistically analyzing empirical damage data from the damage reports of the Loma Prieta (Prieta 1989) and Northridge (Northridge 1994) earthquakes (Basöz and Kiremidjian 1998). They compiled structural characteristics for the groups of bridges that were exposed to ground shaking such as abutment type, number of spans, type of superstructure and substructure, length and width of the bridge, skew, etc. They also compiled detailed damage descriptions and the corresponding damage states for bridges damaged in the two earthquakes. Since there were no guidelines for evaluating bridge damage states, they proposed definitions for damage states for columns, abutments, and joints and connections for concrete bridges based on the observed bridge damage in the Northridge earthquake.

Yamazaki et al. proposed fragility curves for expressway structures in Japan based on actual damage data from the 1995 Kobe earthquake (Ymazaki et al. 1999). They estimated spatial distribution of earthquake ground motion indices by using kringing technique, which is a method of stochastic interpolation. They then compared actual data of damage to the expressway network to the estimated ground motion indices and constructed fragility curves with lognormal distributions. Shinozuka et al. considered both empirical and analytical fragility curves. They utilized bridge damage data obtained from the 1994 Northridge and 1995 Kobe earthquake to develop empirical fragility curves (Shinozuka et al. 2000). They made use of the damage reports to establish the relationship between the ground motion intensity and damage state of each bridge. In order to estimate the parameters of the lognormal distribution function they carried out two different methods. In method 1, they developed a fragility curve for each damage state independently for each bridge sample with a given set of attributes. This method assumed that the entire sample was statistically homogeneous. Method 2, they estimated the parameters of lognormal distribution function representing different damage states simultaneously by means of maximum likelihood method. Here the parameters estimated were the medians of each fragility curve and one value of the log-standard derivation arranged to be common to all the fragility curves.

\subsubsection{Fragility Curves Developed by Expert Opinion}

Expert-based fragility curves are those developed from expert opinions. Expert opinions are collected to estimate structural damages from earthquakes. The survey results are then represented in a damage probability matrix describing damage state for different levels of ground motion usually using the Modified Mercalli Intensity (MMI) scale. Damage curves are then developed from the probability matrix. 
ATC performed a survey to gather expert opinions to estimate structural damage (ATC 1991). They had only five bridge experts that responded and offered their opinion on bridge damages. The survey results were represented in a damage probability matrix that described probabilities of specific damage states for different levels of ground shaking using the Modified Mercalli Intensity (MMI) scale. Based on the damage probability matrix, damage curves were developed as shown in Figure 5.1 from the ATC-25 report.

Grossi gathered information from experts on structural vulnerability and the benefits of retrofitting a structure for an earthquake hazard and then proposed a procedure for conversion of this data from mean damage at various levels of ground shaking to a fragility curve (Grossi 2000). Grossi first aggregated expert opinion data on mean damage versus MMI into an analytical distribution of each level of ground shaking. The distribution was then utilized to develop damage probability matrices (DPM). Once the probabilities were developed, a cumulative lognormal distribution function was fit to these cumulative DPM data points. The MMI was then converted to PGA, which in turn was converted to spectral acceleration $\left(\mathrm{S}_{\mathrm{A}}\right)$ and spectral displacement $\left(\mathrm{S}_{\mathrm{D}}\right)$ pairs based on the capacity spectrum method (CSM). The CSM is used to estimate the peak building response at the intersection of the building capacity curve and the response spectral displacement demand.

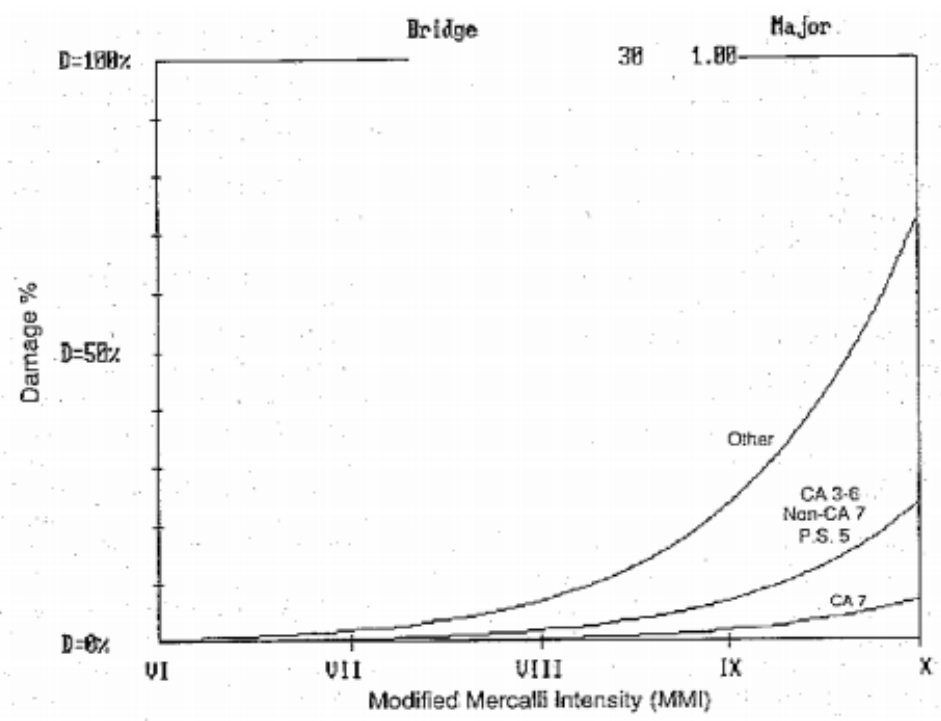

Figure 5.1: Damage percent by intensity for major bridges (ATC-25 1991)

\subsubsection{Fragility Curves Developed by Analytical Methods}

\subsubsection{Elastic Spectral Analysis}

Hwang et al. proposed an analytical method to develop fragility curves for bridges in the Memphis area (Hwang et al. 1999; 2000; 2001). They first established bridge models for each bridge type and then evaluated bridge components that had potential for being damaged during an earthquake to determine their capacity to damage ratios. They determined capacity as described in the Seismic Retrofit Manual for Highway Bridges, and they determined seismic damage from elastic spectral analysis according to the method specified in the Standard Specifications for Highway Bridges (AASHTO 1996). 
There were three damage states considered in their study, namely, no/minor damage, repairable damage and significant damage. For each level of PGA they performed 50 calculations of bridge damage states. The bridge damage data was then statistically analyzed and the results displayed as fragility curves.

\subsubsection{Non-linear Static Analysis}

Mander and Basöz developed a theoretical basis of establishing fragility curves for highway bridges through the use of rapid analysis procedures from the fundamentals of mechanics and dynamics (Mander and Basöz 1999). They made used three sources of data for the analysis, that is National Bridge Inventory (NBI) records that contain the bridge attributes and geographical location, ground motion data (usually best obtained from the USGS web site), and geological maps. They used a capacity-spectrum approach to develop the fragility curves for bridges. They validated the analytically predicted values against fragility curves that were empirically derived from data gathered for bridges damaged in the 1994 Northridge and 1989 Loma Prieta earthquakes. These fragility curves developed by Mander and Basöz were used in a geographic information system-based natural hazard loss estimation software package developed and freely distributed by the Federal Emergency Management Agency (FEMA) called HAZUS. Two types of bridge fragility curves are used in HAZUS. One is based on the peak ground acceleration (PGA) and the second is based on the permanent ground displacement (PGD).

Shinozuka et al. examined fragility curves of a bridge by time history analysis and the capacity spectrum method which is one of the simplified nonlinear static procedures developed for buildings (Shinozuka et al. 2000). To determine capacity they performed pushover analysis. The force-displacement curve was plotted by tracking the total shear force at the column bottoms as a function of displacement of the superstructure. The lateral forces were applied in proportion to the fundamental mode shape from the capacity spectrum method. Their comparison of fragility curves generated by the nonlinear static procedure with those by time-history analysis indicated that there was good agreement for the state of minor damage, but not as good for the state of major damage where nonlinear effects clearly played a vital role.

Liao and Loh used a nonlinear static analysis method for the development of analytical fragility curves in terms of PGA (Liao and Loh 2004). The demand spectrum is given in terms of site amplification coefficients and demand spectral acceleration for different ranges of periods. The demand spectral acceleration at period $\mathrm{T}$ second is obtained by first specifying attributes of the scenario earthquake including location, depth, magnitude, fault rapture type, etc. Then the ground motion levels for the bedrock using appropriate attenuation laws are determined. Site amplification factors are included for short and long periods. The bridge capacity curve is evaluated by first creating a computer model of the prototype bridge structure. This capacity is used to demonstrate the seismic capacity of a bridge structure. The ordinate gives the shear and abscissa is the displacement. Then a nonlinear pushover test, which is the relationship between the base shear and the displacement, can be established and convert the pushover curve to a 
capacity spectrum by using empirical equations. They used the fragility curves generated for seismic loss estimation for the transportation system.

\subsubsection{Non-linear Time History Analysis}

\section{Synthetic Ground Motion Sources}

Shinozuka et al. constructed analytical fragility curves on the basis of the nonlinear time history analysis (Shinozuka 2000). They used two representative bridges with a precast, prestressed continuous deck in the Memphis area. For the seismic ground motion, they used time histories generated by the Center for Earthquake Research and Information at the University of Memphis. They randomly selected 10 time histories from the 50 histories generated for different combinations of magnitude and epicentral distance. They used SAP2000 finite-element code to approximately simulate the state of damage of each bridge under a ground acceleration time history. The median and log-standard deviation parameters for the log-normal fragility curve were estimated by maximum likelihood procedure and the fragility curves are generated.

Hwang et al. presented an analytical method for the development of fragility curves of highway bridges (Hwang et al. 2001). They first created a suitable model of the bridge of interest. They then generated a set of synthetic acceleration time histories that covered a range of ground shaking strength. A nonlinear time history response analysis was then performed for each earthquake-site-bridge sample to simulate a set of bridge response data. A regression analysis was then performed of the simulated response data to set up the probabilistic characteristics of structural demand as a function of a ground shaking. Once the bridge damage states were defined and the probabilistic characteristics of structural capacity corresponding to each damage state established, the conditional probabilities that structural demand exceeds structural capacity for various levels of ground shaking were computed. The fragility curves were then finally plotted as a function of the ground shaking parameter.

Shinozuka et al. studied the impact of stochastic spatial variability of seismic ground motion on the seismic response of long, multi-span, reinforced concrete bridges (Shinozuka et al. 2001). They selected a twelve-span continuous reinforced concrete bridge. They analyzed the bridge with SAP2000 finite element program. They generated the seismic ground motion time histories that were compatible with prescribed response spectra at the supports of the bridge and to reflect a prescribed coherence function, apparent velocity of wave propagation and duration of strong ground motion. They defined five different damage states in terms of ductility demand of the piers. The fragility curves were expressed in the form of two-parameter lognormal distribution functions where the two parameters were estimated by the Maximum Likelihood Method treating each event of bridge damage as a realization from a Bernoulli experiment.

DesRoches et al. developed analytical fragility curves that were based on nonlinear response history analyses and a suite of synthetic ground motions (DesRoches et al. 2003). They represented the bridge by an analytical model that included the inelastic behavior of the appropriate components. They then developed earthquake input motion for various characteristic magnitudes, epicentral distances, and local soil conditions. 
After establishing a set of earthquake-bridge sample where the uncertainties in seismic source, they quantified path attenuation, soil conditions and bridge components. They then performed a non-linear response history analysis on these samples. They defined damage states for column ductility demand, steel fixed and expansion bearing deformations, and elastomeric bearing deformations. And by using these predetermined damage indices, they assigned a damage state to each component of the bridge, which were combined into fragility curves that represented the entire bridge system using firstorder reliability principles.

Pan developed seismic fragility curves as a function of moment magnitude and epicentral distance for individual bridge components and entire bridge systems, and investigated the effectiveness of different seismic retrofit approaches in reducing seismic fragility (Pan 2007). Pan developed three-dimensional finite element models for two typical New York State bridge types, namely, multi-span continuous and multi-span simply supported steel bridges using SAP2000 (9.1.1.V). Pan then performed nonlinear time history analyses of 10 bridge samples for both typical bridges using 100 simulated earthquake ground motions where each bridge sample was subjected to 10 different ground motions selected to cover a wide range of PGAs. She gathered maximum response quantities of bridge components and estimated capacities of bridge samples at various damage states for each of the 100 analysis cases. She then carried out linear and quadratic regressions between the logarithm of demand to capacity ratio, and $\ln$ (PGA). Once the mean and standard deviation were obtained through regression analysis, fragility curves were developed as a function of PGA.

Nielson and DesRoches generated analytical fragility curves for typical bridges in the Central and Southern United States (Nielson and DesRoches 2007). They developed seismic fragility curves for nine classes of bridges (common three-span, zero-skew bridges with non-integral abutments). The methodology they adopted used 3-D analytical models in combination with a suite of 96 synthetic ground motions and nonlinear timehistory analyses. An important aspect of the methodology they selected was that it considered the contribution of multiple bridge components. Their results showed that multi-span steel girder bridges were the most vulnerable of the considered bridge classes while single-span bridges tended to be the least vulnerable. They made a comparison of their proposed fragility curves with the ones that are currently found in HAZUS-MH and they determined that it showed a strong agreement for the multi-span simply supported steel girder bridge class. However, for other simply supported bridge classes (concrete girder, slab), the proposed fragility curves suggested a lower vulnerability level than what the ones in HAZUS-MH suggest.

\section{Strong Ground Motion from Past Records}

Karim and Yamazaki constructed fragility curves for bridge piers of specific RC bridges in Japan and compared the results with the empirically developed fragility curves. They first selected strong motion records for the 1995 Kobe earthquake. In total 50 time histories were taken on the basis of Peak Ground Acceleration (PGA) and Peak Ground Velocity (PGV). They then used this acceleration time histories as input time ground motion and obtained bridge damage indices for the bridge piers. Finally using the damage 
and ground motion indices, they constructed fragility curves for $\mathrm{RC}$ bridge piers. The comparison of the fragility curves they obtained were in agreement with those developed by empirical methods (Yamazaki et al. 1999; Karim and Yamazaki 2000).

Karim and Yamazaki considered an analytical approach to construct the fragility curves for bridge piers of specific bridges designed using the 1964 and 1998 seismic design codes for highway bridges in Japan (Karim and Yamazaki 2001). For a non-linear dynamic response analysis they selected earthquake ground motion records on the basis of large peak ground acceleration (PGA) from the 1995 Hyogoken-Nanbu (Kobe), the 1994 Northridge, the 1993 Kushiro-Oki and the 1987 Chibaken-Toho-Oki earthquakes. They considered a total of 50 acceleration time histories from each earthquake event. After normalizing the PGA of the selected earthquakes to different excitation levels, they created an analytical model of the bridge and obtained the stiffness of the structure. They then selected a hysteretic model for the non-linear dynamic response analysis and carried out the non-linear dynamic response analysis using the selected records. The ductility factors of the structures were then obtained and the damage indices of the structure for each level of excitation were also obtained. Finally, using the damage indices and the ground motion indices, the analytical fragility curves were constructed.

Karim and Yamazaki adopted an analytical approach to construct fragility curves for highway bridge piers (Karim and Yamazaki 2003). Four typical RC bridge piers and two $\mathrm{RC}$ bridge structures were considered, of which one was a non-isolated system and the other was an isolated system. The bridges were designed according to the seismic design code in Japan. The researchers used strong motion records from Japan and the United States, and performed non-linear dynamic response analyses and obtained the damage indices for the bridge piers. The fragility curves for the bridge piers were constructed using the damage indices and ground motion indices assuming a lognormal distribution. They also obtained a relationship between the fragility curve parameters and the overstrength ratio of the structures by performing a linear regression analysis. They observed that the fragility curve parameters showed a strong correlation with the over-strength ratio of the structures.

Simon et al. examined the effects of reinforcement corrosion on strength due to a reduction of reinforcement area, on stiffness due to spalling of the concrete cover, and on seismic fragility (Simon et al. 2010). For the analysis they employed both nonlinear static and dynamic analyses. The nonlinear, time-history dynamic analyses were performed to determine the seismic response of the bridge structure to a group of varying intensity earthquake records. A suite of earthquake records constituting a representative sample of expected seismic activity for the bridge were used as earthquake ground motion. They chose six earthquakes from the Pacific Earthquake Engineering Research Strong Motion Catalog. They then compared the six chosen earthquakes' median spectral acceleration to the theoretical spectra determined using the attenuation law (Abrahamson and Silva 1997). They study the inelastic behavior of the bridge by creating additional bins by scaling up the six records already selected. The seismic demand model developed predicts the maximum total drift based on the spectral accelerations corresponding to the fundamental periods in the longitudinal and transverse directions. The mean drift capacities of 1, 2 and 4\% for insignificant damage (immediate occupancy or 
serviceability), moderate damage (life safety or damage control), and severe damage (collapse prevention), respectively, and defined collapse as the drift corresponding to a decrease in lateral resistance of $20 \%$ compared to peak value are then used to define capacity of bridge. Simon et al then developed a probabilistic seismic demand model, which is then combined with the capacity model and commonly accepted capacity limit states to determine and compare the seismic fragility for different levels of corrosion damage.

\subsubsection{Fragility Curves Developed by Other Methods}

Stojadinović and Mackie developed fragility curves based on the bridge force reduction factors ( $R$-factors) for three damage states, namely concrete cover spalling, longitudinal bar buckling, and column failure (Stojadinović and Mackie 2007). They used sophisticated finite element models and nonlinear time history analyses to define demand and they defined capacities in terms of actual damage states rather than discrete demand levels. The $R$-factor parameterized damage fragility curves accounted for the structural characteristics of each particular bridge through the use of the bridge force reduction factor parameter unlike those provided by HAZUS that utilize the same damage fragility curve for all instances within a class of bridges.

\subsection{FRAGILITY CURVES FOR RETROFITTED BRIDGES}

Shinozuka et al. developed fragility curves for two sample bridges in Southern California strengthened for seismic retrofit by means of steel jacketing of columns (Shinozuka et al. 2002). They used SAP2000 nonlinear finite element computer code for two-dimensional response analysis of the bridge under sixty Los Angeles earthquake time histories, which were developed for the FEMA SAC steel project, to develop fragility curves before and after column retrofit.

Padgett reviewed bridge seismic retrofit practice in the Central and Southeastern United States, along with the current state of the art in bridge fragility curve development with the intention to establish a framework for further investigation of the development of analytical fragility curves for bridges in their retrofitted conditions (Padgett 2005). Padgett developed an analytical, twodimensional nonlinear model that was modified to incorporate elements for the retrofits at the locations of the bridge using the Open System for Earthquake Engineering Simulation (OpenSees) computational analysis program. Each bridge sample was matched with 48 earthquake samples from the suite of ground motions that were randomly selected from each magnitude and distance combination. Padgett then performed a non-linear time history analysis for each of the earthquake-bridge samples while keeping an eye on the maximum quantities of interest for the components. Once the median values of seismic demand as a function of ground motion intensity were determined, the structural capacity or structural limit states with a descriptive damage state were determined. Padgett finally determined the fragility of a structural system or structural component by the probability that the structural demand exceeded the structural capacity. The fragility was modeled by a lognormal cumulative distribution function where the structural demand and capacity were assumed to be lognormally distributed.

Padgett and DesRoches evaluated the modeling parameters which significantly affect the seismic response of an example class of retrofitted bridges (Padgett and DesRoches 2007). They developed three-dimensional analytical models in OpenSees and used them in time history 
analyses to simulate the seismic response of the retrofitted bridges. They also developed retrofit models with an emphasis on representing potential nonlinear behavior of the retrofitted component. They used two suites of synthetic ground motions for the central and southeastern United States (CSUS) for their analysis. Their study showed that the seismic responses of various components in the retrofitted bridges were sensitive to a number of different modeling parameters. They found the fragility to be particularly sensitive to the spread of uncertainty in the base geometry span length, column height, deck width which is inherent to vulnerability assessments for structural portfolios.

Padgett and DesRoches presented an analytical methodology for developing fragility curves for classes of retrofitted bridge systems (Padgett and DesRoches, 2007; $2008 ; 2009$ ). Since there were no records of strong motions for the Central and Southeastern U.S., they used two suites of synthetic ground motions for the study. The scenario ground motions were developed based on stochastic methods, considering non-linear site response, and the influence of the deep soil column of the upper Mississippi embayment. Open System for Earthquake Engineering Simulation (OpenSees) was used to create a 2D model of the bridge for the fragility analysis.

\subsection{FRAGILITY CURVE FOR A DEFICIENT THREE SPAN CONCRETE CONTINUOUS GIRDER BRIDGE}

Bridge fragility curves for deficient 3-span concrete continuous stronger/girder bridges have been developed (Roberts and Dusicka 2011). These fragilities will be used in the computer model developed by PSU for the ODOT-identified freight routes of Western Oregon and Columbia River highway network using REDARS2.

\subsubsection{Procedure for the Seismic Fragility Development}

The seismic fragility analysis of highway bridges followed the procedure outlined below:

- OpenSees was used to model the bridge of interest in the study.

- A set of earthquake acceleration time histories was generated, which covered various levels of ground shaking intensity.

- Uncertainties were computed in modeling the seismic source, path attenuation, local site condition, and bridge to establish a set of earthquake-site-bridge samples.

- A nonlinear time history response analysis was done to simulate a set of bridge response data.

- Regression analysis was performed of simulated response data to establish the probabilistic characteristics of structural demand as a function of a ground shaking parameter (spectral acceleration or peak ground acceleration).

- Damage states were defined to establish probabilistic characteristics of structural capacity corresponding to each damage state. 
- Conditional probabilities that structural demand exceeds structural capacity for various levels of ground shaking were determined.

- Fragility curves as a function of the selected ground shaking parameter were plotted.

\subsubsection{OpenSees Model Verification}

In order to verify the usage of concrete and hysteretic material types, Roberts and Dusicka used results from a monotonic analysis and compared those to the cyclic hysteresis (Roberts and Dusicka 2011). One numerical model was created in OpenSees using a fixed-free RC column and applying lateral load at the top of the column. The column was modeled according to a typical continuous concrete stringer/girder bridge column from a 3 span bridge with a fixed base and free top with an axial load applied to it. The lateral force at the base of the column that was recorded while the column was being loaded laterally was compared to the analytical techniques. The results from the model showed reasonable representation of the peaks achieved through the experimental testing as shown in Figure 5.2.

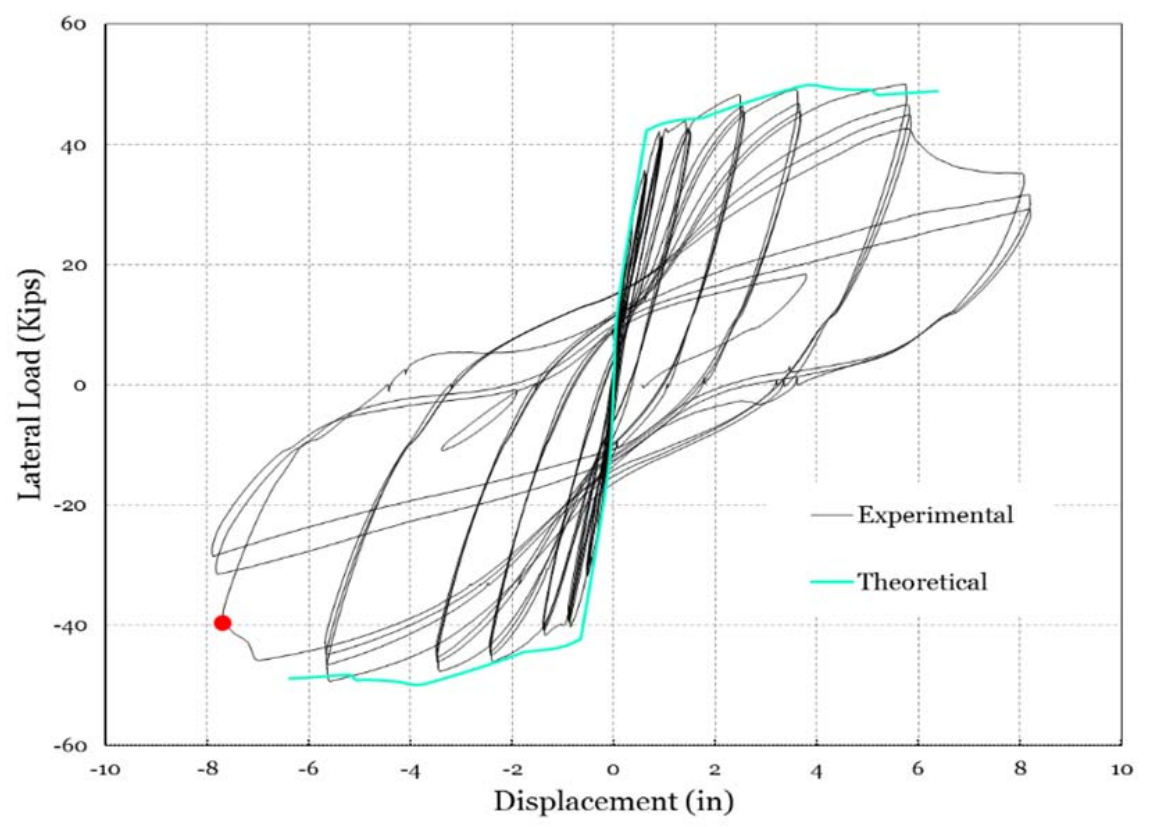

Figure 5.2: Comparison of Experimental and OpenSees Model of Test Column

\subsubsection{Damage States}

Bridge damage resulting from an earthquake event can be classified into damage states ranging from no damage to complete collapse. The bridge model utilized for SRA of the Oregon transportation network was based on HAZUS99-SR2, which defines bridge capacities in terms of spectral accelerations leading to the onset of five damage states listed in Table 5.1 for each of several "standard bridge" classifications.

REDARS тм 2 ground motion model estimates the bridge's site-specific demand ground motions for each seismic event. Each bridge's demand spectral acceleration is compared to the bridge's 
spectral acceleration capacity, as defined by the fragility curve, which leads to the onset of each damage state. Hence, a bridge's damage state is the damage state for which the demand spectral acceleration first exceeds the bridge's spectral acceleration capacity.

Table 5.1: Damage States considered in HAZUS99-SR2 Bridge Model

\begin{tabular}{l|l|l}
\hline \multicolumn{2}{l|}{$\begin{array}{l}\text { Damage State } \\
\text { Designation }\end{array}$} & Description of Typical Expected Damage \\
\hline Number & Level & Up to first yield. \\
\hline 1 & None & $\begin{array}{l}\text { Minor cracking and spalling of the abutment, cracks in shear keys at } \\
\text { abutment, minor spalling and cracking at hinges, minor spalling of } \\
\text { column requiring no more than cosmetic repair, or minor cracking of } \\
\text { deck. }\end{array}$ \\
\hline 2 & Slight & $\begin{array}{l}\text { Any column experiencing moderate shear cracking and spalling (with } \\
\text { columns still structurally sound), moderate movement of abutment (< } \\
5.1 \text { cm) (<2 inches), extensive cracking and spalling of shear keys, } \\
\text { connection with cracked shear keys or bent bolts, keeper bar failure } \\
\text { without unseating, rocker bearing failure, or moderate settlement of } \\
\text { approach. }\end{array}$ \\
\hline 4 & Extensive & $\begin{array}{l}\text { Any column degrading without collapse (e.g., shear failure) but with } \\
\text { column structurally unsafe, significant residual movement of } \\
\text { connections, major settlement of approach fills vertical offset or shear } \\
\text { key failure at abutments, or differential settlement. }\end{array}$ \\
\hline 5 & Complete & $\begin{array}{l}\text { Collapse of any column or unseating of deck spans leading to collapse } \\
\text { of deck. Tilting of substructure due to foundation failure. }\end{array}$ \\
\hline
\end{tabular}

\subsubsection{Developed Bridge Fragility Curves for 3-Span CCGS}

The calculated median and dispersion values are provided in Table 5.2 and Figure 5.3.

Table 5.2: Fragility Curve values for Typical 3-Span Bridge (Roberts and Dusicka 2011)

\begin{tabular}{c|c|c}
\hline Damage State & Median & Dispersion \\
\hline Slight & 0.06 & 0.64 \\
\hline Moderate & 0.07 & 0.68 \\
\hline Extensive & 0.11 & 0.73 \\
\hline Collapse & 0.33 & 0.78 \\
\hline
\end{tabular}




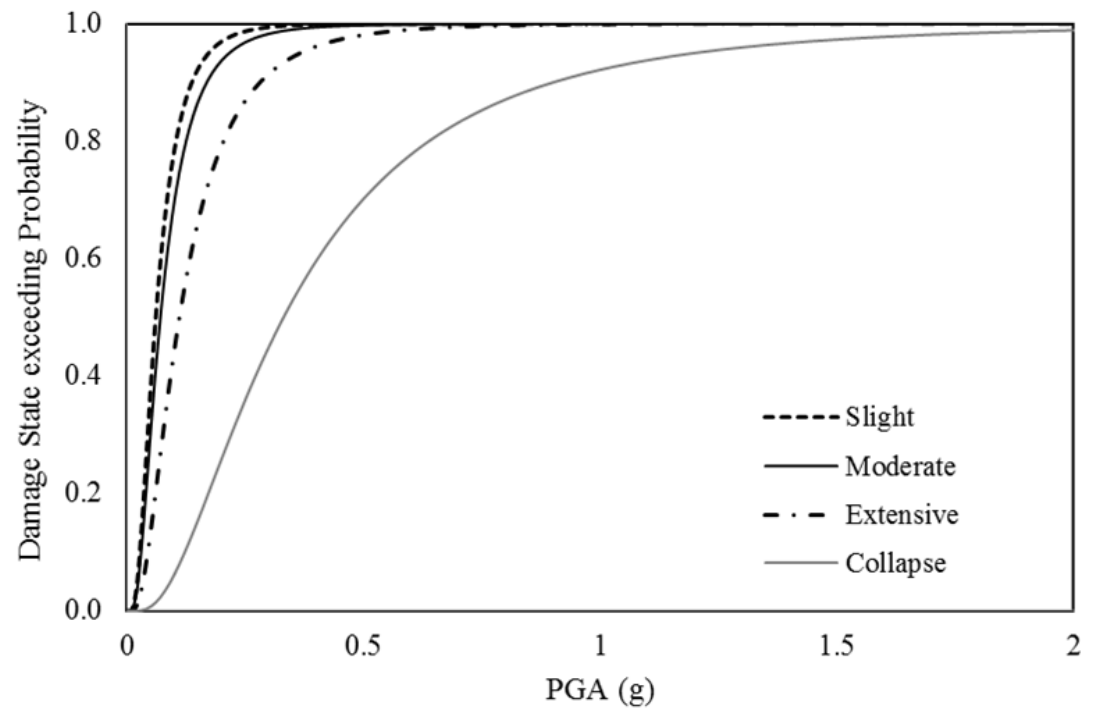

Figure 5.3: Fragility Curves for 3-Span CCSG bridges

\subsection{FRAGILITY CURVE FOR A RETROFITTED THREE SPAN CONCRETE CONTINUOUS GIRDER BRIDGE}

Limited bridge fragility had been developed for retrofitted bridges in Oregon, and fragility curves that were available were primarily based on numerical analyses of California type bridges (Shinozuka et al. 2002; Padgett and DesRoches 2009).

Bridge seismic retrofit practices in Oregon were reviewed along with the current state of the art in bridge fragility curve development with the intention to establish a framework for further investigation of the development of analytical fragility curves for bridges in their retrofitted conditions. For this stage in the study, the default HAZUS fragility curves for a seismically designed bridge were adapted.

The calculated median and dispersion values for these fragility curves are provided in Table 5.3 and Figure 5.4.

Table 5.3: Fragility Curve values for Seismically Designed 3-Span Bridge (FEMA 2010)

\begin{tabular}{c|c|c}
\hline Damage State & Median & Dispersion \\
\hline Slight & 0.9 & 0.6 \\
\hline Moderate & 0.9 & 0.6 \\
\hline Extensive & 1.10 & 0.6 \\
\hline Collapse & 1.50 & 0.6 \\
\hline
\end{tabular}




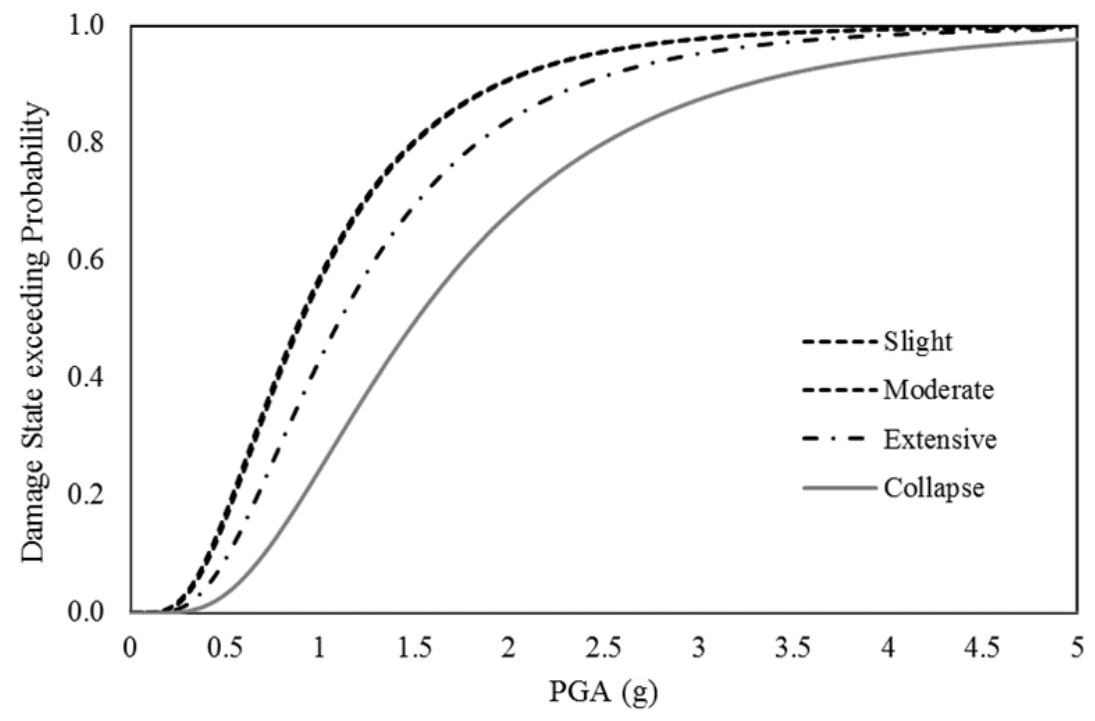

Figure 5.4: Fragility Curves for a Seismically Designed 3-Span CCSG bridges 


\subsection{REVIEW OF SEISMIC RETROFIT PRIORITIZATION METHODS}

Many screening and prioritization methods have been proposed in the past. Most of these methods develop a Seismic Rating System first, and then use the results of this rating exercise to prioritize the inventory. Other methods compare the severity of expected damage for each bridge in the inventory, for the same earthquake, and bridges are rated accordingly. Recent advancement in seismic risk assessment methods has led to the development of fragility functions for specific classes of bridges. These in turn have led to loss estimation methodologies for highway systems and estimation of the effect on system performance as measured by traffic flow (Werner et al. 2006).

These three major methods have been mentioned in the Seismic Retrofitting Manual for Highway Structures (Buckle et al. 2006). The methods are Indices Method, Expected Damage Method and Seismic Risk Assessment Method. A brief overview of the literature on the above mentioned methods and other approaches is provided below.

\subsection{INDICES METHOD}

Indices method is the simplest of the three methods. In this method indices are used to characterize the bridges' vulnerability and hazard level and are then combined to give a single rating for each bridge. Indices range from 0 to 10 and are based on conservative, semi-empirical rules. Prioritization is determined by this rating together with a qualitative evaluation of importance, redundancy, non-seismic issues, and socioeconomic factors.

California Department of Transportation (Caltrans) (Roberts 1991), Applied technology Council (ATC-6-2 1983), The Illinois Department of Transportation (IDOT) (Woodward-Clyde Consultants 1991), Washington State Department of Transportation (WSDOT) (Babaei and Hawkins 1993) etc. have used Indices Method to characterize the structure vulnerability and hazard level and then combining to give a single rating for each bridge. In all these cases the three major variables considered were the vulnerability of the bridge, seismicity of the bridge site and the importance of the bridge.

\subsection{EXPECTED DAMAGE METHOD}

In the Expected Damage Method, the level of expected damage for each bridge in the inventory is compared for the same earthquake. Severity of damage is measured either by sustained damage states or by estimating direct economic losses. The higher the expected damage and/or loss, the higher the priority for retrofitting. Fragility functions are used to address the uncertainties in ground motion and the unpredictability in soil and structure properties and to estimate damage-state probabilities (Buckle et al. 2006). Furthermore, a qualitative assessment of indirect losses, network redundancy, and non-seismic issues are included in the final ranking assessment. 
Cherng et al. presented a method that considered retrofit priority and amount of upgrading (Cheng et al. 1992). They used a retrofit criterion instead of the concept of priority index. The retrofit criterion considered the consequence of failure of the component that included cost of reconstruction, casualty and loss of functionality; loss due to network failure; and retrofit cost for a component increased from before-retrofit strength coefficient to after-retrofit strength coefficient. The main objective of this method was to maximize the net profit benefit for a given budget putting into consideration the network reliability and the criticality of the bridge to the community and the bridges' vulnerability to seismic hazard.

Kim et al. proposed a GIS-based regional risk analysis program with a purpose to interactively study the vulnerability of bridges in a regional highway system (Kim et al. 1992). Basöz and Kiremidjian on the other hand proposed a prioritization/ranking method that was more comprehensive and was based on vulnerability and importance (Basöz and Kiremidjian 1995). In this approach, vulnerability and seismicity were interrelated and their relationship was considered in the ranking process. Vulnerability was assessed by first classifying bridges according to the material type, structure type and other factors such as number of spans, span continuity, column bents, abutment type, etc. Then bridge location and soil condition were used to compute a seismic hazard curve. Corresponding ground-motion damage relationships for the bridge class were then used to evaluate the vulnerability parameter. The consequence of failure of a bridge to public safety and the socio-economic benefit of a community was reflected by the Importance Factor. Transportation lifeline network analysis and decision analysis were the main tools used to evaluate the importance criterion. The Importance Factor was evaluated as a function of public safety, emergency response, long term economic impacts, defense route, interaction with other lifelines and historical significance of the bridge. Assessment of importance depended on the decision makers values. The bridges were then ranked as a function of their vulnerability and importance.

\subsection{SEISMIC RISK ASSESSMENT METHOD}

Seismic Risk Assessment Method is the most complex but least conservative of all three methods. In this approach analysis of the highway network is performed for a given seismic hazard level and the resulting damage states of the bridges are used to estimate the effect on highway system performance. A number of prioritization options can be considered, and the impact on postearthquake system performance is considered in establishing prioritization criteria. This is achieved by using the methodology to assess how much the seismic performance of the overall roadway system performance is improved when different sequences of bridge retrofits are followed. This performance is evaluated in terms of losses due to travel time delays (Werner et al. 2006). Independent qualitative assessment of non-seismic issues and socioeconomic factors are also included in the final prioritization criteria. In the Seismic Risk Assessment Method, systemic effects associated with the loss of a given bridge and the combined effects associated with the loss of other bridges in the highway system are taken into account. This consideration of both systemic and combined effects is what can provide a much more rational basis for establishing seismic retrofit priorities. 
Basöz and Kiremidjian have included network analysis when assessing importance criterion (Basöz and Kiremidjian 1995). However, ranking of bridges depends on the bridges function and criticality in the network system as an entity. The systemic effects associated with the loss of a bridge and the combined effects associated with the loss of other bridges in the highway system are not considered. Shinozuka et al. developed a retrofit prioritization strategy which maximizes the expected benefit from seismic retrofitting under any future earthquake (Shinozuka et al. 2008).

Werner et al. described a methodology for probabilistic or deterministic seismic risk analysis (SRA) of highway systems (Werner et al. 2004). The process was programmed into a publicdomain software package named REDARS ${ }^{\text {TM }} 2$ (Risks from Earthquake Damage to Roadway Systems). REDARS2 addresses system characteristics that affect post-earthquake traffic flows such as the highway system network configuration; locations, redundancies, and traffic capacities and volumes of the system's roadway links; and component locations within these links. The overall project was carried out by the Multidisciplinary Center for Earthquake Engineering Research (MCEER) under the sponsorship of the Federal Highway Administration (FHWA). Werner, et al. demonstrated how REDARS2 can be used when establishing priorities for retrofit of bridges and other roadway components. REDARS enables users to consider how various prioritization options could impact post-earthquake system performance. Another application of REDARS2 is as a guide in the planning of the most effective post-earthquake response and recovery strategies in the presence of damage to the highway system. The REDARS2 output can be employed in prioritization options that would optimize the effectiveness of Post-Earthquake Response and Recovery operations after an earthquake.

In an effort to better utilize any future funding for seismic retrofit, ODOT came up with a preliminary prioritization strategy (ODOT 2009). The methodology attempted to capture the major factors that would make the prioritization process reasonable and understandable. What made this method different from the other methods mentioned above was, instead of prioritizing bridges as single entities, the method looked at the major highway routes. The key criteria in prioritizing the system were improving longer stretches of highways with lower costs at the same time considering areas that were most populated. Hence route length and the average daily traffic were assumed to be very important factors. Retrofit cost was also compared to the maximum earthquake loss for the same highway segment. The route that produced the largest reduction in cost after retrofit was given the highest priority.

\subsection{OTHER METHODS}

Transit New Zealand developed a twelve stage screening process for evaluating bridges within New Zealand with regard to seismic hazards (Transit New Zealand 1998). The process used estimates of the bridge's vulnerability, its probability of experiencing high magnitude earthquakes, and the impact to the economy if the bridge is damaged and out of service. The economic ranking indicator took into consideration the relative consequences and probabilities of loss of serviceability of a bridge. It was calculated as a ratio of the product of probability factor of PGA value, service life factor and traffic cost parameter to the rough cost of retrofit. The traffic cost parameter was calculated as a factor of number of days to reinstate the bridge to existing traffic capacity, number of days for which the detour would have to be used until the crossing can be reopened with either repaired or temporary crossing, annual average daily traffic, 
length of normal and detour route, and journey speed along normal and detour route. Risk events were then ranked taking into account the consequence and relevance of the indicators relating to safety of people, ratio of retrofit to depreciated value of bridge, ratio of retrofit to replacement, and economic ranking order. This list was then used to rank bridges considered to warrant detailed seismic assessment.

Seville and Metcalfe used a GIS framework to combine the seismic hazard map showing the peak ground acceleration (PGA) for given return periods and the probability of exceeding certain demand intensities in the road network system (Seville and Metcalfe 2005). They integrated the vulnerability analysis of bridges using the outputs of the screening process for bridges (Transit New Zealand 1998). They included liquefaction hazard maps in the model. They then assessed other risks that may follow an earthquake such as landslides, tsunamis and rock falls by consulting experienced geologists. They finally estimated the total risk for each section of the state highway network that could be affected by seismic events.

Wang presented a generic decision support system for selecting a cost-effective bridge seismic retrofit strategy implementing analytical fragility curves (Wang 2006). An Economic Index (EI) was proposed to identify the most cost-effective solution when decision-makers face multiple alternatives. Bridge fragility curves corresponding to various cost levels of retrofit were constructed to compare their effectiveness. The approach provided engineers and owners with a quantifiable solution for selecting retrofit alternatives. The four levels of retrofit were classified as do-nothing, basic level retrofit, full-blown rehabilitation and total replacement. To calculate the EI, first typical bridge fragility curves before and after various level of retrofit were generated and plotted on an acceleration coefficient vs. relative displacement ductility ratio graph. Then the area between the curves and the cost increment between the different retrofit measures was determined. To evaluate the EI, a cost-benefit ratio was computed as the ratio of the area between curves and the incremental cost. The highest value of EI means it was the most economical solution.

Padgett considered lifetime sustainable performance of systems applied to bridge retrofit and prioritization in the face of seismic hazards (Padgett 2010). Padgett took a scientific approach to mitigate the risks to bridges posed by earthquakes, while balancing broader goals for sustainability. Life-cycle costs and cost-benefit analysis were elaborated as a key metrics for selecting seismic retrofit of bridges in Central and Southern United States. As an extension to that, Padgett considered seismic upgrade of bridges prioritized based on multiple sustainable impact metrics including social and environmental consequences of seismic damage. Padgett did a case study life cycle cost and cost benefit analysis of seismic retrofit in a multi-span continuous concrete girder bridge with non-seismic detailing that is common of the Central and Southern US. In this study the expected life-cycle costs were evaluated for the bridge in its as-built and retrofitted condition. The benefit of a retrofit was evaluated as the difference between the expected present life cycle cost of the bridge without retrofit and present life cycle cost of the bridge with retrofit. A cost-benefit ratio (CBR) was calculated as the ratio of net present benefit of the investment in retrofit to the initial cost of the retrofit. CBR greater than one meant a positive return on savings. A retrofit option with the largest CBR had a larger expected saving in losses over remaining life per amount of money invested in mitigation. 
Stevanovic and Nadimpalli prepared a study on seismic vulnerability and emergency response analysis of Utah DOT lifelines (Stevanovic and Nadimpalli 2010). They estimated the delaybased user costs following an earthquake and also helped UDOT make informed decisions on disaster mitigation plans. Stevanovic and Nadimpalli selected two scenario seismic events for the study. Since it was impractical to attempt to improve all vulnerable bridges for seismic hazards, they concentrated on selecting road segments (links) for rehabilitation that were vulnerable in one scenario but could still carry a considerable amount of detour traffic in the other scenario. Links that were damaged under both earthquake scenarios were classified as most vulnerable links. Links with the highest increase in traffic under both earthquake scenarios were classified as most critical links. Finally, a list of links that were both critical and vulnerable was prepared for both scenarios. These lists can be useful to effectively utilize the rehabilitation resources and to reduce the vulnerability of the critical link.

\subsection{ADVANTAGES AND DISADVANTAGES OF THE DIFFERENT PRIORITIZATION METHODOLOGIES}

The Indices Method is the easiest and most conservative of the three methods. In this method seismic rating systems are developed first and are used to prioritize the inventory. The Expected Damage Method on the other hand compares the severity of expected damage for each bridge in the inventory for the same earthquake, and bridges are rated accordingly. Recent advancement in seismic risk assessment methods has led to the development of fragility functions for specific classes of bridges. These fragility functions address the uncertainties in ground motion and the unpredictability in soil and structure properties and can be used to estimate damage-state probabilities. The Seismic Risk Assessment Method is the most advanced of the three methods. The methodology makes it possible to estimate loss of highway systems and the effect on system performance as measured by traffic flow.

In both Indices Method and Expected Damage Method each bridge is treated as an individual entity only without regard to how the extent of its damage from earthquakes may impact highway system performance. Both methods represent the importance of the bridge as a trafficcarrying entity only and use average daily traffic, route type and detour length as parameters in prioritization. These criteria do not account for the systemic effects associated with the loss of a given bridge or the combined effects associated with the loss of other bridges in the highway system. The Seismic Risk Assessment Method is the most complex and least conservative of all three. However, detailed structural and geotechnical information is required. 


\subsection{RETROFIT PRIORITIZATION METHOD}

This study used the REDARS2 application to estimate the potential impact of an earthquake event on an affected region. This capability of REDARS2 to estimate the potential impact of an earthquake event for different scenarios was then used to evaluate effectiveness of retrofitting for a highway segment and the relative impacts on post-earthquake traffic flows and travel times. The network analysis of the transportation network in REDARS2 looked into the spatial distribution of the system and accounted for the redundancy in the system or lack thereof. This analysis made it possible to gauge which highway route was more critical and gave the highest return on investment by reducing system-wide traffic disruptions and economic losses, as well as overall repair costs. Cost-Benefit Analysis of highway segments was assessed and the highway segments were ranked according to largest expected savings in losses over the remaining life per amount of money invested in retrofitting.

The probabilities of meeting or exceeding different levels of a damage state were described by a fragility curve for given intensity measures such as peak ground acceleration or spectral acceleration. The fragility curves give insight regarding the vulnerability of the bridge for different levels of earthquake events and the impact of retrofit. Hence, the conditional probability of failure was provided by the fragility curve and the ground motion intensity at a particular location is given as a seismic hazard curve.

The study was initially based on assumptions regarding retrofit performance based on attempting to incorporate published retrofit fragilities, but those were modified for relevant cases as results of the research were realized. Assessment of the benefits was achieved through experimental and numerical retrofit evaluation of a representative bridge, which was selected from ODOT's inventory. Following a seismic analysis of the structure, retrofit measures were considered including FRP wrap of the column. The benefit of a retrofit was evaluated by comparing the expected present value of the losses without retrofit and the present value of the losses with retrofit for the different retrofit options.

\subsection{COST-BENEFIT ANALYSIS FOR PRIORITIZATION}

Economic and social costs and benefits are the key matrices used in the cost-benefit analysis for seismic retrofit prioritization. In this study the expected costs and losses were evaluated for the bridge in its as-built and retrofitted condition. The benefit of a specific retrofit was evaluated as the difference between the expected costs of the bridge without retrofit and the bridge with retrofit. Costs without retrofit included repair and replacement of the bridge and travel time delays. Costs with retrofit included damage to the bridge and the cost of the retrofit. Similar to the previous study (Padgett 2010), the Cost-Benefit ratio was then calculated as the ratio of net present benefit of the investment in retrofit to the initial cost of the retrofit. A retrofit option with the largest cost-benefit ratio has a larger expected return per amount of money invested in retrofitting. The schematic in Figure 7.1 shows the procedures in performing the cost-benefit analysis. 


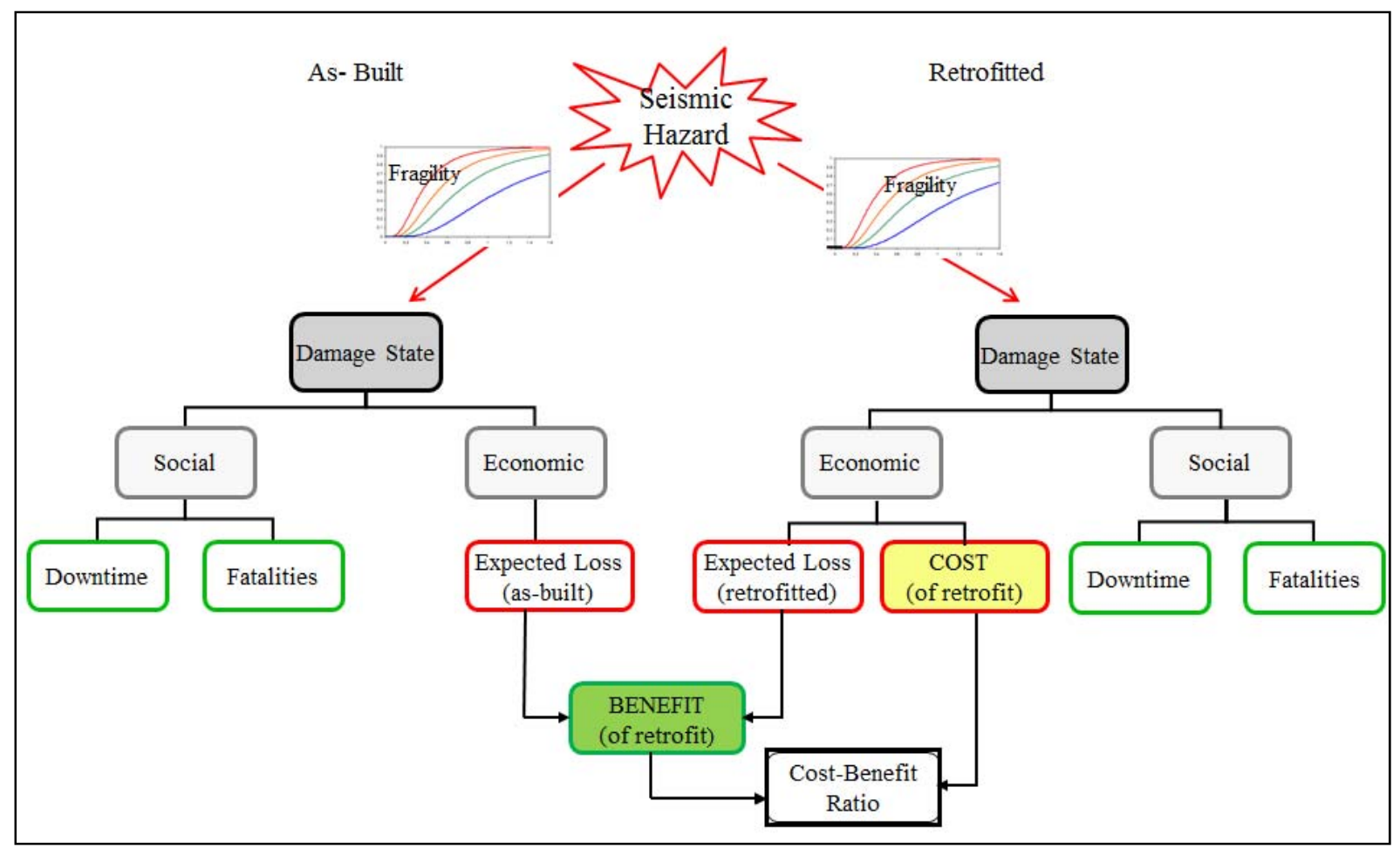

Figure 7.1: Cost-Benefit Analysis schematic

\subsection{SEISMIC HAZARD}

Seismic hazard is the expected earthquake ground motions and the likely effects on a highway network. The extent of its effects depends on the magnitudes, locations, and frequencies of occurrence of earthquakes in the region, and on the local geology and soil conditions throughout the system.

The Seismic Risk Analysis methodology in REDARS2 incorporates regional earthquake source models that have been adapted from models used by the United States Geological Survey (USGS) during their development of seismic hazard maps for the conterminous United States. The seismic hazards are available in the form of probabilistic annual ground motions maps, scenario hazard maps, etc. For this study, shake maps for the Cascadia subduction zone earthquake scenario earthquake developed by USGS were used.

\subsection{FRAGILITIES}

The default fragility values were modified with relevant cases as described in sections 5.3 and 5.4. The default fragility values for a few bridge classes are shown in Table 7.1. 


\begin{tabular}{|c|c|c|c|}
\hline \multirow[t]{2}{*}{ Bridge Type } & \multirow[t]{2}{*}{ NBI Class } & \multirow[t]{2}{*}{$\begin{array}{c}\text { Damage } \\
\text { State }\end{array}$} & $\begin{array}{c}\text { Median Spectral Acceleration, } \\
\text { g, at Period } 1.0 \text { sec. for Damage } \\
\text { Functions due to Ground } \\
\text { shaking }\end{array}$ \\
\hline & & & Non California \\
\hline \multirow{4}{*}{ Single Span } & \multirow{4}{*}{ All } & 2 & 0.80 \\
\hline & & 3 & 1.00 \\
\hline & & 4 & 1.20 \\
\hline & & 5 & 1.70 \\
\hline \multirow{4}{*}{$\begin{array}{l}\text { Multi-Column Bents } \\
\text { and simply supported } \\
\text { concrete } \\
\text { Superstructures }\end{array}$} & \multirow{4}{*}{$\begin{array}{l}101-106 \\
501-506\end{array}$} & 2 & 0.25 \\
\hline & & 3 & 0.35 \\
\hline & & 4 & 0.45 \\
\hline & & 5 & 0.70 \\
\hline \multirow{4}{*}{$\begin{array}{c}\text { Continuous } \\
\text { Reinforced-Concrete } \\
\text { Superstructures }\end{array}$} & \multirow{4}{*}{$201-204$} & 2 & 0.90 \\
\hline & & 3 & 0.90 \\
\hline & & 4 & 1.10 \\
\hline & & 5 & 1.50 \\
\hline
\end{tabular}

\subsection{ECONOMIC MODULE}

The economic module comprises the value of investment on the highway bridges in the form of retrofits and expected losses after sustaining a seismic event. These expected losses include loss due to replacement cost, repair cost and travel time losses. Default REDARS2 values have been updated with typical values provided by ODOT and are provided in the sections below.

\subsubsection{Cost of Retrofit}

Retrofit Cost $($ Phase I $)=\frac{\$ 35}{f t^{2}} \times$ the deck area

Equation 7.1

$$
\text { Retrofit Cost }(\text { Phase II })=\frac{\$ 90}{f t^{2}} \times \text { the deck area }
$$

\footnotetext{
${ }^{1}$ The Federal Emergency Management Agency's (FEMA's) Methodology for Estimating Potential Losses from Disasters
} 


\subsubsection{Expected Loss}

${\text { Expected } \text { Loss }_{\text {as-built }}=\text { Repair Cost }}_{\text {as-built }}+$ Travel Time Cost ${ }_{\text {as-built }}$

Equation 7.2

\subsubsection{Replacement Cost}

ODOT calculates the replacement costs of their bridges as a product of a base cost of $\$ 165 / \mathrm{ft}^{2}$, the deck area and a factor of 3.2 (to incorporate associated costs such as approaches, traffic control, etc.) with a $\$ 3$ million minimum cost. When estimating the cost of a new bridge with an old bridge, a further multiplication factor of 1.2 is used, since a new bridge is expected to be of a larger dimension than the old one (ODOT 2009).

Replacement cost is calculated as the larger of:

$$
\frac{\$ 165}{f t^{2}} \times \text { deck area }\left(f t^{2}\right) \times 3.2 \times 1.2
$$

or

Equation 7.3

$\$ 3$ million

\subsubsection{Repair Cost}

Estimation of economic impacts of earthquake damage to the system is one of the most important end results from SRA of roadway systems. Bridge damage results not only in high cost of structural repair but also safety concerns by severely disrupting traffic flow which in turn will impact post-earthquake emergency response, repair and reconstruction operations and long term economic consequences due to the valued loss of time when commuter and freight travel slows down due to the disrupted network. From this, it is apparent that earthquake damage to certain components (e.g., those along important and non-redundant links within the system) will have a greater impact on the system performance than will other components.

The SRA methodology uses the bridge and network data to estimate direct and indirect economic losses due to disruption in the system. The SRA considers repair costs, losses due to earthquake-induced travel-time delays and losses from trips foregone due to earthquake-induced increases in traffic congestion. The default REDARS model estimates cost as the product of a unit replacement cost (assumed to be $\$ 150 / \mathrm{ft} 2$ ) and the bridge deck's surface area. However, these repair costs ratios and unit replacement costs can be overridden by the user. Hence, the replacement in this study are calculated as a product of a base cost of $\$ 165 / \mathrm{ft} 2$, the deck area and a factor of 3.2 with a $\$ 3$ million minimum cost. And when estimating the cost of a new bridge with an old bridge, a further multiplication factor of 1.2 is used (Equation 7.3), because the new bridge is expected to be of a larger dimension than the old one. The repair cost is computed as the product of a repair cost ratio and replacement cost. The repair cost ratio depends on the bridge's damage state as shown in Table 7.2. 
Table 7.2: Repair Cost Estimate

\begin{tabular}{c|c|c}
\hline Damage State & Repair Cost Ratio & Min Cost \\
\hline None & 0 & 0 \\
\hline Slight & 0.03 & $\$ 100,000$ \\
\hline Moderate & 0.25 & $\$ 500,000$ \\
\hline Extensive & 1.0 & Min \$3 Million \\
\hline Collapse & 1.0 & Min \$3 Million \\
\hline
\end{tabular}

\subsubsection{Travel time Loss and Trips Foregone}

Travel times are affected by earthquake-induced increases in traffic disruptions. This loss is the value of time lost by users of the system and the value of trips not taken due to earthquake-induced congestion in the damaged system. REDARS2 incorporates the cost estimation method that was used by Caltrans to estimate losses in the Northridge earthquake, which included user-specified estimates of vehicle occupancy rates, trucktrip dollar value, cost of excess fuel, etc. to develop these costs. REDARS тм 2 uses default unit losses of $\$ 13.45 /$ (pcu-hour) for automobile trips and $\$ 71.05 /$ (pcu-hour) for commercial-vehicle (freight-transport) trips.

\subsubsection{Benefit}

Benefit is defined as the difference between values of losses without retrofit (Expected Loss asbuilt) and the present value of losses after retrofit (Expected Loss retrofitted).

$$
\text { Benefit }=\text { Expected Loss }_{\text {as-built }}-\text { Expected Loss }_{\text {retrofitted }}
$$

Equation 7.4

\subsubsection{Cost-Benefit Ratio}

Cost-Benefit Ratio (CBR) is basically a measure of return on investment. CBR is used to compare the efficiency of a number of different investments. It is the ratio net profit and investment. In this case the net profit is the 'benefit' and the initial cost of retrofit is the investment. A CBR of less than one indicates a negative return on investment (loss). Hence the retrofit with the largest CBR has the most expected savings.

$$
C B R=\frac{\text { Benefit }}{\text { Retrofit Cost }}
$$

\subsection{SOCIAL MODULE}

The social module includes estimation of downtime in days and expected number of casualties from a seismic hazard. 


\subsubsection{Downtime}

The amount of time it takes to repair and restore a highway bridge after earthquake damage is given by restoration curves that were developed based on a best fit to ATC-13 data for the four damage states (ATC-13 1985). Figure 7.2 represents restoration curves for highway bridges. Theses functionality relations employ past work (FEMA 2010). The means and standard deviations for each restoration curve are given in Table 7.3. Distributions on functionality for each restoration period based on damage state immediately after the earthquake are given in Table 7.4. However, there are apparent uncertainties in estimating downtime such as the availability of resources to make the repair or replacement, accessibility to bridge, and environmental and regional regulations (ODOT 2013).

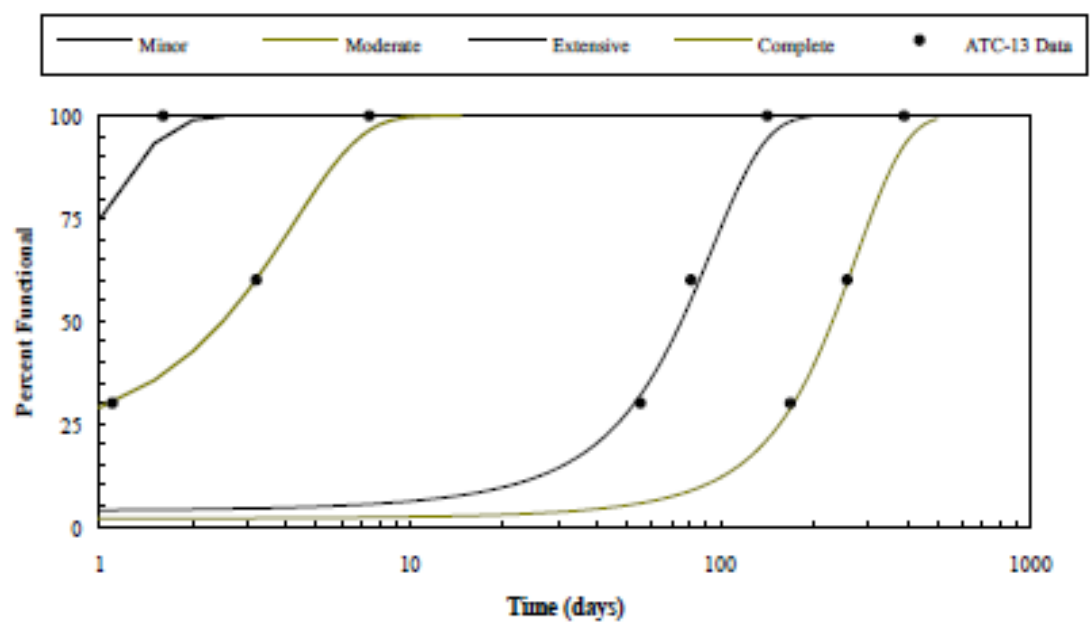

Figure 7.2: Restoration Curves for Highway Bridges (ATC-13 1985)

Table 7.3: Continuous Restoration Functions for Highways (ATC-13 1985)

\begin{tabular}{c|c|c}
\hline \multirow{2}{*}{ Damage State } & \multicolumn{2}{|c}{ Highway Bridges } \\
\cline { 2 - 3 } & \multirow{2}{*}{ Mean (Days) } & $\boldsymbol{\sigma}$ (Days) \\
\hline Slight/Minor & 0.6 & 0.6 \\
\hline Moderate & 2.5 & 2.7 \\
\hline Extensive & 75.0 & 42.0 \\
\hline Complete & 230.0 & 110.0 \\
\hline
\end{tabular}




\section{Table 7.4: Discrete Restoration Functions for Highways}

\begin{tabular}{c|cccc}
\hline \multirow{2}{*}{$\begin{array}{c}\text { Restoration } \\
\text { Period }\end{array}$} & \multicolumn{4}{|c}{ Functional Percentage } \\
\cline { 2 - 5 } & Slight & Moderate & Extensive & Complete \\
\hline 1 & 70 & 30 & 2 & 0 \\
3 & 100 & 60 & 5 & 2 \\
7 & 100 & 95 & 6 & 2 \\
30 & 100 & 100 & 15 & 4 \\
90 & 100 & 100 & 65 & 10 \\
\hline
\end{tabular}

\subsubsection{Fatalities}

Estimation of casualties from a seismic hazard is based on the assumption that there is a strong correlation between building damage (both structural and nonstructural) and the number and severity of casualties. In HAZUS, the model attempts to estimate casualties to people either on or under bridges that experience complete damage. The number of people on or under bridges is calculated from Table 7.5 and Equation 7.6. The bridge casualty rates for complete structural damage of bridges without collapse are found in Table 7.6. For this study, however, fatality estimation has not been included in the prioritization.

Table 7.5: Default Relationships for Estimating Population Distribution (HAZUS®MH MH4 Technical manual)

\begin{tabular}{c|c|c|c}
\hline \multicolumn{4}{c}{ Distribution of People in Census Tract } \\
\hline Occupancy & $\mathbf{2 : 0 0}$ a.m. & $\mathbf{2 : 0 0}$ p.m. & $\mathbf{5 : 0 0}$ p.m. \\
\hline $\begin{array}{c}\text { Commuting in cars } \\
\text { Commuting using } \\
\text { other modes }\end{array}$ & $0.005(\mathrm{POP})$ & (PRFIL) $0.05(\mathrm{POP})$ & (PRFIL) $[0.05(\mathrm{POP})+$ \\
$1.0(\mathrm{COMM})]$ \\
\hline
\end{tabular}

Where:

POP

COMM

PRFIL is the census tract population taken from census data is the number of people commuting inferred from census data is a factor representing the proportion of commuters using automobiles, inferred from profile of the community ( 0.60 for dense urban, 0.80 for less dense urban or suburban, and 0.85 for rural). The default is 0.80 .

$N B R D G=C D F \times$ Commuter Population

\section{Equation 7.1}

Where:

NBRDG

$\mathrm{CDF}$
Number of people on or under bridges in the census tract

Commuter Distribution Factor: Percent of commuters on or under bridges in census tract (Defaults: $\mathrm{CDF}=0.01$ day, $\mathrm{CDF}=0.01$ night and $\mathrm{CDF}=0.02$ commute time.) 
Table 7.6: Casualty Rates by Model Building Type for Complete Structural Damage (No Collapse) (HAZUS®MH MH4 Technical manual)

\begin{tabular}{c|c|c|c|c}
\hline \multirow{2}{*}{ Building Type } & \multicolumn{4}{|c}{ Casualty Severity Level } \\
\cline { 2 - 5 } & $\begin{array}{c}\text { Severity } \mathbf{1} \\
(\mathbf{\% )}\end{array}$ & $\begin{array}{c}\text { Severity } \mathbf{2} \\
(\mathbf{\% )}\end{array}$ & $\begin{array}{c}\text { Severity 3 } \\
\mathbf{( \% )}\end{array}$ & $\begin{array}{c}\text { Severity 4 } \\
(\mathbf{\%})\end{array}$ \\
\hline Major Bridge & 17 & 20 & 37 & 7 \\
\hline $\begin{array}{c}\text { Continuous } \\
\text { Bridge }\end{array}$ & 17 & 20 & 37 & 7 \\
\hline S.S. Bridge & 5 & 25 & 20 & 5 \\
\hline
\end{tabular}

Injury categories or severity levels have been have been defined by various researchers (Durkin and Thiel 1991) (Coburn and Spence 1992), etc. casualties are calculated as a percentage of the population at the census tract level. Injury classification scales as defined in the HAZUS ${ }^{\circledR M H}$ MH4 Technical manual are given in Table 7.7 below.

Table 7.7: Injury Classification Scale (HAZUS®MH MH4 Technical manual)

\begin{tabular}{c|l}
\hline Injury Severity Level & Injury Description \\
\hline Severity 1 & $\begin{array}{l}\text { Injuries requiring basic medical aid without requiring } \\
\text { hospitalization }\end{array}$ \\
\hline Severity 2 & $\begin{array}{l}\text { Injuries requiring a greater degree of medical care and } \\
\text { hospitalization, but not expected to progress to a life threatening } \\
\text { status }\end{array}$ \\
\hline Severity 3 & $\begin{array}{l}\text { Injuries that pose an immediate life threatening condition if not } \\
\text { treated adequately and expeditiously. The majority of these injuries } \\
\text { are the result of structural collapse and subsequent entrapment or } \\
\text { impairment of the occupants. }\end{array}$ \\
\hline Severity 4 & Instantaneously killed or mortally injured \\
\hline
\end{tabular}

\subsection{DEMONSTRATION OF COST-BENEFIT ASSESSMENT}

\subsubsection{Objective and Scope}

The objectives of this analysis were to demonstrate the application of cost-benefit analysis for prioritization of highway segments after seismic retrofit bridges. Because of limitations in the seismic analysis software used (REDARS2), the highways network model developed and current data, the results should be regarded as a first order estimate that could be further refined.

\subsubsection{Study Area}

The focus of the seismic vulnerability assessment was on highway bridges lying on or crossing over Oregon highway routes in the area defined by Figure 7.3. The area included all highway routes lying inside or west of the I-5 corridor, highway routes in the Portland area, the entire length of US-101 and a partial I-84 Columbia River Highway. A representative bridge was first selected from the state's database as described in Section 2.0 of this report. That representative 
bridge for the State of Oregon was found to be a three span concrete girder bridge with square columns with non-seismic detailing in both longitudinal and transverse confining reinforcement.

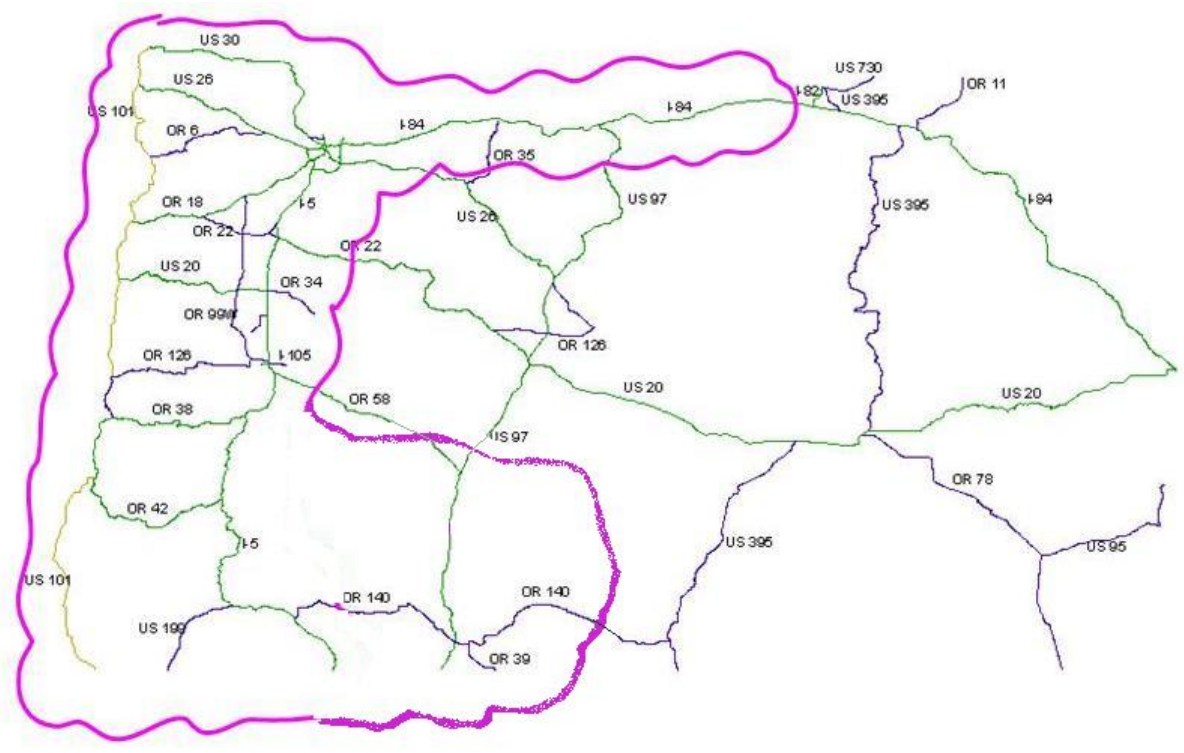

Figure 7.3: Study Area Focus

\subsubsection{Emergency Routes}

Oregon Department of Transportation (ODOT) recognizes that retrofitting all vulnerable bridges in the near future is not an option; however, it is necessary that the process to reach that point needs to be get under way. In order to start the prioritization process of major highway segments that are vulnerable under seismic loading, ODOT has selected routes that are considered top priority for rescue and recovery operations. These emergency routes are shown in Table 7.8 below.

Table 7.8: Emergency Routes

\begin{tabular}{c|l|l}
\hline \multicolumn{1}{c|}{ Phase I } & \multicolumn{1}{|c}{ Phase II } \\
\hline US-97 (I-84 to CA) & I-405 (I-5 to US30) & US101 (OR 18 to US20) \\
OR-58 (I-5 to US 97) & US30 (US101-I-405) & US101 (OR 18 to Tillamook) \\
I-84 (I-205 to US 97) & US99W \& OR18 & US101 (OR 38 to OR 42) \\
I-5 \& OR 22 (Salem) & I-5 (OR58 to CA) & US101 (OR 38 to OR 126) \\
I-205 (WA to I-5) & OR38 (US101 to CA) & I-5 \& I-405 (US30 to WA) \\
\hline
\end{tabular}

ODOT approaches retrofitting in two stages. Phase I retrofitting deals with the superstructure and includes replacing unstable bearings, adding seat width, and limiting movement of girders parallel and perpendicular to roadways. Phase II retrofitting, on the overhand, includes strengthening the substructure elements. This comprises retrofitting caps, columns, footings and pilings. The cost of Phase II work is typically three times that of Phase I as illustrated in Figure 7.4. ODOT has performed very limited Phase II retrofit work. In this study (ODOT 2009), a 
prioritization methodology was used based on the 10 segments of highway routes listed in Table 7.8 under phase II retrofitting.

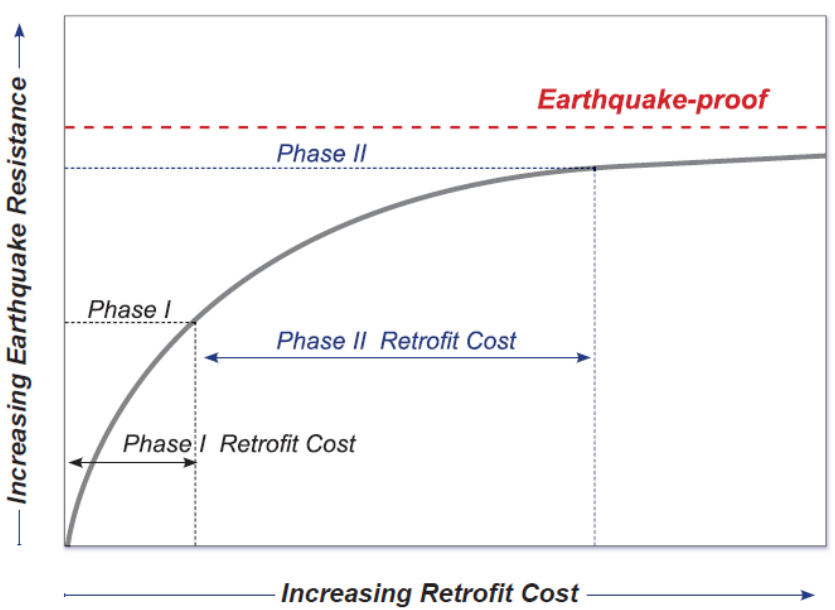

Figure 7.4: Cost-to-Benefit Comparison for Seismic Retrofit (ODOT 2009)

\subsubsection{Results}

\subsubsection{System Module}

An updated version of the bridge network model developed for Oregon (Dusicka et al. 2007) was applied for seismic risk analysis of the transportation network system.

\subsubsection{Scenario Earthquake}

The earthquake hazard considered was ground motion only. Possible liquefaction, landslide and other hazards that can result due to an earthquake were not included in the scope of this study. Seismic Risk Analysis was performed for subduction zone earthquake scenario events of magnitudes 9.0, 8.5 North and 8.5 South, and the hazard maps are given in Figure 7.5, Figure 7.6 and Figure 7.7 respectively. 

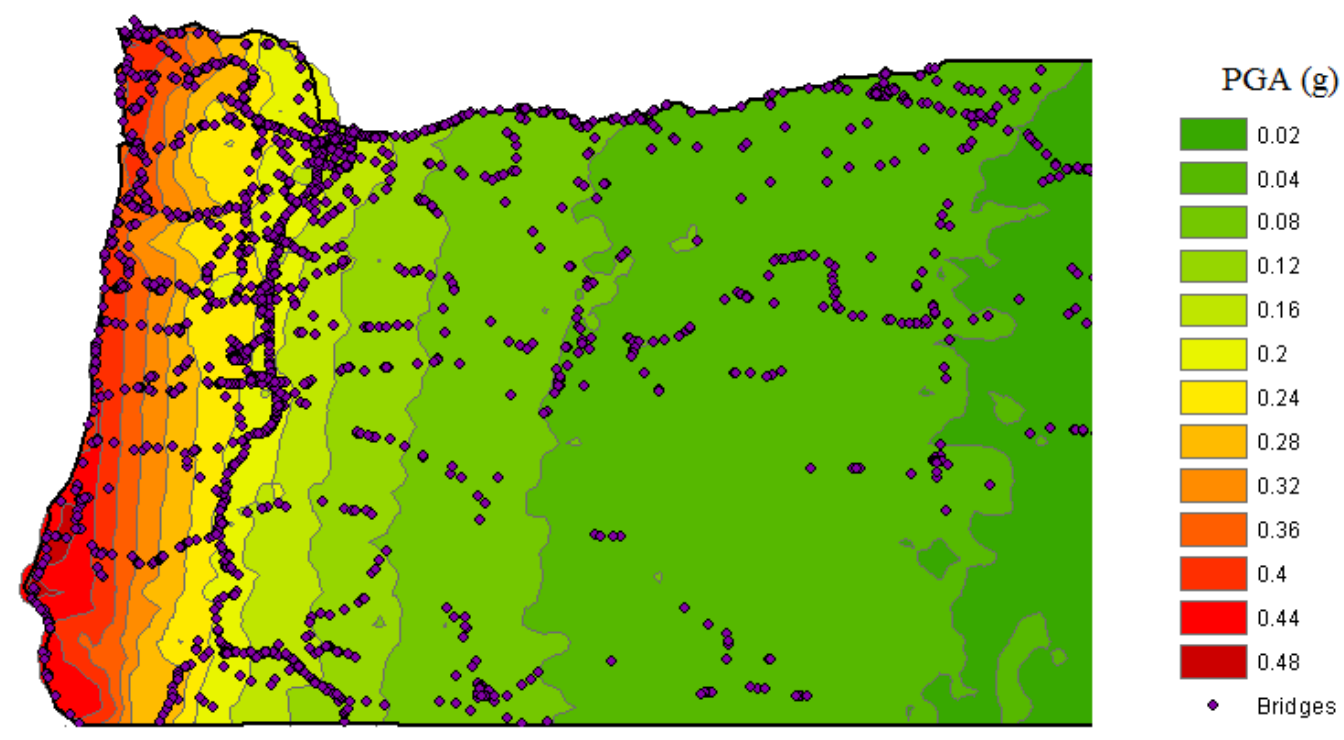

Figure 7.5: Scenario Shake Maps -CSZ magnitude 9.0
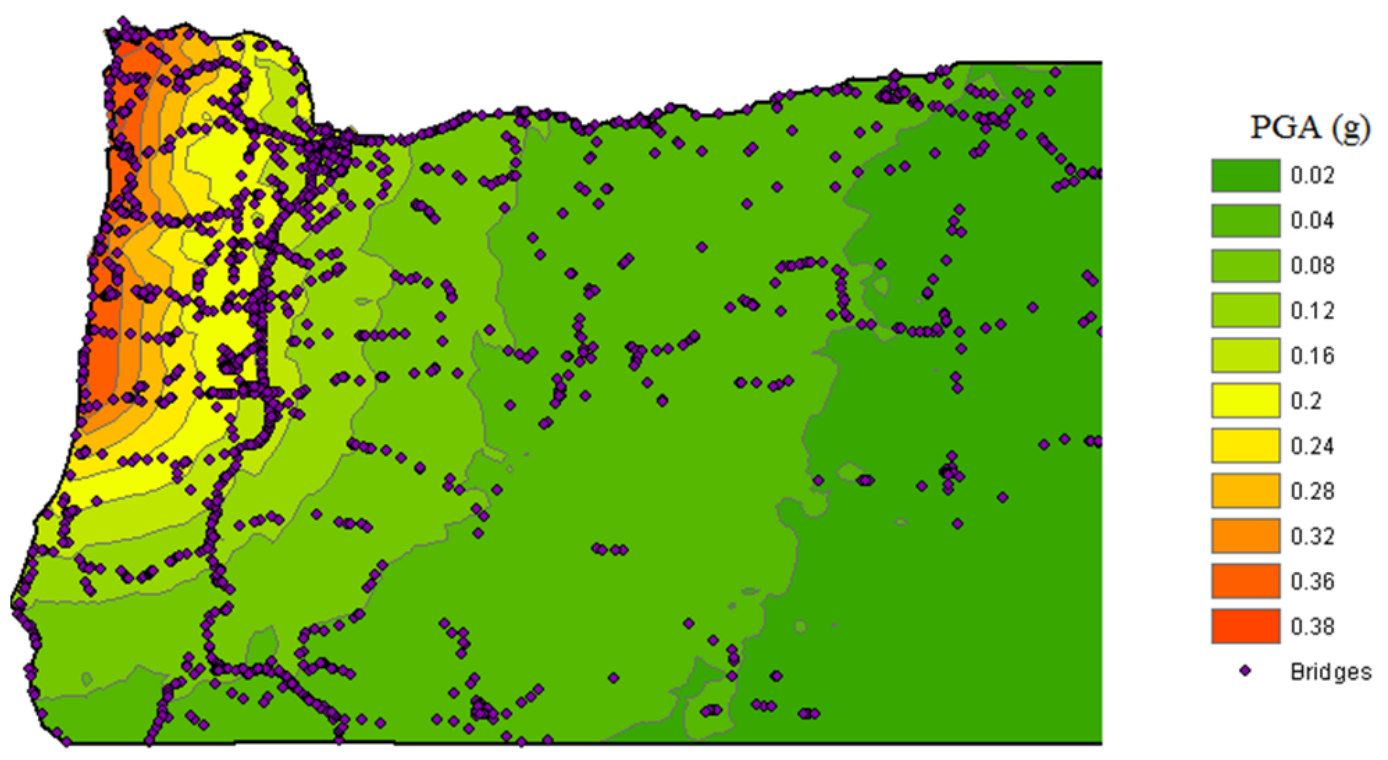

Figure 7.6: Scenario Shake Maps -CSZ magnitude 8.5 North 


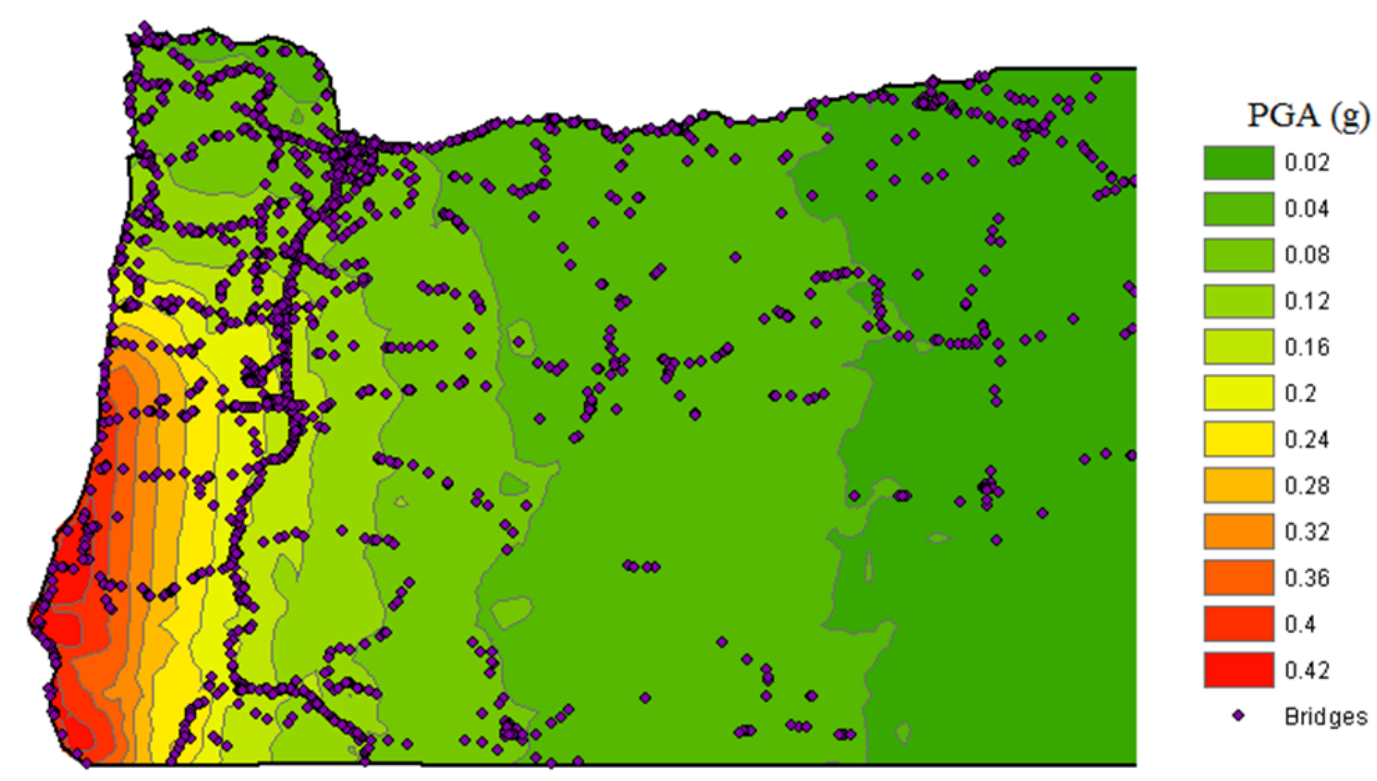

Figure 7.7: Scenario Shake Maps -CSZ magnitude 8.5 South

\subsubsection{System Analysis}

The study began with an assumption that the default published fragilities for the concrete girder bridges were not representative. Hence, fragility values were developed (Roberts and Dusicka 2011) for the as-built state and the default published fragilities for seismically designed continuous concrete girder bridges were considered as their retrofitted state. The analysis was done by changing the fragility curves of continuous concrete stringer/girder (CCSG) bridges in the transportation network one highway segment at a time, for the ten highway segments that were selected by ODOT as top priority for rescue and recovery.

The capabilities of REDARS 2 to analyze both direct losses due to damage and indirect losses due to traffic flow disruption were used as a means to assess the cost-benefit of a retrofit. In this deterministic seismic risk analysis, shake maps were selected and earthquake ground motions were estimated throughout the transportation system. Once the ground motion hazards were estimated, direct and indirect system losses were evaluated. Transportation network analysis then gave an estimate in system-wide travel times, access/egress times to/from key locations and travel times along major lifeline routes. Post- and pre- earthquake travel time differences showed how much reduction there was in the system's ability to carry traffic after an earthquake event. The economic module in REDARS2 then estimated losses due to travel time delays and trips foregone.

\subsubsection{Cost-Benefit Analysis Results}

The results of the cost benefit analysis are given in Table 7.9, Table 7.10 and Table 7.11 for Cascadia Subduction Zone (CSZ) earthquake scenarios of magnitudes 9.0, 8.5 North and 8.5 South respectively. The first column lists the routes or route segments, each of which were individually changed to reflect the updated fragility of a specific bridge type; 
continuous concrete girder bridge. Number of bridges on each route that were virtually retrofitted varied and one of the segments, I-5 \& I-405 (US30 to WA), had none. The calculated expected losses are for the entire highway transportation network, resulting in overall numbers that are of the same order of magnitude regardless of as-built or retrofitted cases. The difference between the as-built and retrofitted expected losses for the bridge costs is the benefit of the retrofit. The retrofit costs were calculated as described earlier in the report according to Equation 7.1 and are listed for each route as applied to the continuous concrete girder bridges only. The resulting benefit to cost ratios are listed in the last column. The analyses were repeated in a similar manner for the other Cascadia Subduction Zone (CSZ) earthquake scenarios.

Even for the case of retrofitting a single bridge type along a route, all benefit to cost ratios were greater than one. This result underscores the importance of seismically retrofitting bridges. The continuous concrete girder bridges along I-5 route South of OR58 would be the most costly to retrofit. The overall benefit to the system was also the highest for all of the scenarios. However, when considered as a benefit to cost ratio, that segment was not the highest. The benefit to cost ratios were calculated along US101. Similar patterns were observed for the different earthquake scenarios, although the benefit to cost ratios as well as the relative values were different.

\subsubsection{Social Module}

Social module is another important component that should be considered in the prioritization of bridges for retrofit. Section 7.5 describes the methodology to quantify the social aspect of seismic hazard in terms of downtime and fatalities. Unfortunately, only minor contributions to the overall benefit were recorded in the analyses due to the aforementioned limitations of REDARS2. In a more rigorous traffic analyses, which would have to be conducted outside the REDARS2 software, the travel losses are expected to be significantly higher and further contribute to the overall benefit to cost ratios.

Downtime, which is the amount of time it takes to repair and restore a highway bridge after earthquake damage is given by restoration curves that were developed based on a best fit to ATC-13 data for the four damage states. However, these assumptions come with some uncertainties in estimating downtime such as the availability of resources to make the repair or replacement, accessibility to component, environmental and regional regulations. Single bridges on some major routes may be replaced with in a year. However, it will probably take over 5 years to replace $70+$ bridges due to limited resources. Completely damaged links contribute more to the total delay costs. This is not only due to their severity of damage, but also due to larger rehabilitation periods required. Another issue in recovery of the network system is that some streets cannot carry the increased traffic volumes that could possibly be diverted to them.

Availability of resources to make the repair or replacement, accessibility to components, environmental and regional regulations should be studied and applied in the estimation of downtime of a bridge component to make estimates of downtime. Even though the ability to estimate casualties from a seismic hazard is a great tool in the cost-benefit analysis, it 
is impossible without data for all the regions with information on the census tract population taken from census data.

\subsection{LIMITATIONS}

The results from the demonstration case consider the repair of only one bride type; continuous reinforced concrete bridge. Consequently, bridge routes that have a low number of these types of bridges may not necessarily be significantly affected by the retrofit of these types of bridges. Similar approach can be used to address the retrofit of other types of bridges for more comprehensive estimation.

Damage states of bridges are computed by first computing the bridge's demand spectral acceleration for a given scenario earthquake, it is then compared to each bridge's spectral acceleration capacity that leads to the onset of each damage state. However, these median values of ground motion computed do not necessarily represent the exact levels of ground shaking at the bridge locations since the exact levels of ground shaking of an earthquake will not be known without actually recording the motion with strong motion accelerometers at the time of the event. Consequently, there is a probability that some bridges might perform better or worse during a real earthquake compared to a scenario analysis.

In addition, fragility values are based on probabilistic median expected performances. A particular bridge that had a specific damage state may not exactly correlate to actual events but is more representative as the expected damage state. For these reasons, the aggregate response over the route should be examined and is more informative than considering the damage state of an individual bridge.

For the social module, the availability of resources to make the repair or replacement, accessibility to bridges and other lifelines, environmental and regional regulations should be studied and applied in the estimation of downtime of a bridge component. And in the estimation of fatalities, data should be gathered for the region with information on the census tract population taken from census data and the number of people commuting inferred from census data. This social component can then be used in the decision making for retrofit prioritization.

Furthermore, other devastating effects of earthquakes, such as potential landslides and liquefaction, are not included in these results. These analyses should be done outside or REDARS2 since REDARS2 does not have the capability of analyzing damage caused due to landslides and the results from liquefaction are not well represented. 
Table 7.9: Sample Retrofit Prioritization Benefit-to-Cost Values for CSZ 9.0

\begin{tabular}{|c|c|c|c|c|c|c|c|}
\hline \multicolumn{2}{|c|}{ CATEGORY } & \multicolumn{6}{|c|}{$\overline{\text { ECONOMIC }}$} \\
\hline \multicolumn{2}{|c|}{ Impact Metric $\rightarrow$} & \multicolumn{3}{|c|}{$\begin{array}{l}\text { Expected Loss } \\
\text { (\$Millions) }\end{array}$} & \multirow{2}{*}{$\begin{array}{c}\text { Benefit of } \\
\text { Retrofit } \\
\text { (\$Millions) }\end{array}$} & \multirow{2}{*}{$\begin{array}{c}\text { Retrofit } \\
\text { Cost } \\
\text { (\$Millions) }\end{array}$} & \multirow{2}{*}{$\begin{array}{l}\text { Benefit } \\
\text { Cost } \\
\text { Ratio }\end{array}$} \\
\hline \multicolumn{2}{|l|}{ Routes $\downarrow$} & Bridge & Travel & Total & & & \\
\hline \multirow[t]{2}{*}{ I-405 (I-5 to US30) } & As built & 3336 & 1126 & 4461 & \multirow{2}{*}{9} & \multirow{2}{*}{1.2} & \multirow{2}{*}{7.8} \\
\hline & Retrofitted & 3327 & 1126 & 4453 & & & \\
\hline \multirow[t]{2}{*}{ US30 (US101-I-405) } & As built & 3336 & 1126 & 4461 & \multirow{2}{*}{19} & \multirow{2}{*}{2.5} & \multirow{2}{*}{7.5} \\
\hline & Retrofitted & 3317 & 1126 & 4442 & & & \\
\hline \multirow[t]{2}{*}{ US99W \& OR18 } & As built & 3336 & 1126 & 4461 & \multirow{2}{*}{71} & \multirow{2}{*}{9.6} & \multirow{2}{*}{7.4} \\
\hline & Retrofitted & 3267 & 1123 & 4390 & & & \\
\hline \multirow[t]{2}{*}{ I-5 (OR58 to CA) } & As built & 3336 & 1126 & 4461 & \multirow{2}{*}{478} & \multirow{2}{*}{65.3} & \multirow{2}{*}{7.3} \\
\hline & Retrofitted & 2859 & 1124 & 3983 & & & \\
\hline \multirow[t]{2}{*}{ US101 (OR38 to CA) } & As built & 3336 & 1126 & 4461 & \multirow{2}{*}{3} & \multirow{2}{*}{2.3} & \multirow{2}{*}{1.3} \\
\hline & Retrofitted & 3318 & 1140 & 4458 & & & \\
\hline \multirow{2}{*}{$\begin{array}{l}\text { US101 (OR } 18 \text { to } \\
\text { US20) }\end{array}$} & As built & 3336 & 1126 & 4461 & \multirow{2}{*}{44} & \multirow{2}{*}{3.8} & \multirow{2}{*}{11.7} \\
\hline & Retrofitted & 3309 & 1108 & 4417 & & & \\
\hline \multirow{2}{*}{$\begin{array}{l}\text { US101 (OR } 18 \text { to } \\
\text { Tillamook) }\end{array}$} & As built & 3336 & 1126 & 4461 & \multirow{2}{*}{29} & & \\
\hline & Retrofitted & 3308 & 1125 & 4432 & & 3.0 & 1.0 \\
\hline US101 (OR 38 to OR & As built & 3336 & 1126 & 4461 & & & \\
\hline & Retrofitted & 3329 & 1126 & 4455 & T & 0.9 & 1.3 \\
\hline US101 (OR 38 to OR & As built & 3336 & 1126 & 4461 & 10 & 10 & 8 \\
\hline & Retrofitted & 3327 & 1124 & 4451 & 10 & 1.2 & $0 . J$ \\
\hline I-5 \& I-405 (US30 to & As built & 3336 & 1126 & 4461 & & & \\
\hline & Retrofitted & 3336 & 1126 & 4461 & - & - & - \\
\hline
\end{tabular}


Table 7.10: Sample Retrofit Prioritization Benefit-to-Cost Values for CSZ 8.5 North

\begin{tabular}{|c|c|c|c|c|c|c|c|}
\hline \multicolumn{2}{|l|}{ CATEGORY } & \multicolumn{6}{|c|}{ ECONOMIC } \\
\hline \multicolumn{2}{|c|}{ Impact Metric $\rightarrow$} & \multicolumn{3}{|c|}{$\begin{array}{l}\text { Expected Loss } \\
\text { (\$Millions) }\end{array}$} & \multirow{2}{*}{$\begin{array}{c}\text { Benefit of } \\
\text { Retrofit } \\
\text { (\$Millions) }\end{array}$} & \multirow{2}{*}{$\begin{array}{c}\text { Retrofit } \\
\text { Cost } \\
\text { (\$Millions) }\end{array}$} & \multirow{2}{*}{$\begin{array}{c}\text { Benefit } \\
\text { Cost } \\
\text { Ratio }\end{array}$} \\
\hline \multicolumn{2}{|l|}{ Routes $\downarrow$} & Bridge & Travel & Total & & & \\
\hline \multirow[t]{2}{*}{ I-405 (I-5 to US30) } & As built & 2264 & 1014 & 3278 & \multirow{2}{*}{8} & \multirow{2}{*}{1.2} & \multirow{2}{*}{6.7} \\
\hline & Retrofitted & 2255 & 1014 & 3270 & & & \\
\hline \multirow[t]{2}{*}{ US30 (US101-I-405) } & As built & 2264 & 1014 & 3278 & \multirow{2}{*}{19} & \multirow{2}{*}{2.5} & \multirow{2}{*}{7.4} \\
\hline & Retrofitted & 2245 & 1014 & 3259 & & & \\
\hline \multirow[t]{2}{*}{ US99W \& OR18 } & As built & 2264 & 1014 & 3278 & \multirow{2}{*}{91} & \multirow{2}{*}{9.6} & \multirow{2}{*}{9.4} \\
\hline & Retrofitted & 2195 & 992 & 3187 & & & \\
\hline \multirow[t]{2}{*}{ I-5 (OR58 to CA) } & As built & 2264 & 1014 & 3278 & \multirow{2}{*}{277} & \multirow{2}{*}{65.3} & \multirow{2}{*}{4.2} \\
\hline & Retrofitted & 1992 & 1009 & 3001 & & & \\
\hline \multirow[t]{2}{*}{ US101 (OR38 to CA) } & As built & 2264 & 1014 & 3278 & \multirow{2}{*}{10} & \multirow{2}{*}{2.3} & \multirow{2}{*}{4.3} \\
\hline & Retrofitted & 2246 & 1022 & 3268 & & & \\
\hline \multirow{2}{*}{$\begin{array}{l}\text { US101 (OR } 18 \text { to } \\
\text { US20) }\end{array}$} & As built & 2264 & 1014 & 3278 & \multirow{2}{*}{42} & \multirow{2}{*}{3.8} & \multirow{2}{*}{11.0} \\
\hline & Retrofitted & 2237 & 999 & 3236 & & & \\
\hline \multirow{2}{*}{$\begin{array}{l}\text { US101 (OR } 18 \text { to } \\
\text { Tillamook) }\end{array}$} & As built & 2264 & 1014 & 3278 & \multirow{2}{*}{57} & & \\
\hline & Retrofitted & 2236 & 985 & 3221 & & & \\
\hline US101 (OR 38 to OR & As built & 2264 & 1014 & 3278 & & & \\
\hline & Retrofitted & 2257 & 1014 & 3271 & 1 & 0.7 & 1.0 \\
\hline US101 (OR 38 to OR & As built & 2264 & 1014 & 3278 & & & \\
\hline & Retrofitted & 2255 & 1013 & 3268 & (3) & 1.2 & 1.0 \\
\hline I-5 \& I-405 (US30 to & As built & 2264 & 1014 & 3278 & & & \\
\hline & Retrofitted & 2264 & 1014 & 3278 & - & - & - \\
\hline
\end{tabular}


Table 7.11: Sample Retrofit Prioritization Benefit-to-Cost Values for CSZ 8.5 South

\begin{tabular}{|c|c|c|c|c|c|c|c|}
\hline \multirow{2}{*}{\multicolumn{2}{|c|}{$\begin{array}{l}\text { CATEGORY } \\
\qquad \text { Impact Metric } \rightarrow\end{array}$}} & \multicolumn{6}{|c|}{ ECONOMIC } \\
\hline & & \multicolumn{3}{|c|}{$\begin{array}{l}\text { Expected Loss } \\
\text { (\$Millions) }\end{array}$} & \multirow{2}{*}{$\begin{array}{l}\text { Benefit of } \\
\text { Retrofit } \\
\text { (\$Millions) }\end{array}$} & \multirow{2}{*}{$\begin{array}{c}\text { Retrofit } \\
\text { Cost } \\
\text { (\$Millions) }\end{array}$} & \multirow{2}{*}{$\begin{array}{l}\text { Benefit } \\
\text { Cost } \\
\text { Ratio }\end{array}$} \\
\hline \multicolumn{2}{|l|}{ Routes $\downarrow$} & Bridge & Travel & Total & & & \\
\hline \multirow[t]{2}{*}{ I-405 (I-5 to US30) } & As built & 2166 & 548 & 2714 & \multirow{2}{*}{2} & \multirow{2}{*}{1.2} & \multirow{2}{*}{1.5} \\
\hline & Retrofitted & 2164 & 548 & 2712 & & & \\
\hline \multirow[t]{2}{*}{ US30 (US101-I-405) } & As built & 2166 & 548 & 2714 & \multirow{2}{*}{2} & \multirow{2}{*}{2.5} & \multirow{2}{*}{0.8} \\
\hline & Retrofitted & 2164 & 548 & 2712 & & & \\
\hline \multirow[t]{2}{*}{ US99W \& OR18 } & As built & 2166 & 548 & 2714 & \multirow{2}{*}{113} & \multirow{2}{*}{9.6} & \multirow{2}{*}{11.8} \\
\hline & Retrofitted & 2116 & 484 & 2601 & & & \\
\hline \multirow[t]{2}{*}{ I-5 (OR58 to CA) } & As built & 2166 & 548 & 2714 & \multirow{2}{*}{484} & \multirow{2}{*}{65.3} & \multirow{2}{*}{7.4} \\
\hline & Retrofitted & 1690 & 540 & 2230 & & & \\
\hline \multirow[t]{2}{*}{ US101 (OR38 to CA) } & As built & 2166 & 548 & 2714 & \multirow{2}{*}{17} & \multirow{2}{*}{2.3} & \multirow{2}{*}{7.5} \\
\hline & Retrofitted & 2149 & 548 & 2697 & & & \\
\hline \multirow{2}{*}{$\begin{array}{l}\text { US101 (OR } 18 \text { to } \\
\text { US20) }\end{array}$} & As built & 2166 & 548 & 2714 & \multirow{2}{*}{24} & \multirow{2}{*}{3.8} & \multirow{2}{*}{6.3} \\
\hline & Retrofitted & 2139 & 551 & 2690 & & & \\
\hline \multirow{2}{*}{$\begin{array}{l}\text { US101 (OR } 18 \text { to } \\
\text { Tillamook) }\end{array}$} & As built & 2166 & 548 & 2714 & \multirow{2}{*}{28} & \multirow{2}{*}{3.8} & \\
\hline & Retrofitted & 2139 & 548 & 2687 & & & 1.2 \\
\hline US101 (OR 38 to OR & As built & 2166 & 548 & 2714 & & & \\
\hline & Retrofitted & 2160 & 535 & 2695 & & & \\
\hline US101 (OR 38 to OR & As built & 2166 & 548 & 2714 & & & \\
\hline & Retrofitted & 2158 & 545 & 2702 & 12 & 1.2 & 10.0 \\
\hline I-5 \& I-405 (US30 to & As built & 2166 & 548 & 2714 & & & \\
\hline & Retrofitted & 2166 & 548 & 2714 & - & - & - \\
\hline
\end{tabular}




\subsection{SUMMARY AND CONCLUSIONS}

\subsection{RETROFIT MEASURE}

The CFRP retrofitting measure achieved the desired outcome of increasing the ductility of the plastic hinge zone so that the column response does not degrade. Without the retrofit, the column could exhibit shear failure, longitudinal bar buckling and/or lap splice failure. Hence, it can be concluded that applying CFRP wrap is an effective retrofit measure for seismically deficient reinforced concrete square columns with lap splices in the plastic hinge regions. The CFRP helps to prevent bond failures in lap splices by increasing confinement, resulting in just minimal spalling of concrete and longitudinal bar yielding under severe displacement demands.

The moderate ductility response of the as-built column could be utilized in assessment of bridges. For cases where the demands impose moderate ductility, these types of columns may not necessarily need retrofit. While other retrofit measures may be needed for the overall bridge, cost savings could be realized for the column retrofit aspect.

\subsection{SEISMIC RETROFIT BENEFIT TO COST VALUES}

The REDARS2 software was used for seismic risk analysis (SRA) of the highway network in this study. Damage states of bridges were computed comparing the bridges' median demand spectral acceleration for a given scenario earthquake to the median capacity that leads to the onset of each damage state. The median values of ground motion computed may not necessarily represent the exact levels of ground shaking at the bridge locations since the exact levels of ground shaking of an earthquake will not be known without actually recording the motion with strong motion accelerators at the time of the event. Subsequently, there is a probability that some bridges might perform better or worse during a real earthquake compared to a scenario analysis. In addition, fragility values are based on probabilistic median expected performances. A particular bridge that had a specific damage state may not exactly correlate to actual events but is more representative as the expected damage state. For these reasons, the aggregate response over the route should be examined and is more informative than considering the damage state of individual bridges.

The SRA in REDARS2 also considers losses due to earthquake-induced travel-time delays and losses from trips foregone due to earthquake-induced increases in traffic congestion. Generally losses associated with travel time delays and trips foregone dominate the total economic losses, i.e. repair costs constitute a smaller fraction of the total cost. However, the travel time related losses computed in REDARS2 are lower than repair costs and hence do not seem realistic. But the comparison of the losses estimated for the different scenario earthquakes and different retrofit options could be a cost-benefit measure. However, actual numbers presented should not be taken at face value, but that the overall magnitude of differences should be considered.

The capability of REDARS2 to perform network analysis of the transportation network by looking into the spatial distribution of the system and account for the redundancy in the system, 
or lack thereof, is an attractive aspect of the software. However, the shortcoming in the traveltime delays and losses from trips foregone estimation need to be looked into further or other external software needs to be used for this key transportation analysis portion.

Economic and social costs and benefits are the key matrices suggested to be used for seismic retrofit prioritization. The demonstration case of cost-benefit analysis for the Cascadia subduction zone earthquake of magnitude 9 is given in Table 7.9. Ten highway routes have been selected as top priority for rescue and recovery operations. These routes were analyzed whereby the fragilities of all continuous concrete girder bridges in the routes were changed from the deficient to the retrofitted fragility values. In the analysis, it was seen that the highway route on US-101 from OR 18 to US-20 gave the highest return on investment. It can be seen that retrofitting prioritization for different seismic scenarios gives different results.

The segment of I-5 \& I-405 (US30 to WA) do not have continuous concrete girder bridges within the route and so did not exhibit a benefit. This is not to imply that the route has no seismic retrofit needs as the deficiencies are likely manifested in other bridge types. Similar methodology can be adopted for including other types of retrofit and would result in more comprehensive assessment. 


\subsection{REFERENCES}

AASHTO. Standard Specifications for Highway Bridges. Washington, D.C.: American Association of State Highway and Transportation Officials. 1996.

Abrahamson, N.A. Empirical Response Spectral Attenuation Relations for Shallow Crustal Earthquakes. Seismological Research Letters, 1997, pp. 94-127.

ATC. Seismic Vulnerability and Impact of Disruption of Lifelines in the Conterminous United States. Applied Technology Council, Redwood City, CA: ATC. 1991.

ATC-13. Earthquake Damage Evaluation Data for California”. Applied Technology Council, Redwood City, CA, 1985.

ATC-6-2. Seismic Retrofitting Guidlines for Highway Bridges. Applied Technology Council, Redwood, CA, 1983.

Babaei, K., and N.M. Hawkins. Bridge Seismic Retrofit Planning Program. Report No. WA-RD 217.1, Washington State Department of Transportation, Olympia, WA, 1993.

Basöz, N., and A. Kiremidjian. Evaluation of Bridge Damage Data from the Loma Prieta and Northridge, CA Earthquakes. Multidisciplinary Center for Earthquake Engineering Research, Buffalo, NY, 1998.

Basöz, N., and A.S. Kiremidjian. Prioritization of Bridges for Seismic Retrofitting.

Multidisciplinary Center for Earthquake Engineering, Buffalo, NY, 1995.

Basöz, N., and J. Mander. Enhancement of the Highway Transportation Lifeline Module in HAZUS. National Institute of Building Sciences, 1999.

Bazaez, R., and P. Dusicka. Development of Cyclic Loading Protocol for Bridge Columns Considering Subduction Zone Mega Earthquakes. Portland, OR, 2013.

Buckle, I., I. Friedland, J. Mander, G. Martin, R. Nutt, and M. Power. Seismic Retrofitting Manual for Highway Structures: Part 1 - Bridges. Publication FHWA-HRT-06-032. FHWA, U.S. Department of Transportation, 2006.

Chai, Y.H., M.J. Priestley, and F. Seible. Retrofit of Bridge Columns for Enhanced Seismic Performance. Seismic Assessment and Retrofit of Bridges, (SSRP 91/03), 1991, pp. 177-196.

Cherng, R., and Y.K. Wen. Reliability Based Cost-Effective Retrofit of Highway Transportation Systems Against Seismic Hazard. Civil Engineering, University of Illinois, 1992. 
Cheung, P., T. Pauley, and R. Park. New Zealand Tests on Full-Scale Reinforced Concrete Beam-Column-Slab Sub-assemblages Designed for Earthquake Resistance. American Concrete Institute. ACI Special Publication SP 123-1, Detroit, MI, 1991,

Coburn, A., and R. Spence. Factors Determining Human Casualty Levels in. Proceedings of the Tenth World Conference on Earthquake Engineering. Madrid, Spain, 1992, pp. 5989-5994.

DesRoches, R., B. Nielson, and E. Choi. Seismic Fragility of Typical Bridges in Moderate Seismic Zones. Engineering Structures, 2003, pp. 187-199.

Dunwoodie, D. Seismic Retrofit of Bridge Columns Using Fibre-reinforced Concrete. McGill University, Department of Civil Engineering and Applied Mechanics. McGill University: National Library of Canada, 1997.

Durkin, M., and C. Thiel. Integrating Earthquake Casualty and Loss. Proceedings of the Workshop on Modeling Earthquake Casualties for Planning. Sacramento, CA, 1991.

Dusicka, P., M. Glickman, and H. Oppenheimer. Seismic Vulnerability of Oregon Highway Bridges. Final Report. Oregon Department of Transportation, Salem, OR, 2007.

Endeshaw, M., M. El Gawady, R.L. Sack, and D.I. McLean. Retrofit of Rectangular Bridge Columns Using CFRP Wrapping.: Washington State Transportation Center (TRAC), Pullman, WA, 2008.

FEMA. HAZUS MR4 Multi-Hazard Loss Estimation Methodology. Federal Emergency Management Agency, Washington, D.C., 2010.

FHWA. Recording and Coding Guide for the Structure Inventory and Appraisal of the Nation's Bridges. Report No. FHWA-PD-96-001, Federal Highway Administration, Washington D.C., 1995.

FHWA. Seismic Retrofitting Manual for Highway Structures: Part 1 - Bridges. Federal Highway Administration, FHWA, Buffalo, NY, 2006.

Grossi, P. Earthquake Damage Assessment From Expert Opinion to Fragility Curves. 8th ASCE Specialty Conference on Probabilistic Mechanics and Structural Reliability. Notre Dame, IN, 2000 .

Haroun, M.A., and H.M. Elsanadedy. Fiber-Reinforced Plastic Jackets for Ductility Enhancement of Reinforced Concrete Bridge Columns with Poor Lap-Splice Detailing. Journal of Bridge Engineering, Vol. 10, No. 6, 2005, pp. 749-757.

Hwang, H., J.B. Jernigan, and Y. Lin. Expected Seismic Damage to Memphis Highway Systems. 5th U.S. Conference on Lifeline Earthquake Engineering. American Association of Civil Engineers, Seattle, WA, 1999, pp. 1-10.

Hwang, H., J.B. Jernigan, and Y. Lin. Evaluation of Seismic Damage to Memphis Bridges and Highway Systems. Journal of Bridge Engineering, 2000, pp. 322-330. 
Hwang, H., J.B. Liu, and Y.-H. Chiu. Seismic Fragility Analysis of Highway Bridges. Center for Earthquake Research and Information, Memphis, TN, 2001.

Karim, K.R., and F. Yamazaki. Effect of Earthquake Ground Motions on Fragility Curves of Highway Bridge Piers Based on Numerical Simulation. Earthquake Engineering and Structural Dynamics, Vol. 30, 2001, pp. 1839-1856.

Karim, K.R., and F. Yamazaki. A Simplified Method of Constructing Fragility Curves for Highway Bridges. Earthquake Engineering and Structural Dynamics, Vol. 32, 2003, pp. 16031626.

Karim, K., and F. Yamazaki. Comparison of Analytical Fragility Curves for RC Bridge Piers in Japan. 8th ASCE Specialty Conference on Probabilistic Mechanics and Structural Reliability, 2000.

Kim, S., M. Gaus, G. Lee, and K. Chang. A GIS-Based Regional Risk Approach for Bridges Subjected to Earthquakes. In proceedings of 8th Conference on Computing in Civil Engineering and Geographical Information System Symposium, Texas, 1992, pp. 460-467.

Kowalsky, M., Montejo, L., and Hassan, T. (2009). Seismic Behavior of Flexural Dominated Reinforced Concrete Bridge Columns at Low Temperatures. Journal of Cold Regions Engineering, ASCE, 23(1), 18-42.

Kunnath, S., A. El-Bahy, A. Taylor, and W. Stone. Cumulative Seismic Damage of Reinforced Concrete Damage Piers. Building and Fire Research Laboratory, National Institute of Standards and Technology, Gaithersburg, MD, 1997.

Liao, W.-I., and C.-H Loh. Priliminary Study on the Fragility Curves for Highway Bridges in Taiwan. Journal of the Chinese Institute of Engineers, Vol. 27, No. 3, 2004, pp. 367-375.

Mander, J., and N. Basöz. Enhancement of the Highway Transportation Lifeline Module in HAZUS. National Institute of Building Sciences, 1999.

McLean, D.I., and Bernards, L.L. Seismic Retrofitting of Rectangular Bridge Column for Shear. Washington State Transportation Center (TRAC), Pulman, WA, 1992.

Moore, J.E., S. Cho, Y.Y. Fan, and S. Werner. Quantifying Economic Losses from Travel Forgone Following a Large Metropolitan Earthquake. Pacific Earthquake Engineering Research Center (PEER), Berkeley, CA, 2006.

Nielson, B.G., and R. DesRoches. Analytical Seismic Fragility Curves for Typical Bridges in the Central and Southeastern United States. Earthquake Spectra, Vol. 23, No. 3, 2007, pp. 615-633.

ODOT. Seismic Vulnerability of Oregon State Highway Bridges: Mitigation Strategies to Reduce Major Mobility Risks. Bridge Engineering Section, Oregon Department of Transportation (ODOT), Salem, OR, 2009. 
ODOT. Oregon Highways Seismic Options Report. Bridge and Geo-Environmental Sections Technical Services Branch, Oregon Department of Transportation (ODOT). 2013.

Padgett, J. Retrofitted Bridge Fragility Curves for Assessing the Consequences of an Earthquake Event. Mid-America Earthquake Center, 2005.

http://mae.cee.uiuc.edu/documents/slc online magazine 2005 july padgett.pdf. Accessed December 11, 2010.

Padgett, J.E. Sustainability as a Guide for Selecting and Prioritizing Seismic Sustainable Bridges. 2010 Concrete Bridge Conference. Phoenix, AZ, 2010.

Padgett, J.E., and R. DesRoches. Sensitivity of Seismic Response and Fragility to Parameter Uncertainty. Journal of Structural Engineering, 2007, pp. 1710-1718.

Padgett, J.E., and R. DesRoches. Methodology for the Development of Analytical Fragility Curves. Earthquake Engineering and Structural Dynamics, Vol. 37, 2008, pp. 1157-1174.

Padgett, J.E., and R. DesRoches. Retrofitted Bridge Fragility Analysis for Typical Classes of Multispan Bridges. Earthquake Spectra, 2009, 117-141.

Pan, Y. (2007). Seismic Fragility and Risk Management of Highway Bridges in New York State. The City University of New York, NY, 2007.

Priestley, M., F. Seible, and E. Hines. Seismic Performance of Hollow Rectangular Reinforced Concrete Piers with Highly-Confined Boundary Elements. Report No. SSRP-99/15. La Jolla, California: Department of Structural Engineering, University of California, San Diego, CA, 2002.

Roberts, J. Recent Advances in Seismic Design and Retrofit of California Bridges. In Proceedings of the 3rd U.S. National Conference on Lifeline Earthquake Engineering. Los Angeles, CA, 1991, pp. 52-64.

Roberts, J., and P. Dusicka. Bridge Damage Models for Seismic Risk Assessment of Oregon Highway Network. Oregon Transportation Research and Education Consortium (OTREC), Portland, OR, 2011.

Rodriguez, M., and R. Park. Seismic Load Test on Reinforced Concrete Columns Strengthened by Jacketing. ACI Structural Journal, Vol. 91, No. 2, 1994, pp. 150-159.

Saatcioglu, M., and C. Yalcin. External Prestressing Concrete Columns for Improved Seismic Shear Resistance. Journal of Structural Engineering, 2003, pp. 1057-1070.

Seible, F., G. Hegemier, M. Priestley, D. Innamorato, and F. Ho. Carbon Fiber Jacket Retrofit Test of Rectangular Flexural Column with Lap Spliced Reinforcement. Report No. ACTT-95/04. Advanced Composites Technology Transfer Consortium, University of California, San Diego, CA, 1995. 
Seville, E., and J. Metcalfe. Developing a Hazard Risk Assessment Framework for the New Zealand State Highway Network. Land Transport New Zealand. 2005.

Shinozuka, M., M.Q. Feng, H. Kim, and S. Kim. Nonlinear Static Procedure for Fragility Curve Develipment. Journal or Engineering Mechanics, Vol. 126, No. 12, 2000, pp. 1287-1295.

Shinozuka, M., M.Q. Feng, J. Lee, and T. Naganuma. Statistical Analysis of Fragility Curves. Journal of Engineering Mechanics, Vol. 126, No. 12, 2000, pp. 1224-1231.

Shinozuka, M., S. Kim, S. Kushiyama, and J. Yi. Fragility Curves of Concrete Bridges Retrofitted By Column Jacketing. Earthquake Engineering and Engineering Vibration, Vol. 1, No. 2, 2002, pp. 195-202.

Shinozuka, M., V. Saxena, G. Deodatis, and M.Q. Feng. Development of Fragility Curves for Multi-Span Reinforced Concrete Bridges. 2001. http://www.civil.columbia.edu/iassar/: http://www.civil.columbia.edu/iassar/downloadfiles/SC1 texts/. Accessed September 30, 2010.

Shinozuka, M., M. Sgaravato, and S. Banerjee. Optiaml Seismic Bridge Retrofit Strategy Under Budget Constraint. The 14th World Conference on Earthquake Engineering. Beijing, China, 2008 .

Simon, J., J.M. Bracci, and P. Gardoni. Seismic Response and Fragility of Deteriorated Reinforced Concrete Bridges. Journal of Structural Engineering, Vol. 136, No. 10, 2010, pp. 1273-1281.

Song, J., and G. Lee. Cascading Effects of 2011 Tohoku Earthquake to Structural Damages of Bridges. Buffalo, NY, 2012.

Stevanovic, A., and P. Nadimpalli. Seismic Vulnerability and Emergency Response Analyses of UDOT Lifelines. Department of Civil and Environmental Engineering, University of Utah, 2010.

Stojadinović, B., and K. Mackie. R-Factor Parameterized Bridge Damage Fragility Curves. Journal of Bridge Engineering, Vol. 12, No. 4, 2007, pp. 500-510.

Transit New Zealand. Manual for Seismic Screening of Bridges. Criteria and Guidline manual, Wellington. 1998.

Wang, E. Optimizing Bridge Seismic Retrofit Strategy Implementing Bridge Fragility Curves. Proceedings of the Structures Congress, 2006.

Werner, S.D., C.E. Taylor, S. Cho, J.-P. Lavoie, C. Huyck, C. Eitzel, H. Chung, and R.T. Eguchi. Technical Manual: REDARS 2 Methodology and Software for Seismic Risk Analysis of Highway Systems. Oakland, CA, 2006.

Werner, S.D., C.E. Taylor, S. Cho, J.-P. Lavoie, C.K. Huyck, R.T. Eguchi, and J.E. Moore. New Developments in Seismic Risk Analysis of Highway Systems. 13th World Conference on Earthquake Engineering. Vancouver, B.C., Canada, 2004. 
Woodward-Clyde Consultants. Report of Seismic Bridge Condition Survey. Vol. 1, (Prepared for Illinois Dept. of Transportation), Oakland, CA, 1991.

WSDOT. Bridge Design Manual M 23-50. Washington State Department of Transportation (WSDOT), 2006.

Yamazaki, F., J. Ohnishi, and S. Tayama. (1999). Earthquake Damage Assessment of Expressway Structures in Japan. Asia-Pacific Symposium on Structural Reliability and its Application. Taipei, Taiwan. 1999, pp. 205-214. 